\title{
Developing MXenes from Wireless Communication to Electromagnetic Attenuation
}

Cite as

Nano-Micro Lett.

(2021) 13:115

\author{
Peng $\mathrm{He}^{1}$, Mao-Sheng $\mathrm{Cao}^{1}{ }^{凶}$, Wen-Qiang $\mathrm{Cao}^{1}, \mathrm{Jie}$ Yuan $^{2}$
}

Received: 19 February 2021

Accepted: 21 March 2021

Published online: 27 April 2021

(C) The Author(s) 2021

\section{HIGHLIGHTS}

- The industrial application and foundational research of MXenes at gigahertz frequency are systematically reviewed.

- The design principles of "lightweight, wide, and strong" are specifically highlighted.

- Current challenges and future directions for MXenes in wireless communication and electromagnetic attenuation are outlined.

ABSTRACT There is an urgent global need for wireless communication utilizing materials that can provide simultaneous flexibility and high conductivity. Avoiding the harmful effects of electromagnetic (EM) radiation from wireless communication is a persistent research hot spot. Two-dimensional (2D) materials are the preferred choice as wireless communication and EM attenuation materials as they are lightweight with high aspect ratios and possess distinguished electronic properties. MXenes, as a novel family of 2D materials, have shown excellent properties in various fields, owing to their excellent electrical conductivity, mechanical stability, high flexibility, and ease of processability. To date, research on the utility of MXenes for wireless communication has been actively pursued. Moreover, MXenes have become the leading materials for EM attenuation. Herein, we systematically review the

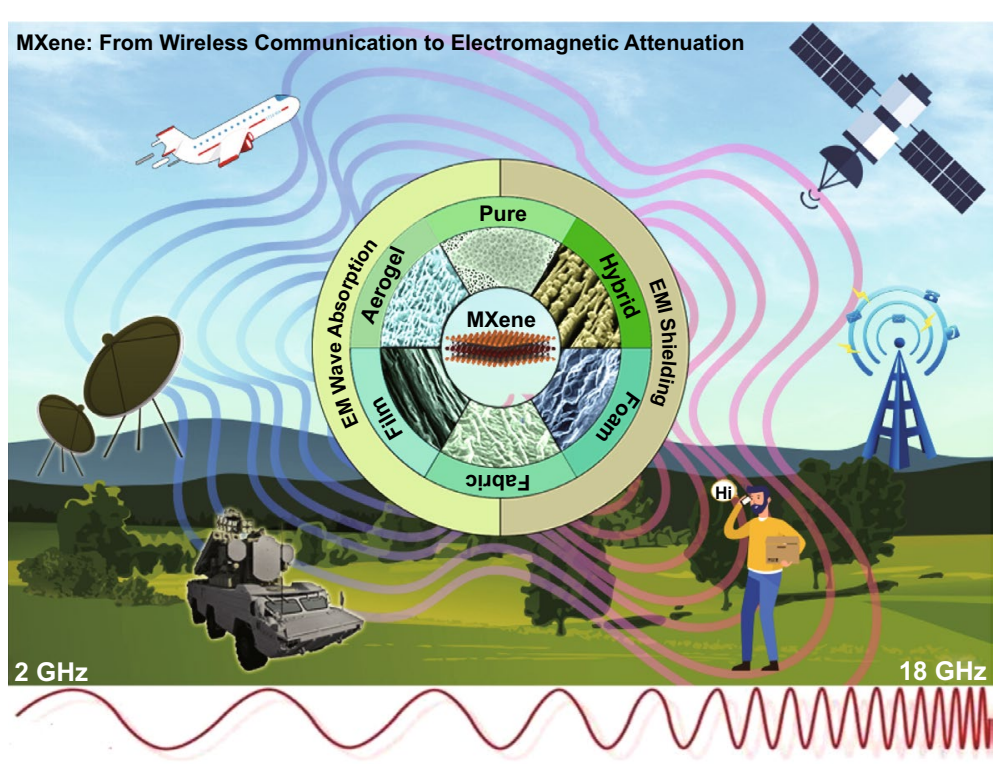
recent advances in MXene-based materials with different structural designs for wireless communication, electromagnetic interference (EMI) shielding, and EM wave absorption. The relationship governing the structural design and the effectiveness for wireless communication, EMI shielding, and EM wave absorption is clearly revealed. Furthermore, our review mainly focuses on future challenges and guidelines for designing MXene-based materials for industrial application and foundational research.

KEYWORDS MXene; Wireless communication; Electromagnetic wave absorption; Electromagnetic interference shielding

Mao-Sheng Cao, caomaosheng@ bit.edu.cn

School of Materials Science and Engineering, Beijing Institute of Technology, Beijing 100081, People's Republic of China

2 School of Information Engineering, Minzu University of China, Beijing 100081, People's Republic of China 


\section{Introduction}

Wireless communication has been gaining popularity with the arrival of the age of artificial intelligence [1-3]. This is accompanied by a surge in the demand for all kinds of portable devices. These devices require a concealed integration of radio communication electronics without sacrificing lightweight and transportability [4-6]. Therefore, it is necessary to develop new routes of antenna fabrication $[7,8]$. It is difficult to fabricate ultra-thin, flexible, and conformal antenna using traditional metal materials because of the skin depth limitation [9]. To overcome this shortcoming, carbon-based nanomaterials have been explored for wireless communication applications. For example, Elwi et al. prepared multi-walled carbon nanotube antennas that afforded a remarkable enhancement in the bandwidth [6]. Vacirca et al. reported an onion-like carbon antenna that showed a peak gain of $-1.48 \mathrm{dBi}$, just $3 \mathrm{~dB}$ less than that of a copper dipole antenna [8]. However, the low conductivity of carbon inhibits these materials from achieving reasonable radio-frequency performance. Thereafter, two-dimensional (2D) nanomaterials, such as graphene, $\mathrm{MoS}_{2}$, and others, have been used to fabricate antennas, thereby furnishing antennas with thinner patches. For example, Shin et al. fabricated a graphene antenna, affording a high transmitted power efficiency of $96.7 \%$ [1]. To date, it is still a challenge to find a flexible material with high conductivity for antenna fabrication.

On the other hand, the use of a large number of wireless communication devices will lead to an explosive increase in electromagnetic (EM) radiation on the scale of "big data" [10-12]. The undesired EM radiation directly affects the operation of electronic equipment and also indirectly influences human health, as long-term exposure to EM radiation may cause cancer and other health problems [13-16]. How to avoid the harm from EM radiation has always been a research hot spot. The development of electromagnetic interference (EMI) shielding and EM wave absorbing materials is the key to solving the above problem [17-22]. Recently, various materials have been globally studied as EMI shielding or/and EM wave absorbing materials, including zero-dimensional (0D), one-dimensional (1D), and 2D materials. Among them, 2D materials are the materials of choice as they are lightweight, have large aspect ratios, and offer distinguished electronic properties. For example, Cao's group reported that chemically graphitized r-GOs exhibited high-efficiency EMI shielding effectiveness (EMI SE) at elevated temperatures. The EMI SE of the composites with $20 \mathrm{wt} \% \mathrm{r}$-GOs reached a maximum at $\sim 38 \mathrm{~dB}$ [12]. Zhang et al. prepared $2 \mathrm{D} \mathrm{WS}_{2}-\mathrm{rGO}$ heterostructure nanosheets. The composite containing 40 $\mathrm{wt} \% \mathrm{WS}_{2}$-rGO showed a minimum reflection loss $(R L)$ of $-41.5 \mathrm{~dB}$, with the absorption bandwidth reaching up to $13.62 \mathrm{GHz}$ [15].

MXenes, as a novel family of 2D materials, possess huge potential in the fields of wireless communication, EMI shielding, and EM wave absorption owing to their excellent electrical conductivity, numerous family members, mechanical stability, high flexibility, and ease of processability [23, 24]. At present, research on MXene antennas is still in the exploratory stage, but the excellent properties of these materials for wireless communication have been widely regarded. Moreover, since the discovery of the outstanding EMI shielding performance of $\mathrm{Ti}_{3} \mathrm{C}_{2} \mathrm{~T}_{x}$ MXene in 2016, MXenes have become the leading materials for EMI shielding and EM wave absorption with the fastest growing number of related research publications (Fig. 1). Moreover, as EM attenuation materials, the excellent chemical and physical properties of MXenes have facilitated the development of pure MXenes and hybrids with controlled structural designs such as films, foams, aerogels, and fabrics (inset of Fig. 1).

This review systematically summarizes the effects of MXenes with various structural designs on wireless communication, EMI shielding, and EM wave absorption. The most feasible strategies for high-performance wireless communication, EMI shielding, and EM wave absorption are revealed by discussing the different approaches for modifying the structures of MXenes. Finally, we provide an overview of the further development and prospects of MXenes for wireless communication and EM attenuation. 


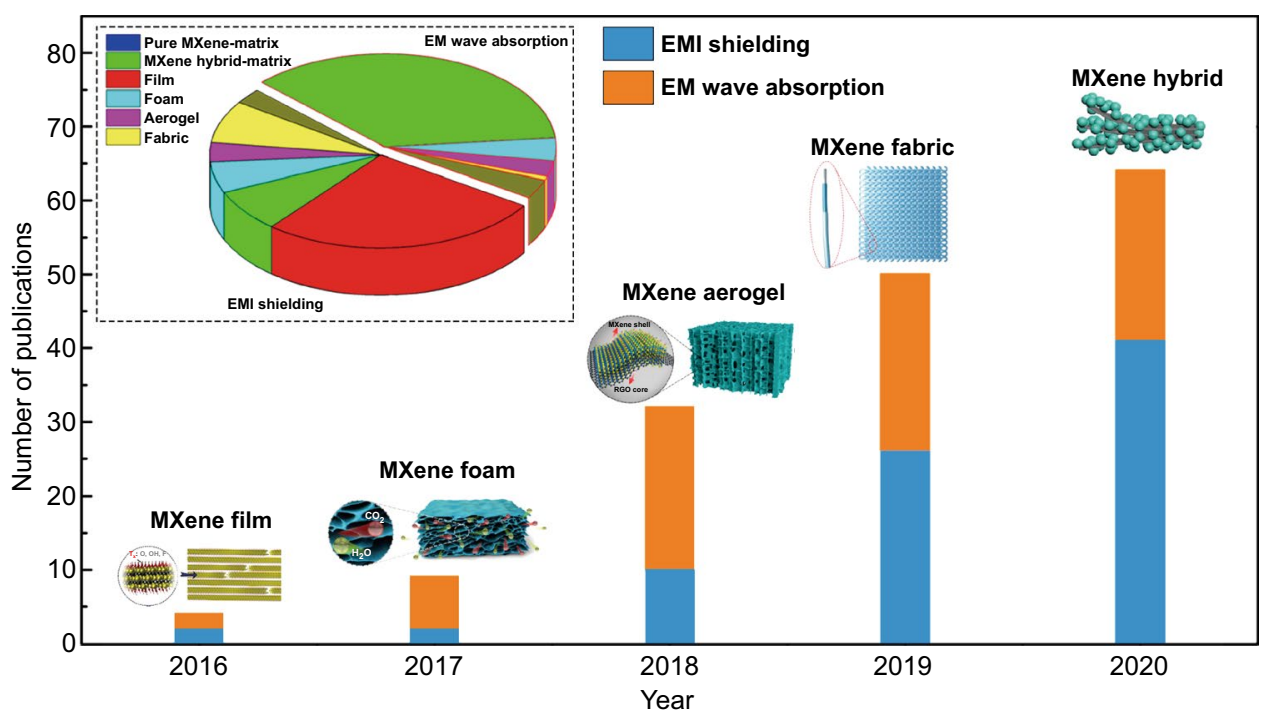

Fig. 1 Number of publications focused on MXenes for EMI shielding and EM wave absorption. Source: Web of Science Core Collection, 2020 (inside: 2D MXenes serve as EMI shielding materials and EM wave absorption materials)

\section{Antenna Mechanism and EM Attenuation Mechanism}

\subsection{Antenna Mechanism}

Actually, the wavelength of substrate-based antennas is inversely proportional to frequency, and the length of designed antenna is selected according to antenna types and wavelength. $\lambda$ is defined as [25-30]:

$\lambda=\frac{c}{f}$

Two important indexes to judge the quality of designed antenna are bandwidth and voltage standing wave ratio (VSWR) or return loss of the antenna [31-33]. The VSWR is to quantify the impedance matching at the operating frequency and different thicknesses, which can be calculated by the formula $[34,35]$ :

$\operatorname{VSWR}=\frac{1+\left|S_{11}\right|}{1-\left|S_{11}\right|}$

where $S_{11}$ represents the reflection coefficients. VSWR is the ratio between the peak amplitude and the minimum amplitude of standing wave. Standing wave is caused by any mismatch at the input of antenna, which will cause the input power to be reflected back [36, 37]. VSWR equal to 1 means that there is no standing wave $\left(S_{11}=-\right.$ infinity), and the antenna is an ideal match.
The research on 2D materials as patch antennas is the most extensive. Different substrates have been proposed for flexible patch antennas, such as rubber, polyethylene, cellulose nanopaper, and others, to achieve improved efficiency. The patch antenna, using natural rubber as substrate, plays a significant role in wireless communication as the mechanical properties of rubber make the antenna flexible. Moreover, an antenna on a polyethylene substrate was designed and fabricated with distinct bending curvature, affording reliable performance within the designed C-band [38].

\subsection{Shielding Mechanism}

The ability of a shield to against the incoming EM radiation is measured by the EMI SE, which is defined as the ratio of the transmitted and incident powers, generally on a logarithmic scale, as expressed in Eq. (3) [39]:

$\mathrm{SE}_{\mathrm{T}}(\mathrm{dB})=10 \log \frac{P_{\mathrm{T}}}{P_{\mathrm{I}}}=20 \log \frac{E_{\mathrm{T}}}{E_{\mathrm{I}}}$

where $P_{\mathrm{I}}$ and $P_{\mathrm{T}}$ represent incident wave power and transmitted wave power, respectively. $E_{\mathrm{I}}$ and $E_{\mathrm{T}}$ represent electric field intensity of incident wave and electric field intensity of transmitted wave power, respectively. According to the theory of Schelkunoffs, the total EMI SE is the sum of 
reflection $\left(S_{\mathrm{R}}\right)$, absorption $\left(\mathrm{SE}_{\mathrm{A}}\right)$, and multiple reflections $\left(\mathrm{SE}_{\mathrm{M}}\right)$, as shown in Eq. (4) [40]:

$\mathrm{SE}_{\mathrm{T}}=\mathrm{SE}_{\mathrm{R}}+\mathrm{SE}_{\mathrm{A}}+\mathrm{SE}_{\mathrm{M}}$

To quantify the value of $\mathrm{SE}_{\mathrm{R}}$ and $\mathrm{SE}_{\mathrm{A}}$, the concept of the absorption $(A)$, reflection $(R)$ and transmission $(T)$ coefficient is proposed. The relation among them can be obtained as follows:

$\mathrm{SE}_{\mathrm{R}}=10 \log \left(\frac{1}{1-R}\right)$

$\mathrm{SE}_{\mathrm{A}}=10 \log \left(\frac{1-R}{T}\right)$

The value of $A, R$, and $T$ can be calculated from the measured scattering parameters $\left(S_{\mathrm{mn}}\right)$. $S_{\mathrm{mn}}$ represents that how energy is scattered from a shield. " $m$ " indicates the port receiving the radiation energy, and " $n$ " indicates the port that is transmitting the incident energy. Accordingly, $A, R$ and $T$ can be calculated via the relationships:

$A+R+T=1$

$R=\left|S_{11}\right|^{2}=\left|S_{22}\right|^{2}$

$T=\left|S_{21}\right|^{2}=\left|S_{12}\right|^{2}$

Both reflection and absorption provide great contributions for excellent EMI shielding. However, in consideration of green shielding, less reflection is better. The ideal EMI shielding involves strong absorption with no reflection and transmission, as shown in Fig. 2b. Multiple reflection also plays an important role in EM wave attenuation. Multiple reflections between the front and back of the shield

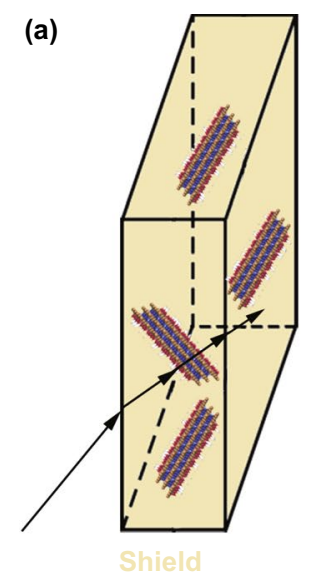

(d)

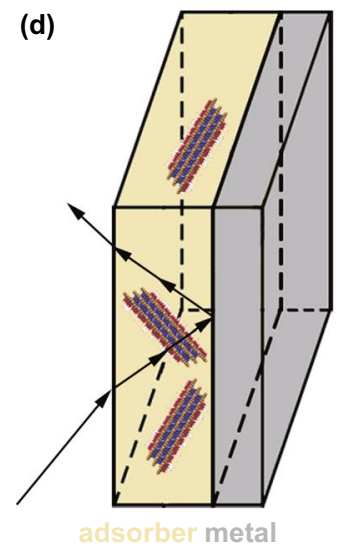

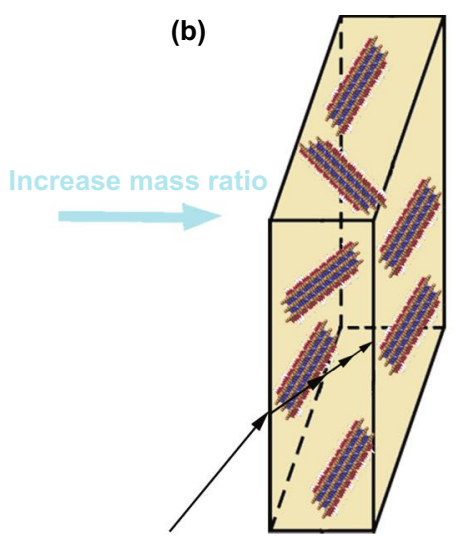

(e)

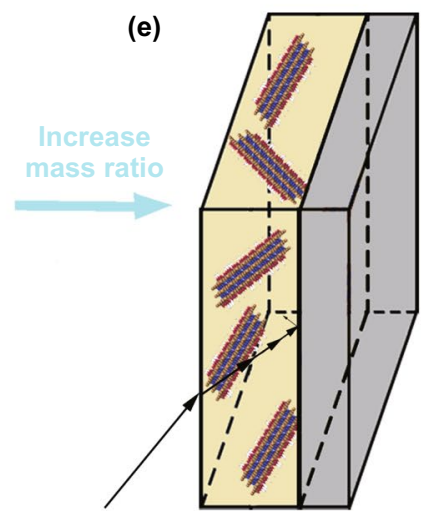

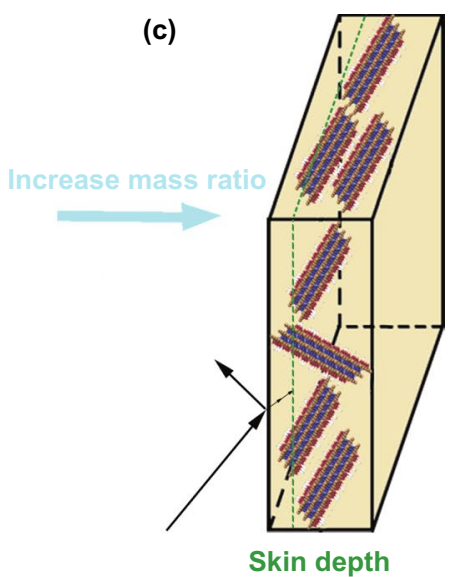

(f)

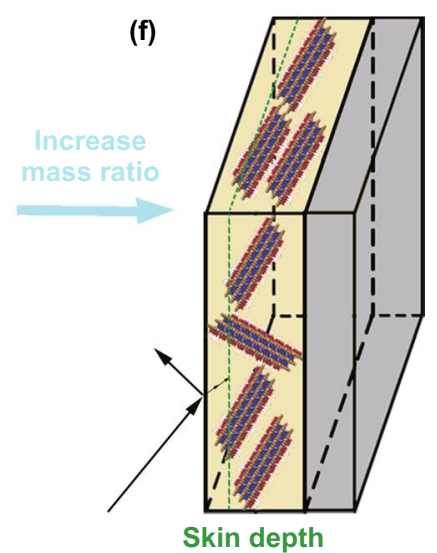

Fig. 2 Situations in which the EMI shield responds to the EM wave: a allowing all waves to enter with large transmission, b allowing all waves to enter with no transmission, and $\mathbf{c}$ strong secondary reflection. The situations in which the absorber responds to the EM wave: $\mathbf{d}$ good impedance matching with weak attenuation, $\mathbf{e}$ an ideal absorber with good impedance matching and strong attenuation, and $\mathbf{f}$ poor impedance matching with strong attenuation 
contribute a lower EMI SE. However, when the thickness of the shield close to or larger than the skin depth $\left(\delta=\left(\sqrt{\pi f \mu_{\mathrm{o}} \mu_{\mathrm{r}} \sigma}\right)^{-1}\right.$, where $\mu_{\mathrm{o}}=4 \times 10^{-7} \mathrm{H} \mathrm{m}^{-1}, \mu_{\mathrm{r}}$ is permeability of an absorber, and $\sigma$ is electrical conductivity) or when the $\mathrm{SE}_{\mathrm{T}}>10 \mathrm{~dB}$, the effect of multiple reflection should be neglected.

Specific shielding effectiveness (SSE) is derived to compare the effectiveness of shielding materials taking into account the density. Lightweight materials afford high SSE. SSE can be calculated as follows:

$\mathrm{SEE}=\mathrm{EMI}$ SE/density $=\mathrm{dB} \mathrm{cm}^{3} \mathrm{~g}^{-1}$

To account for the thickness contribution, the following equation is used to evaluate the absolute effectiveness $\left(\mathrm{SSE}_{t}\right)$ of a material in relative terms

$\mathrm{SSE}_{\mathrm{t}}=\mathrm{SSE} / t=\mathrm{dB} \mathrm{cm} \mathrm{c}^{-1}$

\subsection{Absorption Mechanism}

The responses of an EM wave absorption to an incident EM wave are determined by the absorber's permittivity and permeability. The EM wave absorption capacity can be expressed by the following equations [41]:

$$
\begin{aligned}
& \mathrm{RL}=20 \log \left|\frac{Z_{\text {in }}-1}{Z_{\text {in }}+1}\right| \\
& Z_{\text {in }}=\sqrt{\frac{\mu_{\mathrm{r}}}{\varepsilon_{\mathrm{r}}}} \tanh \left[j\left(\frac{2 f \pi d}{c}\right) \sqrt{\mu_{\mathrm{r}} \varepsilon_{\mathrm{r}}}\right]
\end{aligned}
$$

where $Z_{\text {in }}$ is the normalized input impedance, $\varepsilon_{\mathrm{r}}$ and $\mu_{\mathrm{r}}$ are the relative complex permittivity and permeability of an absorber and $d$ is the thickness of the absorber.

Excellent EM wave absorption performance of an absorber depends not only on efficient EM wave attenuation but also on impedance matching. As shown in Fig. 2e, the absorber exhibits ideal impedance matching, which means that all EM waves are allowed to penetrate the absorber. And, its high-efficiency EM attenuation is usually derived from dielectric loss and magnetic loss, as well as multi-scattering or multi-reflection.

Generally, the dissipation pathway within the absorber is described as dielectric loss. The dielectric loss can be thought as a sort of friction to the displacement of the subatomic particles, then the passing EM wave attenuates, presenting as the subsequent generation of heat. Dielectric loss is constructed by conduction loss and polarization loss; the relation among them can be expressed by the following formula:

$\varepsilon^{\prime \prime}=\varepsilon_{\mathrm{c}}^{\prime \prime}+\varepsilon_{\mathrm{p}}^{\prime \prime}$

where $\varepsilon^{\prime \prime}{ }_{\mathrm{c}}$ and $\varepsilon^{\prime \prime}{ }_{\mathrm{p}}$ represent conduction loss and polarization loss, respectively.

Conduction loss plays an important role in the materials with high conductivity, such as, MXene, graphene and other carbon materials. Actually, the conduction loss is the energy loss of EM wave caused by electron transition. Up to now, Cao's group has done a lot of work to clarify the role of conduction loss. For example, the electron-hopping model (EHM) was established to explain the mechanism of conduction loss in the carbon fibers (CFs) and multiwalled carbon nanotubes (MWCNTs) [42]; a model of aggregation-induced charge transport (AICT) was proposed to illustrate electron transport in whole MWCNTs/ $\mathrm{SiO}_{2}$ composites [43]; electron transition theory was used to explain the loss behavior of $\mathrm{Ti}_{3} \mathrm{C}_{2} \mathrm{~T}_{x}$ MXene [44]. Now, the role of conduction loss caused by electron transition has been widely recognized in the design of EM waveabsorbing materials.

Polarization loss is generated by the behavior of diploes. Diploes are generated in the site of functional groups, defects, and interfaces. Under a high-frequency alternating electric field, when rotation of dipoles cannot follow the change of electric field, dipole orientation polarization loss occurs, which is another key role of dielectric loss. Cao's group made important contributions to the resources, characterization techniques, and semiquantitative methods of polarization relaxation. In 2008 , they proposed a capacitorlike model and an equivalent circuit model to explain the $\mathrm{EM}$ wave response of $\mathrm{CdS}-\mathrm{Fe}_{2} \mathrm{O}_{3}$ heterostructures [45]. In 2012, the perfect polarization relaxation was established in $\mathrm{Fe}_{3} \mathrm{O}_{4}$-MWCNTs and PANI-Fe ${ }_{3} \mathrm{O}_{4}$-MWCNTs [46]. Later, the capacitor-like model is applied to visualize the interfacial polarization in MWCNTs, graphene, MXene, or their nanohybrids, etc. After that, a semiquantitative research strategy of multiple polarization, that is the separation of the contribution of electron transport and dipole polarization, was established by them to accurately analyze the source of polarization [47]. Recently, they proposed a new concept of polarization genes and made a semiquantitative characterization and definition [48]. In conclusion, on the premise of meeting the impedance matching, effectively rising the 
conduction loss and polarization loss will greatly improve the EM wave absorbing performance of absorber.

Magnetic loss is caused by eddy currents, natural resonance, and exchange resonance. The eddy current is inevitable. If magnetic loss only originates from eddy current loss, the value of $\mu^{\prime \prime}\left(\mu^{\prime}\right)^{-2} f^{-1}$ is constant when frequency changes. Natural resonance usually occurs at low frequency (2-10 GHz), while exchange resonance occurs at high frequencies $(>10 \mathrm{GHz})$.

\section{MXene-Based Materials for Antenna}

Research on MXenes for wireless communication applications is still in the exploratory stage. Gogotsi's group has undertaken pioneering research in this field. According to the different usage frequency, MXene antennas can be divided into low-frequency antennas $(<2.4 \mathrm{GHz})$ and highfrequency antennas $(>5.6 \mathrm{GHz})$.

\subsection{Low-Frequency Antenna}

Gogotsi's group firstly designed and investigated the $\mathrm{Ti}_{3} \mathrm{C}_{2} \mathrm{~T}_{x}$ MXene dipole antenna at $2.4 \mathrm{GHz}$ [49]. The translucent MXene antenna with a thickness of $\sim 100 \mathrm{~nm}$ had a reflection coefficient of less than $-10 \mathrm{~dB}$. By increasing the antenna thickness to $8 \mu \mathrm{m}$, the reflection coefficient reached $-65 \mathrm{~dB}$. The VSWR was less than 2 for MXene antennas with various thicknesses despite the fact that the surface resistance increased significantly with thicknesses below $100 \mathrm{~nm}$. The radiation pattern of an 8-mm-thick dipole antenna presented typical dipole radiative behavior. Moreover, the MXene antenna afforded a maximum gain of $2.11 \mathrm{~dB}$ at the thickness of $8 \mu \mathrm{m}$, which converges with the maximum gain of an ideal half-wavelength dipole antenna $(2.15 \mathrm{~dB})$.

Li et al. prepared a stretchable $\mathrm{Ti}_{3} \mathrm{C}_{2} \mathrm{~T}_{x}$ nanosheets (MXene) and single-walled carbon nanotubes (SWNTs) S-MXene dipole antenna (Fig. 3a) [50]. The resonant frequencies of an S-MXene antenna were linearly dependent on the applied strains (Fig. 3b). Moreover, the S-MXene antenna afforded nearly the same reflection $\left|S_{11}\right|(\sim-33 \mathrm{~dB})$ at the same resonant frequency $(1.425 \mathrm{GHz})$ during the fatigue test up to $100 \%$ uniaxial strains for 500 cycles (Fig. 3c).

\subsection{High-Frequency Antenna}

Gogotsi's group reported on micrometer-thin and flexible MXene microstrip patch antennas with target frequencies of 5.6, 10.9, and $16.4 \mathrm{GHz}$, produced by a simple spraycoating fabrication method (Fig. 3d, e) [51]. The return loss values of MXene antennas with a thickness of $5.5 \mu \mathrm{m}$ achieved $-29,-25$, and $-48 \mathrm{~dB}$ at 5.6, 10.9, and $16.4 \mathrm{GHz}$ (Fig. 3f), respectively, which demonstrated that MXene patches were capable of delivering RF power efficiently to the radiator. The radiation efficiency increased with the thickness of MXene patches (Fig. 3g), which was due to the decreasing conductor loss. Moreover, the outstanding performance of MXene patch antennas was comparable to their copper counterparts (Fig. 3h).

\section{MXene-Based Materials for EMI Shielding}

\subsection{Pure MXene Matrix}

\subsubsection{Non-annealing}

Liu et al. prepared multilayer $\mathrm{Ti}_{3} \mathrm{C}_{2} \mathrm{~T}_{x}$ by etching $\mathrm{Ti}_{3} \mathrm{AlC}_{2}$ with $40 \% \mathrm{HF}$ at room temperature (RT) for $24 \mathrm{~h} \mathrm{[52].} \mathrm{The}$ multilayer $\mathrm{Ti}_{3} \mathrm{C}_{2} \mathrm{~T}_{x} /$ wax with the $60 \mathrm{wt} \% \mathrm{Ti}_{3} \mathrm{C}_{2} \mathrm{~T}_{x}$ content displayed outstanding EMI shielding performance of $39.1 \mathrm{~dB}$ at the thickness of $2 \mathrm{~mm}$. Hu et al. fabricated multilayer $\mathrm{Ti}_{3} \mathrm{C}_{2} \mathrm{~T}_{x}$ by etching $\mathrm{Ti}_{3} \mathrm{AlC}_{2}$ with $40 \% \mathrm{HF}$ solution at $50{ }^{\circ} \mathrm{C}$ for only $0.5 \mathrm{~h}$ [53]. The multilayer $\mathrm{Ti}_{3} \mathrm{C}_{2} \mathrm{~T}_{x}$ prepared in such a short time also exhibited excellent EMI shielding performance. For example, the $\mathrm{Ti}_{3} \mathrm{C}_{2} \mathrm{~T}_{x} /$ wax with $70 \mathrm{wt} \%$ $\mathrm{Ti}_{3} \mathrm{C}_{2} \mathrm{~T}_{x}$ showed EMI shielding performance of $34 \mathrm{~dB}$ at $18 \mathrm{GHz}$.

Previous studies focused on the EMI shielding performance of multilayer $\mathrm{Ti}_{3} \mathrm{C}_{2} \mathrm{~T}_{x}$. He et al. investigated the difference between $\mathrm{Ti}_{3} \mathrm{C}_{2} \mathrm{~T}_{x}$ nanosheet and multilayer $\mathrm{Ti}_{3} \mathrm{C}_{2} \mathrm{~T}_{x}$ in EMI shielding performance [54]. Different etchants led to different centrifugal results (Fig. 4a, b) and different morphologies (Fig. 4c-f). The $\mathrm{Ti}_{3} \mathrm{C}_{2} \mathrm{~T}_{x}$ nanosheet showed a much better EMI shielding performance compared with the multilayer $\mathrm{Ti}_{3} \mathrm{C}_{2} \mathrm{~T}_{x}$ owing to the formation of local conductive networks (Fig. $4 \mathrm{~g}-1$ ). The $\mathrm{Ti}_{3} \mathrm{C}_{2} \mathrm{~T}_{x}$-wax matrix with 80 $\mathrm{wt} \% \mathrm{Ti}_{3} \mathrm{C}_{2} \mathrm{~T}_{x}$ loading showed EMI shielding performance of $58.1 \mathrm{~dB}$ at the thickness of only $1 \mathrm{~mm}$. 
(a)

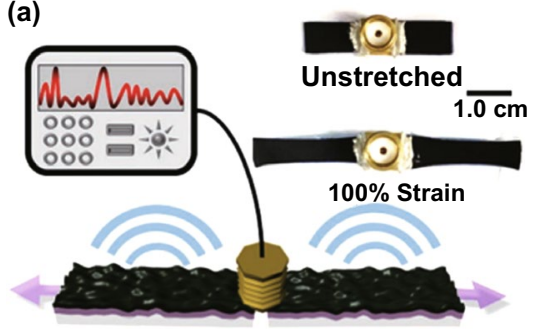

(d)

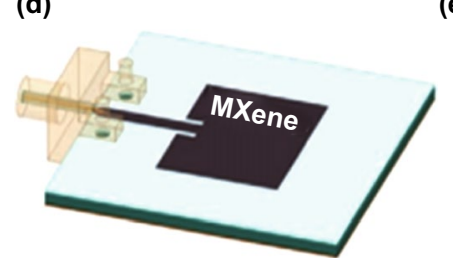

(e) (b) 20 Uniaxial stretching
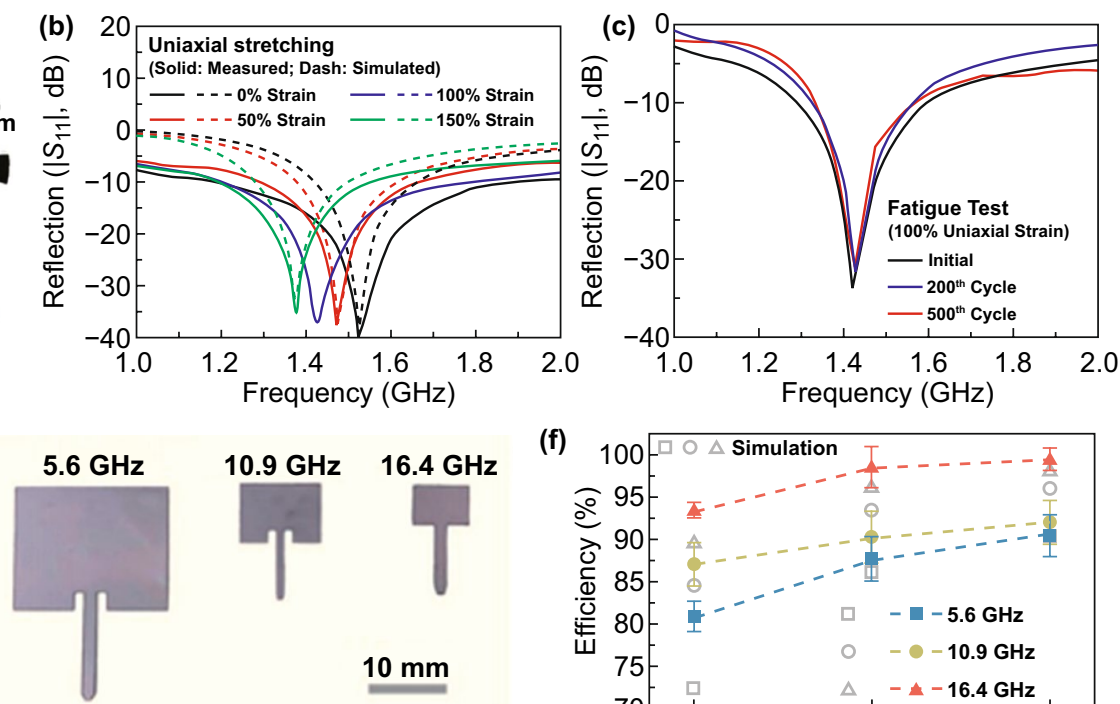

$10 \mathrm{~mm}$

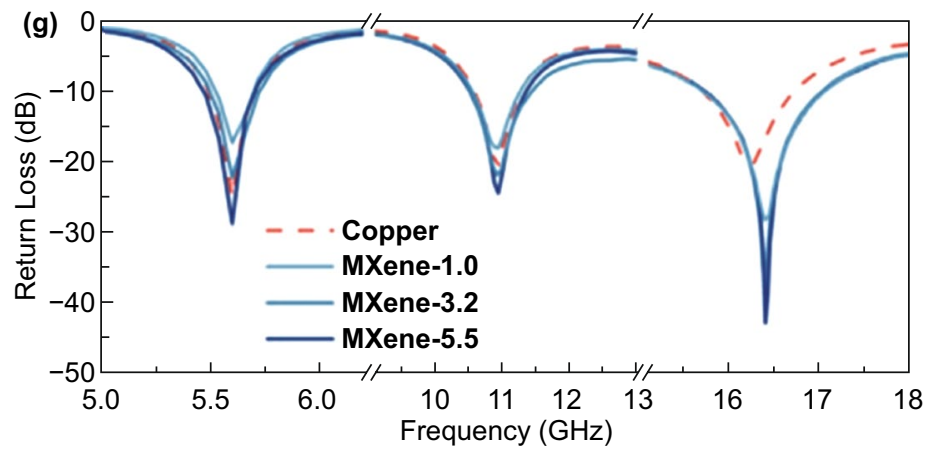

(f)

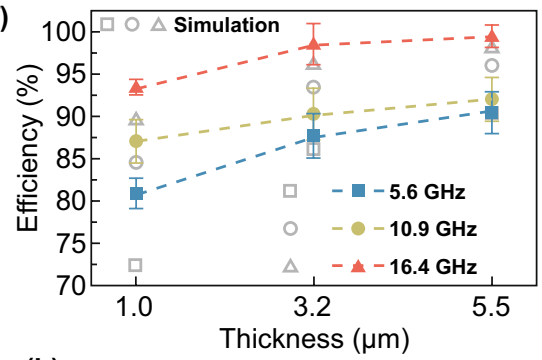

(h)

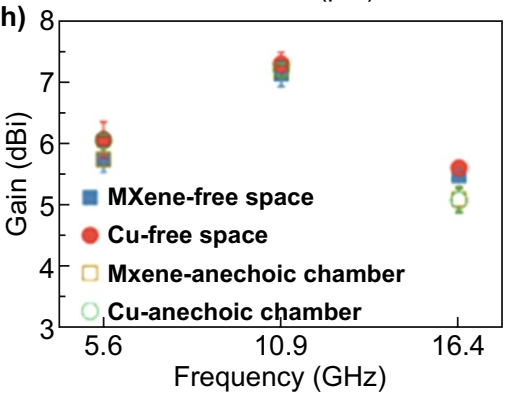

Fig. 3 a Schematic illustration and digital photographs (right) of an S-MXene dipole antenna at different stretching states. b Measured and simulated reflection $\left|S_{11}\right|$ and resonant frequencies of an S-MXene antenna under different uniaxial strains. c Performance of stretchable S-MXene antenna under 200- and 500-cycle fatigue tests with uniaxial strain of up to 100\%. Reproduced with permission from Ref. [50]. Copyright 2019, WILEY-VCH. d Schematic of a MXene microstrip patch antenna on dielectric substrate with SMA connector. e Digital image of asfabricated MXene patch antennas at three target frequencies (5.6, 10.9, and $16.4 \mathrm{GHz}$ ), showing the geometry and size. f Return loss of MXene patch antennas of different thicknesses $(1.0,3.2$, and $5.5 \mu \mathrm{m})$ at different target frequencies; copper patch antennas with the same geometry and dimensions were used as references. $\mathbf{g}$ Measured and simulated radiation efficiency of MXene patch antennas of different thicknesses at different frequencies. $\mathbf{h}$ The maximum gain of 5.5- $\mu \mathrm{m}$-thick MXene antenna and a $35-\mu \mathrm{m}$-thick copper antenna at different frequencies measured in free space and an anechoic chamber, respectively. Reproduced with permission from Ref. [51]. Copyright 2020, WILEY-VCH

$\mathrm{Li}$ et al. prepared the multilayer $\mathrm{Ti}_{2} \mathrm{CT}_{x} \mathrm{MXene}$ by $\mathrm{HCl} /$ $\mathrm{LiF}$ etching $\mathrm{Ti}_{2} \mathrm{AlC}$ for $48 \mathrm{~h}$ at $40{ }^{\circ} \mathrm{C}$ [55]. The multilayer $\mathrm{Ti}_{2} \mathrm{CT}_{x}$ presented outstanding EMI shielding performance of $70 \mathrm{~dB}$ with a thickness of only $0.8 \mathrm{~mm}$ in the X-band, exceeding most of reported graphene-based EMI shielding composites, owing to the multilayered structure and the high electrical conductivity $\left(0.30 \mathrm{~S} \mathrm{~cm}^{-1}\right)$.

The matrix of EMI-absorbing materials is usually made of wave-transparent materials. The imaginary part of the dielectric constant of the matrix is zero, which means there is no EM loss. Paraffin is generally used as the matrix of absorbing materials. There are also other wave-transmitting materials that can be used as the matrix, such as polystyrene (PS) and polyvinylidene fluoride (PVDF). A $\mathrm{Ti}_{3} \mathrm{C}_{2} \mathrm{~T}_{x}$ nanosheet@ PS matrix was fabricated by electrostatic assembling of negative $\mathrm{Ti}_{3} \mathrm{C}_{2} \mathrm{~T}_{x}$ nanosheet on positive polystyrene microsphere [56]. The $\mathrm{Ti}_{3} \mathrm{C}_{2} \mathrm{~T}_{x} @ \mathrm{PS}$ with $1.9 \mathrm{vol} \% \mathrm{Ti}_{3} \mathrm{C}_{2} \mathrm{~T}_{x}$ loading exhibited an outstanding EMI shielding performance of $>54 \mathrm{~dB}$ over the whole X-band. Such excellent EMI shielding performance was attributed to the high conductivity $\left(1081 \mathrm{~S} \mathrm{~m}^{-1}\right)$ of $\mathrm{Ti}_{3} \mathrm{C}_{2} \mathrm{~T}_{x}$ and their highly efficient conducting network within PS matrix. Rajavel et al. reported that the multilayer $\mathrm{Ti}_{3} \mathrm{C}_{2} \mathrm{~T}_{x}$-PVDF with 22.55 vol\% $\mathrm{Ti}_{3} \mathrm{C}_{2} \mathrm{~T}_{x}$ displayed remarkable shielding performance of $48.47 \pm 3.5 \mathrm{~dB}$ with a thickness of $2 \mathrm{~mm}$ [57]. Such outstanding shielding performance 

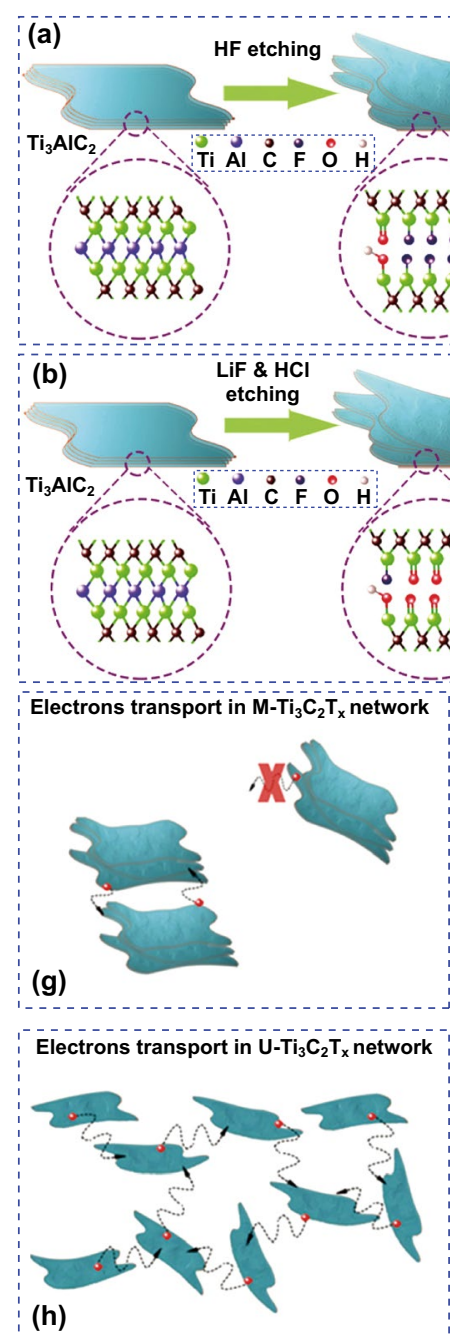

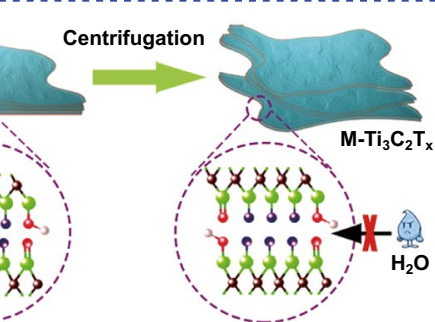

Centrifugation
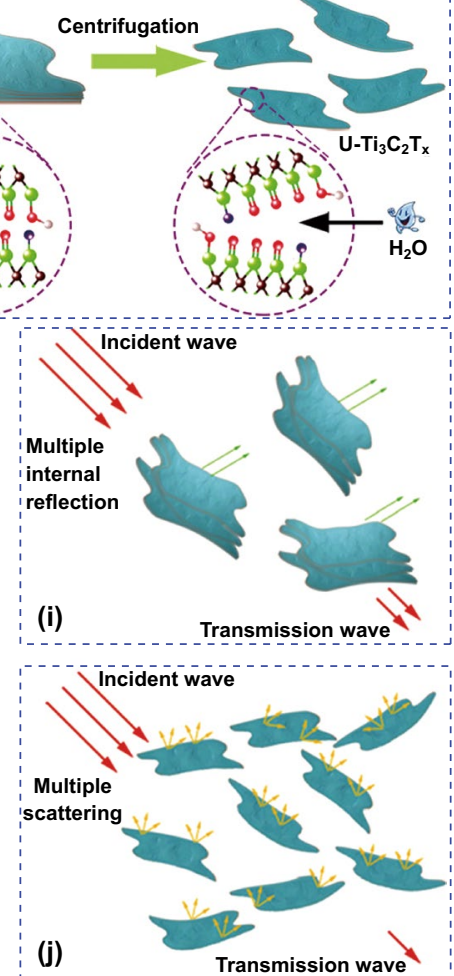
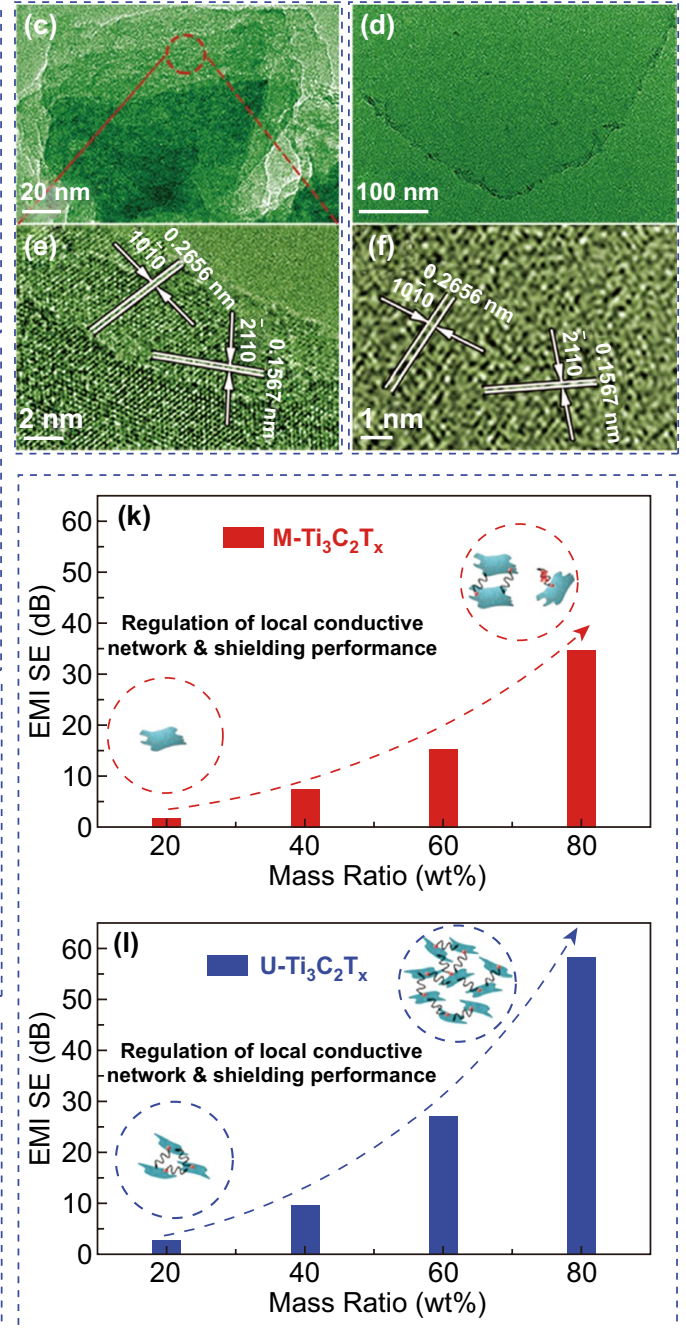

Fig. 4 Synthetic illustration of a multilayer $\mathrm{Ti}_{3} \mathrm{C}_{2} \mathrm{~T}_{\mathrm{x}}$ and $\mathbf{b} \mathrm{Ti}_{3} \mathrm{C}_{2} \mathrm{~T}_{\mathrm{x}}$ nanosheet. The high-magnification TEM images of $\mathbf{c}$ multilayer Ti $\mathrm{C}_{2} \mathrm{~T}_{\mathrm{x}} \mathbf{d}$ $\mathrm{Ti}_{3} \mathrm{C}_{2} \mathrm{~T}_{\mathrm{x}}$ nanosheet. HRTEM images of e multilayer $\mathrm{Ti}_{3} \mathrm{C}_{2} \mathrm{~T}_{\mathrm{x}}$ and $\mathbf{f} \mathrm{Ti}_{3} \mathrm{C}_{2} \mathrm{~T}_{\mathrm{x}}$ nanosheet. Local conductive network of $\mathbf{g}$ multilayer $\mathrm{Ti}_{3} \mathrm{C}_{2} \mathrm{~T}_{\mathrm{x}}$ and h $\mathrm{Ti}_{3} \mathrm{C}_{2} \mathrm{~T}_{\mathrm{x}}$ nanosheet. Microwave propagation model in $\mathbf{i}$ multilayer $\mathrm{Ti}_{3} \mathrm{C}_{2} \mathrm{~T}_{\mathrm{x}}$ and $\mathbf{j} \mathrm{Ti}_{3} \mathrm{C}_{2} \mathrm{~T}_{\mathrm{x}}$ nanosheet. Regulation of local conductive network and shielding performance for $\mathbf{k}$ multilayer $\mathrm{Ti}_{3} \mathrm{C}_{2} \mathrm{~T}_{\mathrm{x}}$ and $\mathbf{l} \mathrm{Ti}_{3} \mathrm{C}_{2} \mathrm{~T}_{\mathrm{x}}$ nanosheet. Reproduced with permission from Ref. [54]. Copyright 2019, The Royal Society of Chemistry

was attributed to the formation of conducting network along with the assembly of micro-capacitor network.

\subsubsection{Annealing}

The improvement of EMI shielding properties by annealing is also widely studied. Yin group investigated the EMI shielding performance of multilayer $\mathrm{Ti}_{3} \mathrm{C}_{2} \mathrm{~T}_{x}$ annealed at $800{ }^{\circ} \mathrm{C}\left(\mathrm{Ti}_{3} \mathrm{C}_{2} \mathrm{~T}_{x}-800\right)$ in $\mathrm{Ar}$ atmosphere. The total $\mathrm{SE}$ of $\mathrm{Ti}_{3} \mathrm{C}_{2} \mathrm{~T}_{x}-800 /$ wax was $32 \mathrm{~dB}$ [58]. After that, the $\mathrm{Ti}_{3} \mathrm{C}_{2} \mathrm{~T}_{x}-200$ was fabricated by annealing $\mathrm{Ti}_{3} \mathrm{C}_{2} \mathrm{~T}_{x}$ at $200{ }^{\circ} \mathrm{C}$ for $2 \mathrm{~h}$ in $\mathrm{Ar}+5 \% \mathrm{H}_{2}$ atmosphere [59]. The $\mathrm{Ti}_{3} \mathrm{C}_{2} \mathrm{~T}_{x}-200 /$ epoxy displayed enhanced EMI shielding performance compared with $\mathrm{Ti}_{3} \mathrm{C}_{2} \mathrm{~T}_{x}$ /epoxy. Ji et al. investigated the EMI shielding performance of multilayer $\mathrm{Ti}_{3} \mathrm{C}_{2} \mathrm{~T}_{x}$ at different annealing temperatures $(800,950,1100,1250,1400$, and $1550{ }^{\circ} \mathrm{C}$ for $1 \mathrm{~h}$ ) in Ar atmosphere [60]. Among them, the multilayer $\mathrm{Ti}_{3} \mathrm{C}_{2} \mathrm{~T}_{x}$ annealed at $1100{ }^{\circ} \mathrm{C}$ displayed the best EMI shielding performance, showing excellent EMI shielding performance of $76.1 \mathrm{~dB}$. 


\subsection{MXene Hybrid Matrix}

It is common that MXene is doped with one-dimensional nanoparticles. $\mathrm{Ti}_{3} \mathrm{C}_{2} \mathrm{~T}_{x}$ nanosheet/Ni chain hybrid was fabricated by a one-step hydrothermal process [61]. $\mathrm{The}^{\mathrm{Ti}_{3} \mathrm{C}_{2} \mathrm{~T}_{x} /}$ Ni hybrid with $50 \mathrm{wt} \% \mathrm{Ti}_{3} \mathrm{C}_{2} \mathrm{~T}_{x}$ showed EMI SE of $66.4 \mathrm{~dB}$. The excellent EMI shielding performance was due to the synergistic effect of conductive $\mathrm{Ti}_{3} \mathrm{C}_{2} \mathrm{~T}_{x}$ and magnetic $\mathrm{Ni}$ chains, by which the dielectric properties and EM loss can be easily controlled to obtain good EM wave dissipation ability. $\mathrm{Nb}_{2} \mathrm{CT}_{x} / \mathrm{Nb}_{2} \mathrm{O}_{5}$-Ag ternary hybrid nanostructures were fabricated by self-reduction and oxidation of $\mathrm{Nb}_{2} \mathrm{CT}_{x}$ in the presence of metallic salt $\left(\mathrm{AgNO}_{3}\right)$ [62]. The $\mathrm{Nb}_{2} \mathrm{CT}_{x} /$ $\mathrm{Nb}_{2} \mathrm{O}_{5}$ - $\mathrm{Ag}$ hybrid-wax matrix with a thickness of $1 \mathrm{~mm}$ showed excellent EMI SE of 68.76 and $72.04 \mathrm{~dB}$ in the $\mathrm{X}$ - and $\mathrm{Ku}$-band region, respectively. The excellent EMI shielding performance was attributed to the strong electrical conductivity, increased interface polarization, and multiple reflection loss between the ternary interfaces.

MXene is not only doped with one-dimensional nanoparticles, but also doped with two-dimensional materials. Song et al. investigated the EMI shielding performance of honeycomb structural rGO- $\mathrm{Ti}_{3} \mathrm{C}_{2} \mathrm{~T}_{x}$ MXene/epoxy nanocomposites [63]. The introduction of $\mathrm{rGO}-\mathrm{Ti}_{3} \mathrm{C}_{2} \mathrm{~T}_{x}$ can fully play synergistic effects of $\mathrm{rGO}$ and $\mathrm{MXene}$, to greatly improve the electrical conductivity and EMI SE of $\mathrm{rGO}-\mathrm{Ti}_{3} \mathrm{C}_{2} \mathrm{~T}_{x}$ MXene/ epoxy nanocomposites. When the cell size of $0.5 \mathrm{~mm}$ with $1.2 \mathrm{wt} \% \mathrm{rGO}+3.3 \mathrm{wt} \% \mathrm{Ti}_{3} \mathrm{C}_{2} \mathrm{~T}_{x}$ loading, the enhanced $\sigma$ $\left(387.1 \mathrm{~S} \mathrm{~m}^{-1}\right)$ and EMI SE (55 dB) values were reached, which were, respectively, 2978 and 5 times of rGM/epoxy nanocomposites ( $\sigma$ of $0.13 \mathrm{~S} \mathrm{~m}^{-1}$, EMI SE of $11 \mathrm{~dB}$ ) at the same loading of directly blending $\mathrm{rGO}-\mathrm{Ti}_{3} \mathrm{C}_{2} \mathrm{~T}_{x}$ fillers.

The shielding properties of multi-doped MXene have also been studied. Raagulan fabricated the $\mathrm{Ti}_{3} \mathrm{C}_{2} \mathrm{~T}_{x}$ MXene-paminophenol (PAT)-conductive polymer (CP) by a costeffective spray coating technique and characterization [64]. The composite showed excellent EMI shielding performance of $45.18 \mathrm{~dB}$ and good electric conductivity of $7.813 \mathrm{~S} \mathrm{~cm}^{-1}$.

\subsection{Film}

The EMI shielding properties of MXene as a film have been widely studied, and there are numerous research results. As a shield, MXene films can be divided into three categories: pristine MXene films, organic-hybrid MXene films, and inorganic-hybrid MXene films. The pristine MXene film refers to the film fabricated from pure MXene nanosheets, organic-hybrid MXene films contain organic substances, and inorganic-hybrid MXene films are MXene films doped with an inorganic substance.

\subsubsection{Pristine}

Koo's group reported that a $45-\mu \mathrm{m} \mathrm{Ti}_{3} \mathrm{C}_{2} \mathrm{~T}_{x}$ film displayed EMI SE of $92 \mathrm{~dB}$ (a $2.5-\mu \mathrm{m}$ film showed $>50 \mathrm{~dB}$ ), which is the highest among synthetic materials of comparable thickness produced to date [65]. The outstanding electrical conductivity of $\mathrm{Ti}_{3} \mathrm{C}_{2} \mathrm{~T}_{x}$ films and multiple internal reflections led to this excellent performance. After that, they systematically studied the EMI shielding of $\mathrm{Ti}_{3} \mathrm{C}_{2} \mathrm{~T}_{x}$ MXene-assembled films over a broad range of film thicknesses, monolayer by monolayer [66]. Theoretical research showed that multiple reflection, the surface reflection, and bulk absorption become significant in the shielding mechanism below skin depth. The 24-layer film of $55 \mathrm{~nm}$ thickness showed EMI SE of $20 \mathrm{~dB}$, revealing an extraordinarily large absolute shielding effectiveness $\left(3.89 \times 106 \mathrm{~dB} \mathrm{~cm}^{2} \mathrm{~g}^{-1}\right)$. Meanwhile, they prepared $\mathrm{Ti}_{3} \mathrm{CNT}_{x}$ and $\mathrm{Ti}_{3} \mathrm{C}_{2} \mathrm{~T}_{x}$ MXene free-standing films of different thicknesses by vacuum-assisted filtration and investigated their EMI shielding performance under different annealing temperatures [67]. It is found that $\mathrm{Ti}_{3} \mathrm{CNT}_{x}$ film provided a higher EMI SE compared with more conductive $\mathrm{Ti}_{3} \mathrm{C}_{2} \mathrm{~T}_{x}$ or metal foils of the same thickness. This excellent EMI shielding performance of $\mathrm{Ti}_{3} \mathrm{CNT}_{x}$ was achieved by thermal annealing, owing to an anomalously high absorption of EM waves in its layered, metamaterial-like structure.

Han et al. systematically studied the shielding properties of 16 different MXene films [68]. All MXene films with micrometer thick displayed excellent EMI shielding performance ( $>20 \mathrm{~dB}$ ). Among them, $\mathrm{Ti}_{3} \mathrm{C}_{2} \mathrm{~T}_{x}$ film displayed the best EMI shielding performance. For example, $\mathrm{Ti}_{3} \mathrm{C}_{2} \mathrm{~T}_{x}$ film with a thickness of only $\sim 40 \mathrm{~nm}$ showed the EMI shielding performance of $21 \mathrm{~dB}$.

\subsubsection{Organic-Hybrid}

The organic substances for hybridization can be divided into three categories: aramid nanofibers (ANFs), cellulose nanofibers (CNFs), and others. 
4.3.2.1 ANF Xie et al. prepared $\mathrm{Ti}_{3} \mathrm{C}_{2} \mathrm{~T}_{x}$ nanosheet/ANF composite film by vacuum-assisted filtration approach [69]. The $\mathrm{Ti}_{3} \mathrm{C}_{2} \mathrm{~T}_{x} / \mathrm{ANF}$ composite film with different $\mathrm{Ti}_{3} \mathrm{C}_{2} \mathrm{~T}_{x}$ addition exhibited outstanding EMI shielding performance, which was accomplished beyond the commercial standard for EMI shielding materials. The $80 \%-\mathrm{Ti}_{3} \mathrm{C}_{2} \mathrm{~T}_{x} / \mathrm{ANF}$ composite film with an ultra-thin thickness $\sim 17 \mu \mathrm{m}$ possessed an EMI SE of $\sim 28 \mathrm{~dB}$ in $8.2-12.4 \mathrm{GHz}$ and electrical conductivity of $173.36 \mathrm{~S} \mathrm{~cm}^{-1}$. Weng et al. further confirmed this conclusion [70]. Lei et al. found that the $\mathrm{Ti}_{3} \mathrm{C}_{2} \mathrm{~T}_{x} / \mathrm{ANF}$ composite film with a loading of $40 \mathrm{wt} \% \mathrm{Ti}_{3} \mathrm{C}_{2} \mathrm{~T}_{x}$ showed high electrical conductivity of $3661.8 \mathrm{~S} \mathrm{~m}^{-1}$ [71], and excellent EMI shielding performance of $24.5 \mathrm{~dB}$, and $\mathrm{SEE}_{\mathrm{t}}$ of $8814.5 \mathrm{~dB} \mathrm{~cm}^{2} \mathrm{~g}^{-1}$ at the thickness of $14 \mu \mathrm{m}$. Wei et al. reported that the $\mathrm{ANF} / \mathrm{Ti}_{3} \mathrm{C}_{2} \mathrm{~T}_{x}$ film with $90 \mathrm{wt} \%$ displayed the EMI SE of $34.71 \mathrm{~dB}$ at the thickness of $11 \mu \mathrm{m}$ and $\mathrm{SEE}_{\mathrm{t}}$ of $21,971.37 \mathrm{~dB} \mathrm{~cm}^{2} \mathrm{~g}^{-1}$, which would be no recession after 1000 times bending [72].

After that, ternary mixed ANF-MXene film was reported [73]. A double-layered and homogeneously blended ANF$\mathrm{Ti}_{3} \mathrm{C}_{2} \mathrm{~T}_{x}$ MXene/silver nanowire (ANF-MXene/AgNW) nanocomposite film was fabricated via the facile twostep vacuum-assisted filtration followed by hot-pressing approach, respectively. Compared with the homogeneously blended ones, the double-layered nanocomposite papers possessed greater advantages in EMI shielding performances, which was due to the massive ohmic losses, multiple internal reflections and polarization relaxation of localized defects, and abundant terminal groups.

4.3.2.2 CNF Cao et al. fabricated an ultrathin and highly

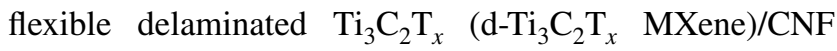
composite film through a vacuum-filtration-induced selfassembly process [74]. The $d-\mathrm{Ti}_{3} \mathrm{C}_{2} \mathrm{~T}_{x} / \mathrm{CNF}$ film with 90 wt $\% d-\mathrm{Ti}_{3} \mathrm{C}_{2} \mathrm{~T}_{x}$ content showed high electrical conductivity (739.4 $\mathrm{S} \mathrm{m}^{-1}$ ) and outstanding EMI shielding performance $\left(\mathrm{SEE}_{\mathrm{t}}=2647 \mathrm{~dB} \mathrm{~cm}^{2} \mathrm{~g}^{-1}\right)$. Zhou et al. found that the CNF/ $\mathrm{Ti}_{3} \mathrm{C}_{2} \mathrm{~T}_{x}$ film showed EMI SE of $\sim 40 \mathrm{~dB}$ and high $\mathrm{SEE}_{\mathrm{t}}$ up to $7029 \mathrm{~dB} \mathrm{~cm}^{2} \mathrm{~g}^{-1}$ with a thickness of only $0.035 \mathrm{~mm}$ [75]. Moreover, the EMI shielding properties could withstand the folding test more than 1000 times without obvious reduction. Cui et al. reported that a $\mathrm{Ti}_{3} \mathrm{C}_{2} \mathrm{~T}_{x} / \mathrm{CNF}$ film exhibited EMI SE of $42.7 \mathrm{~dB}$ with a thickness of $15 \mu \mathrm{m}$, owing to the high electrical conductivity (46.3 $\mathrm{S} \mathrm{cm}^{-1}$ ) [76].

Zhou et al. fabricated a CNF/Ti ${ }_{3} \mathrm{C}_{2} \mathrm{~T} / \mathrm{g}-\mathrm{C}_{3} \mathrm{~N}_{4}$ film with $\mathrm{Ti}_{3} \mathrm{C}_{2} \mathrm{~T} / \mathrm{g}-\mathrm{C}_{3} \mathrm{~N}_{4}$ mass ratio of 5:1 presented outstanding performance with EMI SE of $42.99 \mathrm{~dB}$ in X-band at the thickness of $28.20 \mu \mathrm{m}$ [77]. Moreover, both the electrical conductivity and the EMI SE of the film remained nearly unchanged after bending at $135^{\circ}$ for 10,000 cycles.

$\mathrm{Xin}$ et al. investigated the EMI shielding performance of a $\mathrm{Ti}_{3} \mathrm{C}_{2} \mathrm{~T}_{x} / \mathrm{CNF} /$ silver composite film [78]. The $\mathrm{Ti}_{3} \mathrm{C}_{2} \mathrm{~T}_{x} / \mathrm{CNF} /$ silver composite film exhibited excellent EMI shielding performance $(50.7 \mathrm{~dB})$ and good electrical conductivity (588.2 $\mathrm{S} \mathrm{m}^{-1}$ ), attributed to $\mathrm{Ti}_{3} \mathrm{C}_{2} \mathrm{~T}_{x}$ MXene, self-reduction of silver nanoparticles, and the brick-like structure.

An ultrathin and flexible carbon nanotubes $/ \mathrm{Ti}_{3} \mathrm{C}_{2} \mathrm{~T}_{x} /$ CNF composite film was fabricated via a facile alternating vacuum-assisted filtration process [79]. The film showed a high electrical conductivity of $2506.6 \mathrm{~S} \mathrm{~m}^{-1}$ and EMI SE of $38.4 \mathrm{~dB}$. This result was attributed to the sandwich structure in improving EMI SE, and the gradient structure on regulating the contributions from refection and absorption.

4.3.2.3 Others The flexible green multilayered $\mathrm{Ti}_{3} \mathrm{C}_{2} \mathrm{~T}_{x}$ ' hydroxyethyl cellulose $\left(\mathrm{M}-\mathrm{Ti}_{3} \mathrm{C}_{2} \mathrm{~T}_{x} / \mathrm{HEC}\right)$ composite film was prepared via the filtration-assisted self-assembly method (Fig. 5a-c) [80]. The effect of multilayer stacking on the EMI shielding performance was investigated. The EMI SE of the film exceeded $20 \mathrm{~dB}$ under the stacking thickness reaching $100 \mathrm{~mm}$ (Fig. 5d, e). Notably, the film presented the trend of absorption-dominate green EMI shielding with the decrease of the stacking thickness (Fig. 5f).

Gogotsi's group investigated the EMI shielding performance of a polyethylene terephthalate $(\mathrm{PET}) / \mathrm{Ti}_{3} \mathrm{C}_{2} \mathrm{~T}_{x}$ nanosheet film [81]. The PET/ $/{ }_{3} \mathrm{C}_{2} \mathrm{~T}_{x}$ film exhibited electrical conductivity values of $1080 \pm 175 \mathrm{~S} \mathrm{~cm}^{-1}$, which profoundly exceeded electrical conductivity values of other 2D materials including graphene $\left(250 \mathrm{~S} \mathrm{~cm}^{-1}\right)$ and reduced graphene oxide $\left(340 \mathrm{~S} \mathrm{~cm}^{-1}\right)$. Such excellent EMI shielding performance was ascribed to the high electrical conductivity and layered structure.

A free-standing, ultrathin, and flexible $\mathrm{Ti}_{3} \mathrm{C}_{2} \mathrm{~T}_{x}$ /poly (3,4-ethylenedioxythiophene)-poly (styrene sulfonate) (PEDOT: PSS) film was prepared by a vacuum-assisted filtration process [82]. The composite film with $11.1 \mu \mathrm{m}$ prepared a high EMI SE value of $42.1 \mathrm{~dB}$. Meanwhile, the hybrid film exhibited a superior conductivity of $340.5 \mathrm{~S}$ $\mathrm{cm}^{-1}$ and an excellent specific EMI shielding efficiency of $19,497.8 \mathrm{~dB} \mathrm{~cm}^{2} \mathrm{~g}^{-1}$. This result was due to the lamellar structure of the films and multiple interface reflection and polarization.

Luo et al. fabricated a flexible $\mathrm{Ti}_{3} \mathrm{C}_{2} \mathrm{~T}_{x}$ nanosheet/natural rubber (NR) nanocomposite film via vacuum-assisted filtration approach [83]. In the film, $\mathrm{Ti}_{3} \mathrm{C}_{2} \mathrm{~T}_{x}$ nanosheets 


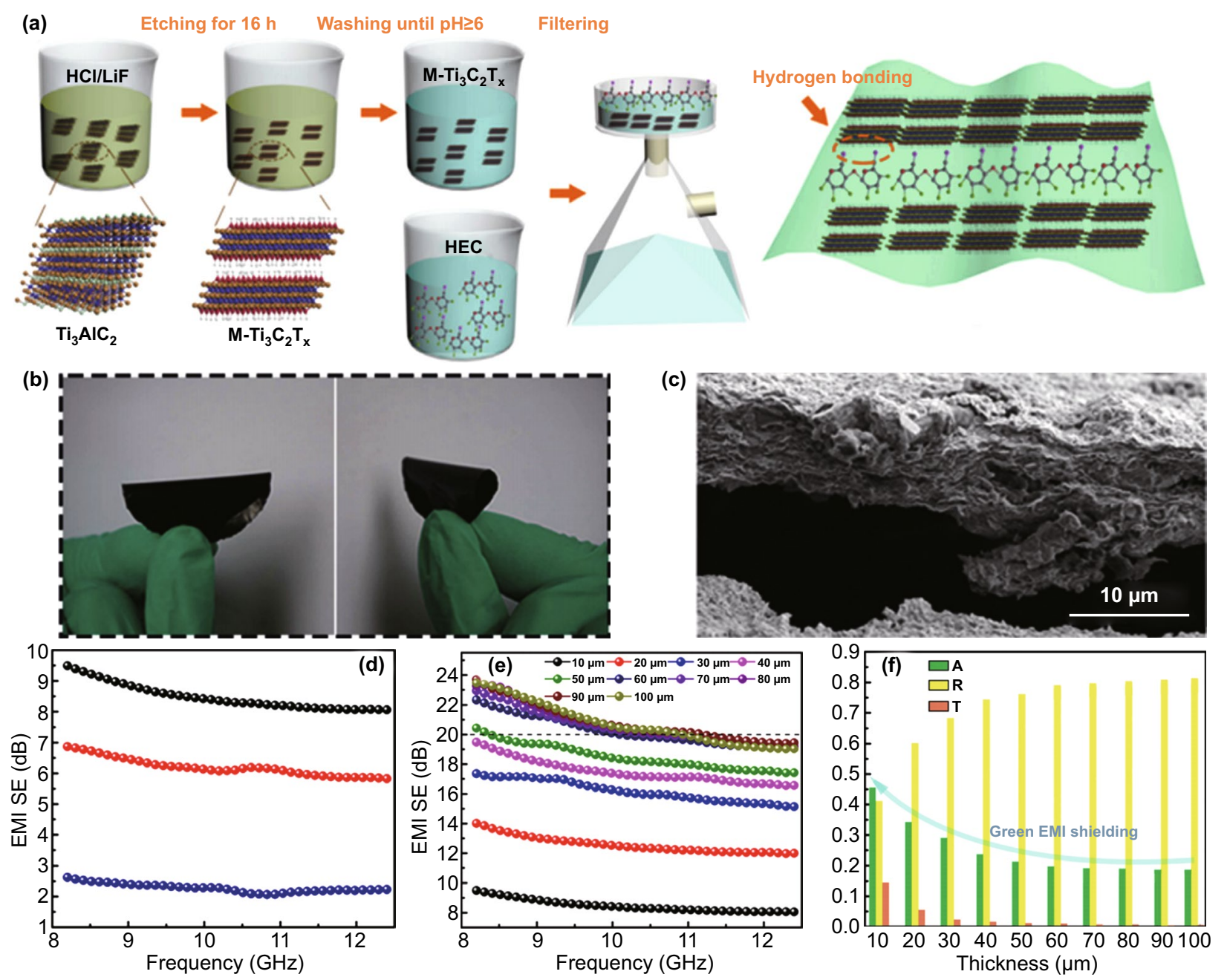

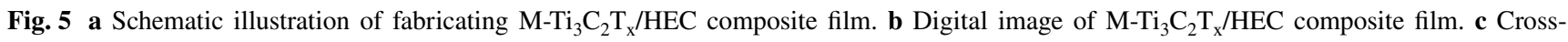
sectional SME images of M-Ti $\mathrm{C}_{2} \mathrm{~T}_{\mathrm{x}} / \mathrm{HEC}$ composite film. d EMI SE $\mathrm{T}_{\mathrm{T}}, \mathrm{SE}_{\mathrm{A}}$ and $\mathrm{SE}_{\mathrm{R}}$ of $\mathrm{M}-\mathrm{Ti}_{3} \mathrm{C}_{2} \mathrm{~T}_{\mathrm{x}} / \mathrm{HEC}$ composite film at $10 \mu$. e EMI SE of $\mathrm{M}-\mathrm{Ti}_{3} \mathrm{C}_{2} \mathrm{~T}_{\mathrm{x}} / \mathrm{HEC}$ composite film at different stacking thicknesses. $f$ The average $\mathrm{A}, \mathrm{R}$ and $\mathrm{T}$ of $\mathrm{M}-\mathrm{Ti}_{3} \mathrm{C}_{2} \mathrm{~T}_{\mathrm{x}} / \mathrm{HEC}$ composite film at different stacking thicknesses. Reproduced with permission from Ref. [80]. Copyright 2019, Elsevier

selectively distributed at the interfaces of the NR particles, forming an interconnected network for efficient electron transport, which leads to excellent EMI shielding performance. $\mathrm{The} \mathrm{Ti}_{3} \mathrm{C}_{2} \mathrm{~T}_{x}$ nanosheet/NR film with $6.71 \mathrm{vol} \%$ of $\mathrm{Ti}_{3} \mathrm{C}_{2} \mathrm{~T}_{x}$ nanosheet showed an outstanding electrical conductivity of $1400 \mathrm{~S} \mathrm{~m}^{-1}$ and a superb EMI shielding performance of $53.6 \mathrm{~dB}$.

Wang et al. prepared a flexible and ultrathin poly (vinylidene fluoride) (PVDF)/ $\mathrm{Ti}_{3} \mathrm{C}_{2} \mathrm{~T}_{x} / \mathrm{Ni}$ chain composite film by physical mixing [84]. The $\mathrm{PVDF} / \mathrm{Ti}_{3} \mathrm{C}_{2} \mathrm{~T}_{x} / \mathrm{Ni}$ chain composite film with only $0.10 \mathrm{~mm}$ thickness showed EMI shielding performance of $19.3 \mathrm{~dB}$, which increased to $34.4 \mathrm{~dB}$ at $0.36 \mathrm{~mm}$ thickness. The outstanding EMI shielding performance was attributed to the excellent electrical conductivity $\left(892 \mathrm{~S} \mathrm{~m}^{-1}\right)$.

An ultrathin $\mathrm{Ti}_{3} \mathrm{C}_{2} \mathrm{~T}_{x}$ /calcium alginate (CA) aerogel film was fabricated via divalent metal ion-induced crosslinking, vacuum-assisted filtration, and freeze-drying. The $\mathrm{Ti}_{3} \mathrm{C}_{2} \mathrm{~T}_{x} / \mathrm{CA}$ aerogel film with a thickness of $26 \mu \mathrm{m}$ presented excellent EMI SE (54.3 dB), owing to its spongelike structure, which facilitated the dissipation of incident EM waves through multi-reflection and scattering in the $\mathrm{Ti}_{3} \mathrm{C}_{2} \mathrm{~T}_{x} / \mathrm{CA}$ aerogel film [85].

Liu et al. fabricated a polyurethane $/ \mathrm{Ti}_{3} \mathrm{C}_{2} \mathrm{~T}_{x}$ MXene film vacuum-assisted filtration [86], thanks to the bioinspired material design and the careful choice of polyurethane as a 
polymer matrix. The polyurethane/ $\mathrm{Ti}_{3} \mathrm{C}_{2} \mathrm{~T}_{x}$ with nacre-like structure showed superior electric conductivity of $\sim 2897.4$ $\mathrm{S} \mathrm{cm}^{-1}$ and $\mathrm{SEE}_{\mathrm{t}}$ of $33,771.92 \mathrm{~dB} \mathrm{~cm}^{2} \mathrm{~g}^{-1}$ with ultra-small thickness $(<10 \mu \mathrm{m})$.

A poly vinyl alcohol/ $/ \mathrm{Ti}_{3} \mathrm{C}_{2} \mathrm{~T}_{x}\left(\mathrm{PVA} / \mathrm{Ti}_{3} \mathrm{C}_{2} \mathrm{~T}_{x}\right)$ film with alternating multilayered structure was prepared by multilayered casting [87]. When the amount of $\mathrm{Ti}_{3} \mathrm{C}_{2} \mathrm{~T}_{x}$ was $19.5 \mathrm{wt} \%, \mathrm{PVA} / \mathrm{Ti}_{3} \mathrm{C}_{2} \mathrm{~T}_{x}$ multilayered film with a thickness of $27 \mu \mathrm{m}$ displayed electrical conductivity of $716 \mathrm{~S} \mathrm{~m}^{-1}$, EMI SE of $44.4 \mathrm{~dB}$, and the $\mathrm{SEE}_{\mathrm{t}}$ of $9343 \mathrm{~dB} \mathrm{~cm}^{2} \mathrm{~g}^{-1}$. This excellent performance was due to the improved multiple interfacial reflection and improved absorption in the MXene layer.

Liu et al. prepared a chitosan (CS)/ $/ \mathrm{Ti}_{3} \mathrm{C}_{2} \mathrm{~T}_{x}$ film by vacuum-assisted filtration [88]. The $\mathrm{CS} / \mathrm{Ti}_{3} \mathrm{C}_{2} \mathrm{~T}_{x}$ film with the $\mathrm{Ti}_{3} \mathrm{C}_{2} \mathrm{~T}_{x}$ content of $75 \mathrm{wt} \%$ displayed high EMI shielding performance of $\sim 34.7 \mathrm{~dB}$ at the thickness of $13 \mu \mathrm{m}$, which was attributed to the outstanding electrical conductivity $\left(\sim 1402 \pm 70 \mathrm{~S} \mathrm{~m}^{-1}\right)$ and multiple internal reflection.

A Ca ion cross-linked sodium alginate (SA)-montmorillonite (MMT)/ $\mathrm{Ti}_{3} \mathrm{C}_{2} \mathrm{~T}_{x}$ MXene (CSA-M-T) film was fabricated by a step-by-step vacuum-assisted filtration process [89]. Compared with the pure $\mathrm{Ti}_{3} \mathrm{C}_{2} \mathrm{~T}_{x}$ layer, such kind of sandwich film can effectively maintain the EMI shielding performance $(50.01 \mathrm{~dB})$.

\subsubsection{Inorganic Hybrid}

4.3.3.1 Carbon-Based A assemble $\mathrm{Ti}_{3} \mathrm{C}_{2} \mathrm{~T}_{x}$ MXene-carbon nanotube (CNT) composite film was fabricated by spin spray layer-by-layer (LbL) [90]. The absolute effectiveness of the film was up to $58,187 \mathrm{~dB} \mathrm{~cm}^{2} \mathrm{~g}^{-1}$, which was due to the both the excellent electrical conductivity $\left(130 \mathrm{~S} \mathrm{~cm}^{-1}\right)$ and the enhanced absorption with the LbL architecture of the films.

Xiang et al. prepared a lightweight and ultrathin $\mathrm{TiO}_{2}-\mathrm{Ti}_{3} \mathrm{C}_{2} \mathrm{~T}$ /graphene film with the range of 5.25-9.17 $\mu \mathrm{m}$ of thickness by vacuum filtration and pyrolysis [91]. The film displayed surface resistance of $7.5 \Omega \mathrm{sq}^{-1}$ and EMI SE of $27 \mathrm{~dB}$. Meanwhile, the value of $\mathrm{SEE}_{\mathrm{t}}$ of the film reached $30,291.43 \mathrm{~dB} \mathrm{~cm}^{2} \mathrm{~g}^{-1}$.

A stretchable $\mathrm{Ti}_{3} \mathrm{C}_{2} \mathrm{~T}_{x}$ nanosheet/single-walled carbon nanotube (SWNT) film was fabricated by $\mathrm{Li}$ et al. by prebuckling of SWNT and $\mathrm{Ti}_{3} \mathrm{C}_{2} \mathrm{~T}_{x}$ nanosheet coatings on latex substrates [50]. A single layer of stretchable $\mathrm{Ti}_{3} \mathrm{C}_{2} \mathrm{~T}_{x} / \mathrm{SWNT}$ film demonstrated a strain-invariant EMI shielding performance of $\approx 30 \mathrm{~dB}$ up to $800 \%$ areal strain.

Zhang's group investigated the EMI shielding performance of $\mathrm{Ti}_{3} \mathrm{C}_{2} \mathrm{~T}_{x}$ MXene-GO film [92]. Thanks to the high electronic conductivity, the $\mathrm{Ti}_{3} \mathrm{C}_{2} \mathrm{~T}_{x}$-GO film with a small film thickness of $7 \mu \mathrm{m}$ displayed the EMI SE of $50.2 \mathrm{~dB}$. Compared with other shielding materials, the MXene-GO films were obviously superior in combining excellent EMI shielding performance and good tensile strength.

A $\mathrm{Ti}_{3} \mathrm{C}_{2} \mathrm{~T}_{x}$-bonded carbon black (CB) film with a porous structure was fabricated by a vacuum-assisted filtration method [93]. With the incorporation of $70 \mathrm{mg}$ of $\mathrm{CB}$, the $\mathrm{Ti}_{3} \mathrm{C}_{2} \mathrm{~T}_{x}$-bonded CB film showed EMI shielding performance of $60 \mathrm{~dB}$ with a $\mathrm{SE}_{\mathrm{A}}$ of $15 \mathrm{~dB}$ and $\mathrm{SE}_{\mathrm{R}}$ of $45 \mathrm{~dB}$. Moreover, the $\mathrm{SEE}_{\mathrm{t}}$ reached $8718 \mathrm{~dB} \mathrm{~cm}^{2} \mathrm{~g}^{-1}$. Research showed that the porous structure could improve the absorption, resulting from enhanced scattering and reflection.

4.3.3.2 Others A aluminum ion-reinforced $\mathrm{Ti}_{3} \mathrm{C}_{2} \mathrm{~T}_{x}$ MXene (Al- $\mathrm{Ti}_{3} \mathrm{C}_{2} \mathrm{~T}_{x}$ ) film was fabricated by Zhang group via vacuum filtration method [94]. The $\mathrm{Al}-\mathrm{Ti}_{3} \mathrm{C}_{2} \mathrm{~T}_{x}$ film displayed a high conductivity of $265,600 \mathrm{~S} \mathrm{~m}^{-1}$. The strong and highly conductive MXene film with a small thickness of $39 \mathrm{~mm}$ showed EMI shielding performances of over $80 \mathrm{~dB}$ in the X-band.

Ning et al. investigated the EMI shielding performance of a Mn ion-intercalated $\mathrm{Ti}_{3} \mathrm{C}_{2} \mathrm{~T}_{x}$ (MIT) film [95]. The MIT film showed an average electronic conductivity of $4268 \mathrm{~S}$ $\mathrm{m}^{-1}$, which was two times than that of pure $\mathrm{Ti}_{3} \mathrm{C}_{2} \mathrm{~T}_{x}$ film (1894 $\mathrm{S} \mathrm{m}^{-1}$ ). The MIT film with a thickness of $2.5 \mu \mathrm{m}$ showed enhanced performance of $44.3 \mathrm{~dB}$ compared with pure $\mathrm{Ti}_{3} \mathrm{C}_{2} \mathrm{~T}_{x}$ film (24.1 dB), owing to the additive internal absorption.

A sliver nanowire $(\mathrm{AgNW}) / \mathrm{Ti}_{3} \mathrm{C}_{2} \mathrm{~T}_{x}$ film was fabricated by a pressured-extrusion film-forming process [96]. The MXene/AgNW composite film with a low loading of nanocellulose $(0.167 \mathrm{wt} \%)$ showed high electrical conductivity of $\sim 30,000 \mathrm{~S} \mathrm{~m}^{-1}$, and remarkable $\mathrm{SEE}_{\mathrm{t}}$ of $16,724 \mathrm{~dB}$ $\mathrm{cm}^{2} \mathrm{~g}^{-1}$.

A $\mathrm{Ti}_{3} \mathrm{C}_{2} \mathrm{~T} /$ /montmorillonite (MMT) film was fabricated by a simple vacuum-assisted filtration technique [97]. The EMI shielding performance of $\mathrm{Ti}_{3} \mathrm{C}_{2} \mathrm{~T}_{x} / \mathrm{MMT}$ film with different concentration ratios was investigated. The composite film with $10 \mathrm{wt} \%$ MMT showed high electrical conductivity $\left(4420 \mathrm{~S} \mathrm{~m}^{-1}\right)$, EMI SE of $65 \mathrm{~dB}$ in the entire X-band 


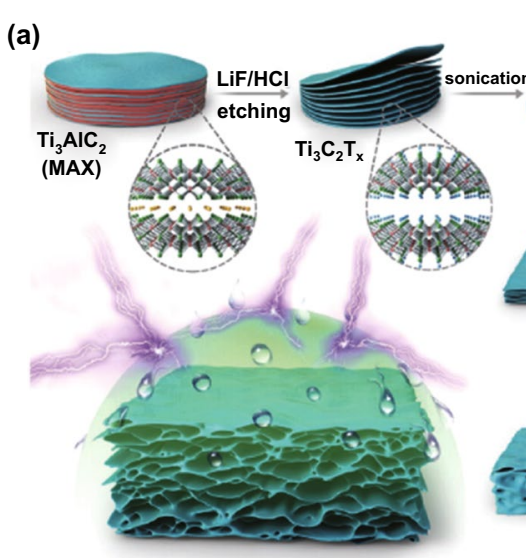

(a)
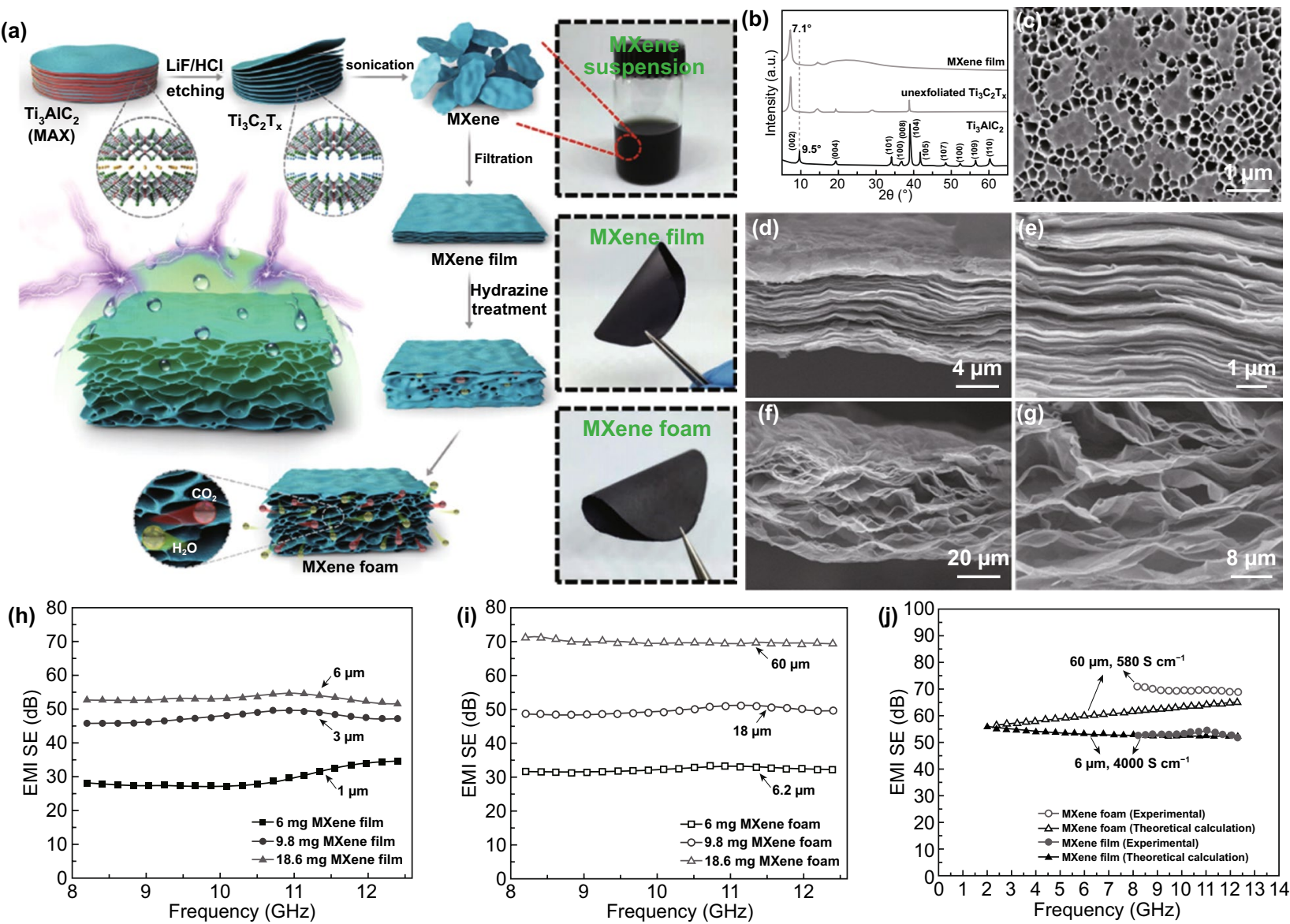

Fig. 6 a Schematic illustration of the fabrication of the hydrophobic and flexible MXene foam. b XRD patterns of $\mathrm{Ti}_{3} \mathrm{AlC}_{2}$, unexfoliated $\mathrm{Ti}_{3} \mathrm{C}_{2} \mathrm{~T}_{\mathrm{x}}$, and the MXene film. c SEM image of the $\mathrm{Ti}_{3} \mathrm{C}_{2} \mathrm{~T}_{\mathrm{x}}$ MXene sheets on an AAO filter. Cross-sectional SEM images of the MXene film d, $\mathbf{e}$ and the MXene foam $\mathbf{f}, \mathbf{g}$. EMI SE of the $\mathbf{h}$ MXene films and $\mathbf{i}$ MXene foams with different thicknesses $(\mu \mathrm{m})$. $\mathbf{j}$ Experimental and theoretical EMI SE of the MXene foam and bulk MXene film. Reproduced with permission from Ref. [98]. Copyright 2017, WILEY-VCH

and $\mathrm{SEE}_{\mathrm{t}}$ of over $10,000 \mathrm{~dB} \mathrm{~cm}^{2} \mathrm{~g}^{-1}$ at a thickness of only $25 \mu \mathrm{m}$.

\subsection{Foam}

\subsubsection{Pristine}

The inceptive study of the EMI shielding performance of pure MXene foam was reported by Yu's group [98]. They used an efficient and facile method to prepare free-standing, flexible, and hydrophobic $\mathrm{Ti}_{3} \mathrm{C}_{2} \mathrm{~T}_{x}$ MXene foam (Fig. 6a-g). In striking contrast to well-known hydrophilic MXene materials, the $\mathrm{Ti}_{3} \mathrm{C}_{2} \mathrm{~T}_{x}$ foams surprisingly had hydrophobic surfaces, with outstanding water resistance and durability. Thanks to the highly efficient wave attenuation in the favorable porous structure, the lightweight $\mathrm{Ti}_{3} \mathrm{C}_{2} \mathrm{~T}_{x}$ foam showed enhanced EMI shielding performance of $70 \mathrm{~dB}$ compared with its unfoamed film counterpart $(53 \mathrm{~dB})($ Fig. $6 \mathrm{~h}-\mathrm{j})$.

\subsubsection{Hybrid}

A porous 3D $\mathrm{Ti}_{3} \mathrm{C}_{2} \mathrm{~T}_{x}$ MXene/C hybrid foam (MCF) was prepared by sol-gel followed by thermal reaction [99]. And, the MCF/epoxy was obtained via vacuum-assisted impregnation followed by curing process. The MCF/epoxy with $4.25 \mathrm{wt} \%$ MCF displayed the EMI shielding performance of $46 \mathrm{~dB}$ and electrical conductivity of $184 \mathrm{~S} / \mathrm{m}$, which was 4.8 and $3.1 \times 10^{4}$ times higher than that of MCF-0/epoxy nanocomposites (without $\mathrm{Ti}_{3} \mathrm{C}_{2} \mathrm{~T}_{x}$ MXene), respectively.

A porous few-layered $\mathrm{Ti}_{2} \mathrm{CT}_{x}\left(\mathrm{f}-\mathrm{Ti}_{2} \mathrm{CT}_{x}\right.$ ) MXene/poly (vinyl alcohol) (PVA) composite foam was fabricated by a 
facile freeze-drying method [100]. The $\mathrm{f}_{-} \mathrm{Ti}_{2} \mathrm{CT}_{x} / \mathrm{PVA}$ foam with a content of only $0.15 \mathrm{vol} \%$ afforded a SEE $\mathrm{t}_{\mathrm{t}}$ of $5136 \mathrm{~dB}$ $\mathrm{cm}^{2} \mathrm{~g}^{-1}$. Such excellent EMI shielding performance was attributed to the multi-porous structure, internal reflection, and polarization effect.

A lightweight $\mathrm{Ti}_{3} \mathrm{C}_{2} \mathrm{~T}_{x}$ MXene/graphene $\left(\mathrm{Ti}_{3} \mathrm{C}_{2} \mathrm{~T}_{x}-\mathrm{GO}\right)$ hybrid foam was fabricated by freeze-drying and reduction heat treatment [101]. Thanks to the improved foam electrical conductivity and highly efficient wave attenuation in interconnected porous structures, the $\mathrm{Ti}_{3} \mathrm{C}_{2} \mathrm{~T}_{x}$-GO hybrid foam showed excellent EMI shielding performance of $50.7 \mathrm{~dB}$ and specific EMI shielding effectiveness of $6217 \mathrm{~dB} \mathrm{~cm}^{3} \mathrm{~g}^{-1}$, which was much higher than that most of the EMI shielding materials.

Silver nanowires (AgNWs)/ $\mathrm{Ti}_{3} \mathrm{C}_{2} \mathrm{~T}_{x}$ foam was fabricated by integrating $\mathrm{AgNWs}$ as the skeleton and $\mathrm{Ti}_{3} \mathrm{C}_{2} \mathrm{~T}_{x}$ as the covering decoration for foaming structure [102]. The AgNWs $/ \mathrm{Ti}_{3} \mathrm{C}_{2} \mathrm{~T}_{x}$ foam showed EMI shielding performance of $41.3 \mathrm{~dB}$ at the thickness of $1.2 \mu \mathrm{m}$ in the X-band. The freespace created during foaming helped to obtain EM wave scattering within the skin depth.

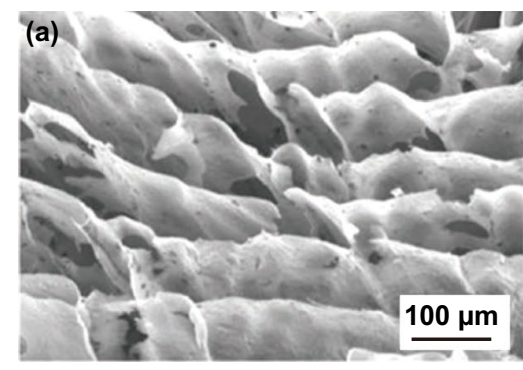

(d)
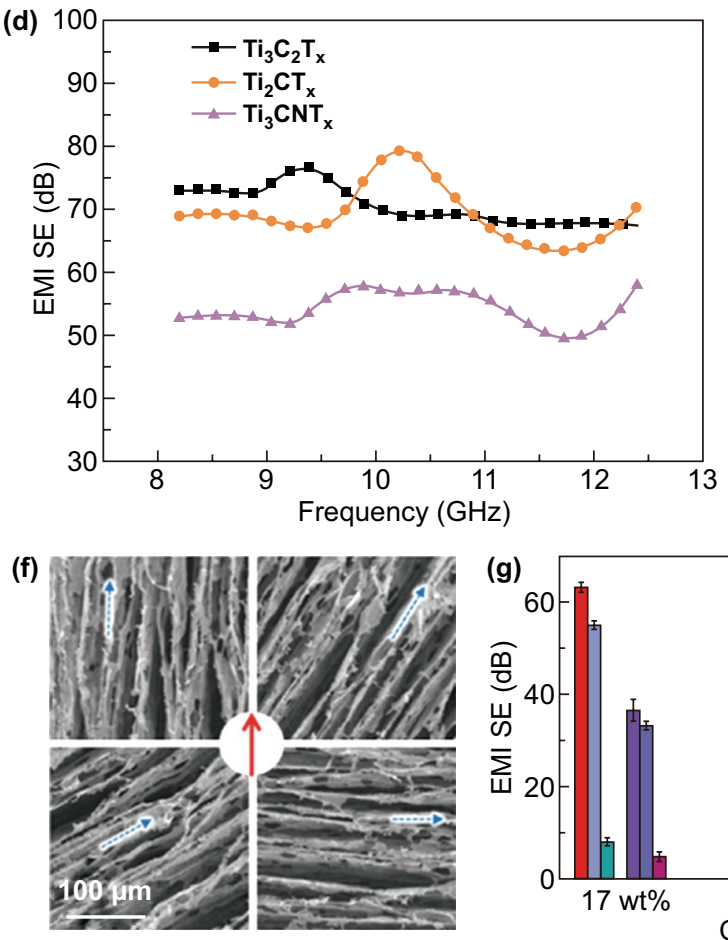
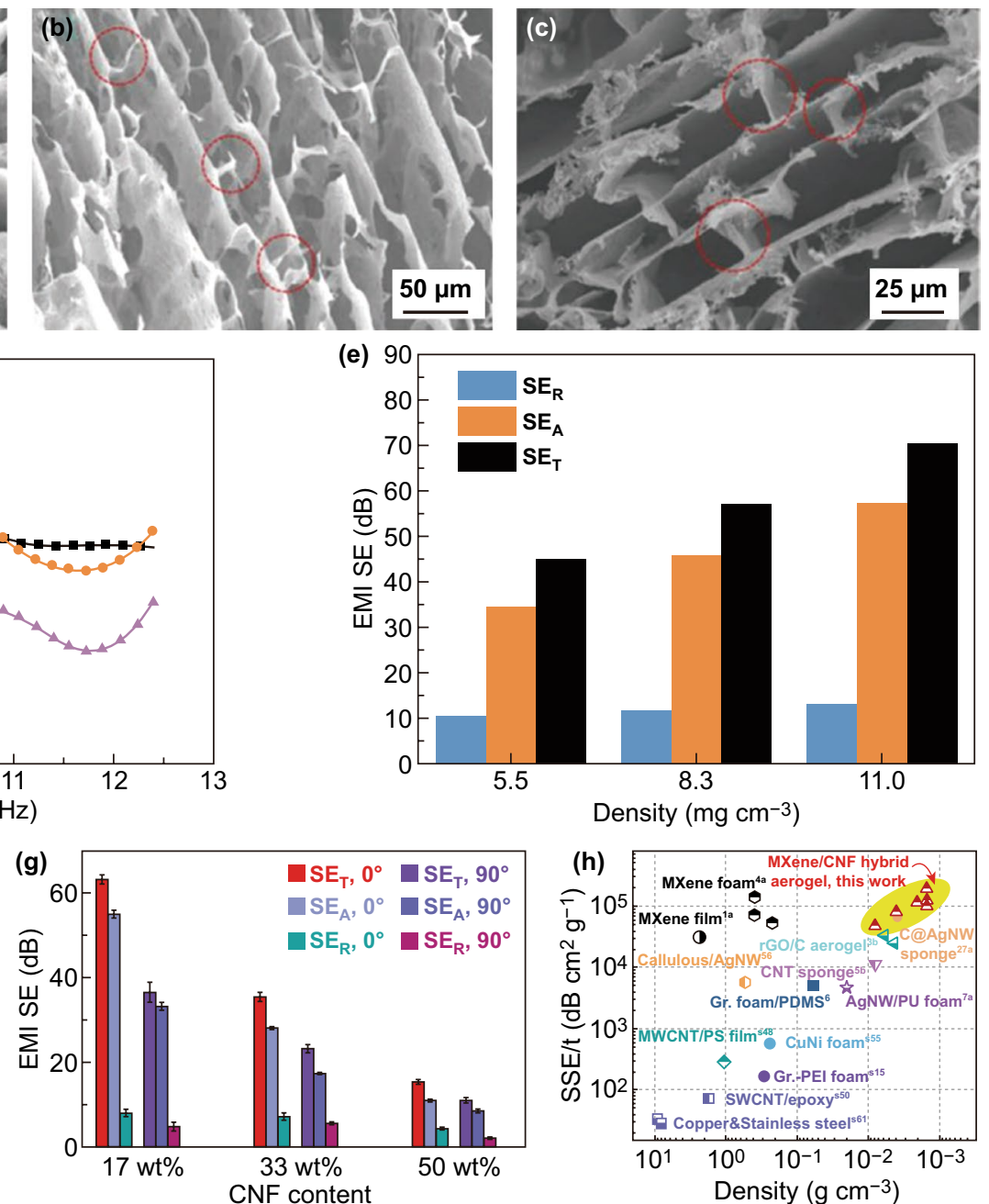

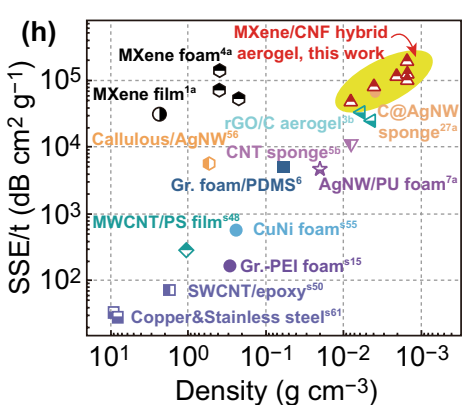

Fig. 7 SEM images of $\mathrm{Ti}_{3} \mathrm{C}_{2} \mathrm{~T}_{\mathrm{x}}$ aerogels with the densities of $\mathbf{a} 5.5, \mathbf{b} 8.3$, and $\mathbf{c} 11.0 \mathrm{mg} \mathrm{cm}^{-3}$, respectively. Interlayer synapses and bridges are circled in red. d Frequency-dependent EMI SE of different MXene aerogels at a density of $11.0 \mathrm{mg} \mathrm{cm}^{-3}$ and a compression thickness of $1 \mathrm{~mm}$. e The average EMI SE of $\mathrm{Ti}_{3} \mathrm{C}_{2} \mathrm{~T}_{\mathrm{x}}$ aerogels with different densities. Reproduced with permission from Ref. [104]. Copyright 2019, WILEY$\mathrm{VCH}$. f SEM images of the MXene/CNF hybrid aerogels with various angles between the cell walls' oriented direction and electric field direction of incident EM waves. $\mathrm{g}$ EMI shielding performance at a fixed frequency of $10 \mathrm{GHz}$ for the MXene/CNF hybrid aerogels $\left(4 \mathrm{mg} \mathrm{cm}^{-3}\right)$ with various CNF contents at cell wall-electric field angles of $0^{\circ}$ and $90^{\circ}$, respectively. $\mathbf{h}$ Comparison of the MXene/CNF hybrid aerogels' shielding performance with other materials. Reproduced with permission from Ref. [106]. Copyright 2020, WILEY-VCH 
A polydimethylsiloxane (PDMS)-coated $\mathrm{Ti}_{3} \mathrm{C}_{2} \mathrm{~T}_{x}$ MXene foam was fabricated by using the $\mathrm{Ti}_{3} \mathrm{C}_{2} \mathrm{~T}_{x}$ assisted with sodium alginate (SA) as template followed by coating a thin layer of PDMS [103]. The $\mathrm{Ti}_{3} \mathrm{C}_{2} \mathrm{~T}_{x} / \mathrm{SA} / \mathrm{PDMS}$ foam with $95 \mathrm{wt} \% \mathrm{Ti}_{3} \mathrm{C}_{2} \mathrm{~T}_{x}$ exhibited an excellent conductivity of $2211 \mathrm{~s} \mathrm{~m}^{-1}$ and EMI shielding performance of $70.5 \mathrm{~dB}$. Moreover, the foam with $74 \mathrm{wt} \% \mathrm{Ti}_{3} \mathrm{C}_{2} \mathrm{~T}_{x}$ displayed EMI SE of $48.2 \mathrm{~dB}$ after 500 compression-release cycles.

\subsection{Aerogel}

\subsubsection{Pristine}

Han et al. fabricated three types of porous MXene aerogels $\left(\mathrm{Ti}_{3} \mathrm{C}_{2} \mathrm{~T}_{x}, \mathrm{Ti}_{2} \mathrm{CT}_{x}\right.$, and $\left.\mathrm{Ti}_{3} \mathrm{CNT}_{x}\right)$ via a bidirectional freeze-casting technique (Fig. 7a-c) [104]. The EMI SE of $\mathrm{Ti}_{3} \mathrm{C}_{2} \mathrm{~T}_{x}, \mathrm{Ti}_{2} \mathrm{CT}_{x}$, and $\mathrm{Ti}_{3} \mathrm{CNT}_{x}$ aerogels reached 70.5, 69.2, and $54.1 \mathrm{~dB}$ at the thickness of $1 \mathrm{~mm}$ (Fig. 7d, e), respectively. Especially, the $\mathrm{SEE}_{\mathrm{t}}$ of $\mathrm{Ti}_{2} \mathrm{CT}_{x}$ aerogel with a density of $5.5 \mathrm{mg} \mathrm{cm}^{-3}$ and a thickness of $1 \mathrm{~mm}$ reached $8818.2 \mathrm{~dB} \mathrm{~cm}^{2} \mathrm{~g}^{-1}$, which was several times higher than that of other materials. Meanwhile, Bian et al. prepared an ultralight $\mathrm{Ti}_{3} \mathrm{C}_{2} \mathrm{~T}_{x}$ aerogel by the freeze-drying method [105]. The $\mathrm{Ti}_{3} \mathrm{C}_{2} \mathrm{~T}_{x}$ aerogel with density of $6.26 \mathrm{mg} \mathrm{cm}^{-1}$ exhibited electrical conductivity of $22 \mathrm{~S} \mathrm{~cm}^{-1}$ and $\mathrm{SEE}_{\mathrm{t}}$ of $9904 \mathrm{~dB} \mathrm{~cm}^{3} \mathrm{~g}^{-1}$. The excellent EMI shielding performance was attributed to the high electrical conductivity and porous structures.

\subsubsection{Hybrid}

A cellulose nanofibril $(\mathrm{CNF}) / \mathrm{Ti}_{3} \mathrm{C}_{2} \mathrm{~T}_{x}$ aerogel was fabricated via an ice-templated freeze-casting approach (Fig. 7f) [106]. The $\mathrm{Ti}_{3} \mathrm{C}_{2} \mathrm{~T}_{x}$ MXene "bricks" bonded by CNF "mortars" of the nacre-like cell walls induced high electrical conductivity, and interfacial polarization led to excellent EMI shielding performance. The $\mathrm{CNF} / \mathrm{Ti}_{3} \mathrm{C}_{2} \mathrm{~T}_{x}$ aerogel with ultralow density showed EMI SE up to $74.6 \mathrm{~dB}$, SEE of as 30,660 dB $\mathrm{cm}^{3} \mathrm{~g}^{-1}$, and $\mathrm{SEE}_{\mathrm{t}}$ achieving $189,400 \mathrm{~dB} \mathrm{~cm}^{2} \mathrm{~g}^{-1}$ (Fig. $7 \mathrm{~g}$, h), exceeding that of other MXene-based or other shielding architectures reported so far.

Zhang et al. fabricated a 3D $\mathrm{Ti}_{3} \mathrm{C}_{2} \mathrm{~T}_{x}$ MXnen/reduced graphene (RGO) hybrid aerogel by directional freezing and freeze-drying [107]. The $\mathrm{Ti}_{3} \mathrm{C}_{2} \mathrm{~T}_{x} / \mathrm{RGO}$ hybrid aerogel with aligned cellular microstructure displayed a high electrical conductivity of $1085 \mathrm{~S} \mathrm{~m}^{-1}$ and an excellent EMI shielding performance of $50 \mathrm{~dB}$ in the $\mathrm{X}$-band at a low $\mathrm{Ti}_{3} \mathrm{C}_{2} \mathrm{~T}_{x}$ content of $0.74 \mathrm{vol} \%$, which was the best results among polymer nanocomposites with similar loading of $\mathrm{Ti}_{3} \mathrm{C}_{2} \mathrm{~T}_{x}$.

Koo's group fabricated a 3D porous $\mathrm{Ti}_{3} \mathrm{C}_{2} \mathrm{~T}_{x}$ /carbon nanotube (CNT) hybrid aerogel by a bidirectional freezing method [108]. The $\mathrm{Ti}_{3} \mathrm{C}_{2} \mathrm{~T}_{x} / \mathrm{CNT}$ aerogel showed excellent electrical conductivity of $9.43 \mathrm{~S} \mathrm{~cm}^{-1}$ and superior EMI shielding performance of $103.9 \mathrm{~dB}$ at $3 \mathrm{~mm}$ thickness over the $\mathrm{X}$-band frequency. The excellent EMI shielding performance of the $\mathrm{Ti}_{3} \mathrm{C}_{2} \mathrm{~T}_{x} / \mathrm{CNT}$ hybrid aerogel was attributed to the $3 \mathrm{D}$ porous structure with a high-conducting and uniform lamellar structure.

Liang et al. prepared a $\mathrm{Ti}_{3} \mathrm{C}_{2} \mathrm{~T}_{x}$ MXene/wood-derived porous carbon (WPC) aerogel via freeze-drying procedure [109]. Such wall-like "mortar-brick" structures profoundly prolong the transmission paths of the EM waves and dissipate the incident EM waves in the form of heat and electric energy, thereby exhibiting the superior EMI shielding performance. The $\mathrm{Ti}_{3} \mathrm{C}_{2} \mathrm{~T}_{x} /$ WPS aerogel showed EMI SE value of $71.3 \mathrm{~dB}$ at density as low as $0.197 \mathrm{~g} \mathrm{~cm}^{-3}$.

\subsection{Fabric}

MXene fabric usually refers to MXene-coated fabric. The main fabrics used for this purpose are cotton or polymers, although other materials are also utilized.

\subsubsection{Cotton}

Geng et al. prepared $\mathrm{Ti}_{3} \mathrm{C}_{2} \mathrm{~T}_{x}$ coated cotton fabrics with low $\mathrm{Ti}_{3} \mathrm{C}_{2} \mathrm{~T}_{x}$ loading (1.5-2.6 mg cm${ }^{-2}$ ) through a facile vacuum filtration process [110]. The fabric with $\mathrm{Ti}_{3} \mathrm{C}_{2} \mathrm{~T}_{x}$ loading of $2.6 \mathrm{mg} \mathrm{cm}^{-2}$ showed $\mathrm{SEE}_{\mathrm{t}}$ of $2969 \mathrm{~dB} \mathrm{~cm}^{2} \mathrm{~g}^{-1}$. Zhang et al. reported that the $\mathrm{Ti}_{3} \mathrm{C}_{2} \mathrm{~T}_{x}$ modified fabric with a low $\mathrm{Ti}_{3} \mathrm{C}_{2} \mathrm{~T}_{x}$ loading $6 \mathrm{wt} \%$ exhibited excellent electrical conductivity of 

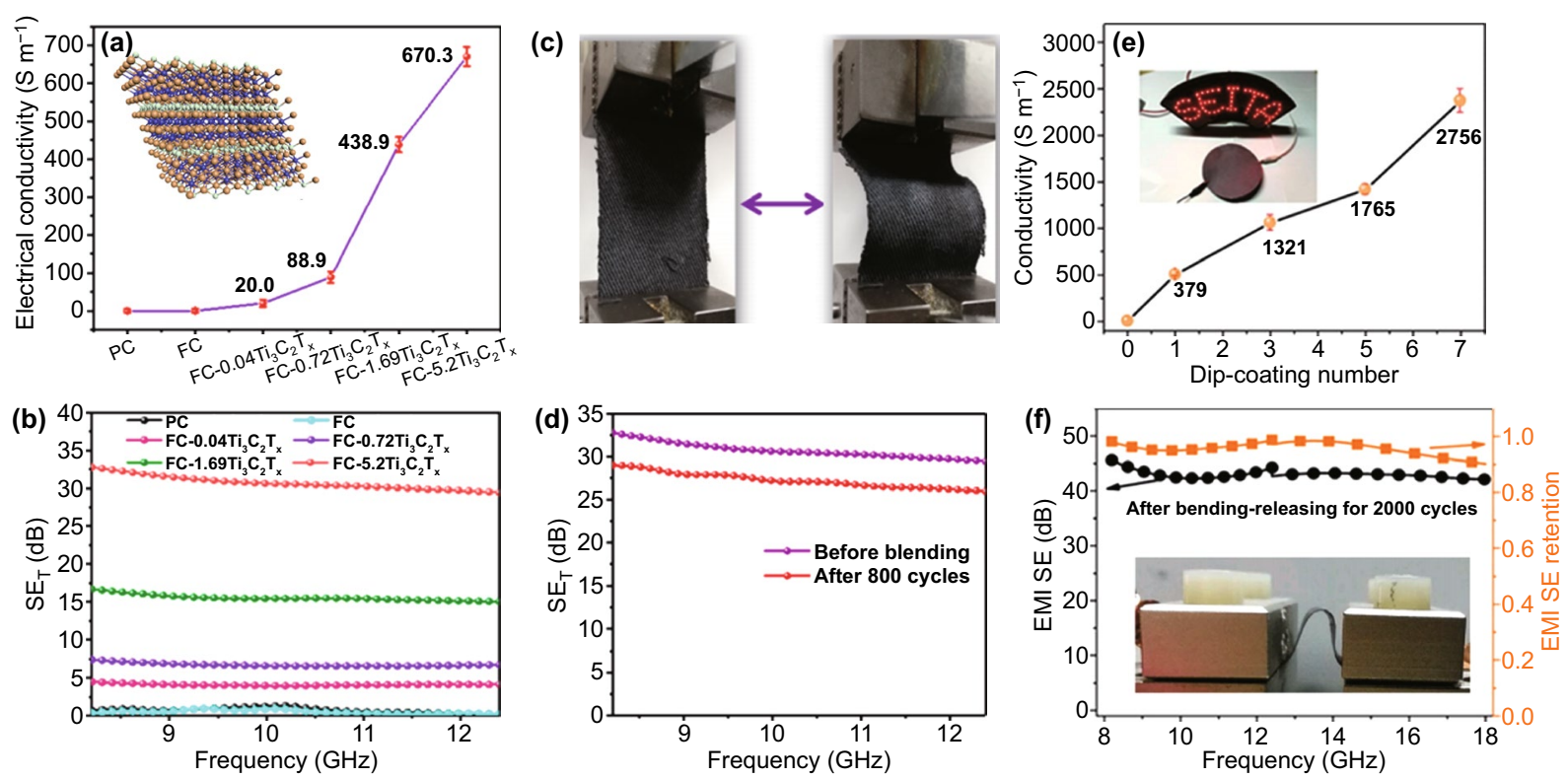

Fig. 8 a Electrical conductivity and b EMI shielding performance of samples in X-band. $\mathbf{c}$ Process of bending test and $\mathbf{d}$ EMI shielding performance of $\mathrm{FC}-5.2 \mathrm{Ti}_{3} \mathrm{C}_{2} \mathrm{~T}_{\mathrm{x}}$ before and after 800 cycles bending test. Reproduced with permission from Ref. [112]. Copyright 2020, American Chemical Society. e Electrical conductivity of M-filter as a function of dip-coating cycles. f EMI SE of the PM-7 after 2000 bending-releasing cycles and the EMI SE retention. Reproduced with permission from Ref. [113]. Copyright 2020, Elsevier

$5 \Omega \mathrm{sq}^{-1}$ and outstanding EMI shielding performance (up to $36 \mathrm{~dB}$ ) [111]. Cheng et al. fabricated a $\mathrm{Ti}_{3} \mathrm{C}_{2} \mathrm{~T}_{x}$ MXenecoated cotton fabric by a simple solution impregnation and dip-coating method [112]. The cotton fabric coated by rising amount of $\mathrm{Ti}_{3} \mathrm{C}_{2} \mathrm{~T}_{x}$ could improve the EMI shielding performance. When the amount of $\mathrm{Ti}_{3} \mathrm{C}_{2} \mathrm{~T}_{x}$ was $5.2 \mathrm{mg} \mathrm{cm}^{-2}$, the fabric afforded excellent electrical conductivity of $670.3 \mathrm{~S}$ $\mathrm{m}^{-1}$ and EMI SE of $31.04 \mathrm{~dB}$ in the X-band (Fig. 8a, b). Moreover, the EMI shielding performance of the fabric was almost not changed after 800 bending times (Fig. 8c, d).

\subsubsection{Polymer}

A flexible and durable cellulose/ $/ \mathrm{Ti}_{3} \mathrm{C}_{2} \mathrm{~T}_{x}$ MXene nanocomposite fabric was fabricated by a simple dip-coating method [113]. The fabric with a $\mathrm{Ti}_{3} \mathrm{C}_{2} \mathrm{~T}_{x}$ nanosheet loading of 1.89 vol\% displayed an outstanding electrical conductivity of $2756 \mathrm{~S} \mathrm{~m}^{-1}$ (Fig. 8e). After a polydimethylsiloxane (PDMS) coating, EMI SE of the fabric could achieve over $43 \mathrm{~dB}$ in the $\mathrm{X}$ and $\mathrm{Ku}$ at the $\mathrm{Ti}_{3} \mathrm{C}_{2} \mathrm{~T}_{x}$ loading of $1.07 \mathrm{vol} \%$, and no apparent decline was observed after 2000 bending-releasing cycles in the durability test (Fig. 8f).
Zhang's group fabricated a $\mathrm{Ti}_{3} \mathrm{C}_{2} \mathrm{~T}_{x}$ MXene-decorated polyester fabric $\left(\mathrm{Ti}_{3} \mathrm{C}_{2} \mathrm{~T}_{x}\right.$-fabric) by depositing in situ polymerized polypyrrole (PPy)-modified $\mathrm{Ti}_{3} \mathrm{C}_{2} \mathrm{~T}_{x}$ nanosheets onto poly (ethylene terephthalate) fabric, followed by silicone coating [114]. The modified fabric displayed a high electrical conductivity of $1000 \mathrm{~S} \mathrm{~m}^{-1}$ and EMI SE of $90 \mathrm{~dB}$, with a thickness of $1.3 \mathrm{~mm}$. Benefiting from the contribution of PPy-to-EM wave absorption due to introduction of the polar group, the EMI shielding performance of the $\mathrm{Ti}_{3} \mathrm{C}_{2} \mathrm{~T}_{x}$-fabric was better than that of the fabric modified by MXene at similar conductivities.

Yuan et al. prepared a flexible and stretchable $\mathrm{Ti}_{3} \mathrm{C}_{2} \mathrm{~T}_{x}$ MXene/polyurethane (PU) fabric [115]. The $\mathrm{Ti}_{3} \mathrm{C}_{2} \mathrm{~T}_{x} / \mathrm{PU}$ fabric with sandwich structure exhibited EMI SE of $\sim 20 \mathrm{~dB}$ at a stretching process within $30 \%$ deformation.

Polyaniline (PANI) $/ \mathrm{Ti}_{3} \mathrm{C}_{2} \mathrm{~T}_{x}$ /carbon fiber (CF) fabric was fabricated based on the LbL assembly approach [116]. The fabric with a thickness of $0.55 \mathrm{~mm}$ possessed a high EMI shielding performance of $26 \mathrm{~dB}$, SSE of $135.5 \mathrm{~dB} \mathrm{~cm}^{3} \mathrm{~g}^{-1}$ and electrical conductivity of $24.57 \mathrm{~S} \mathrm{~m}^{-1}$. 

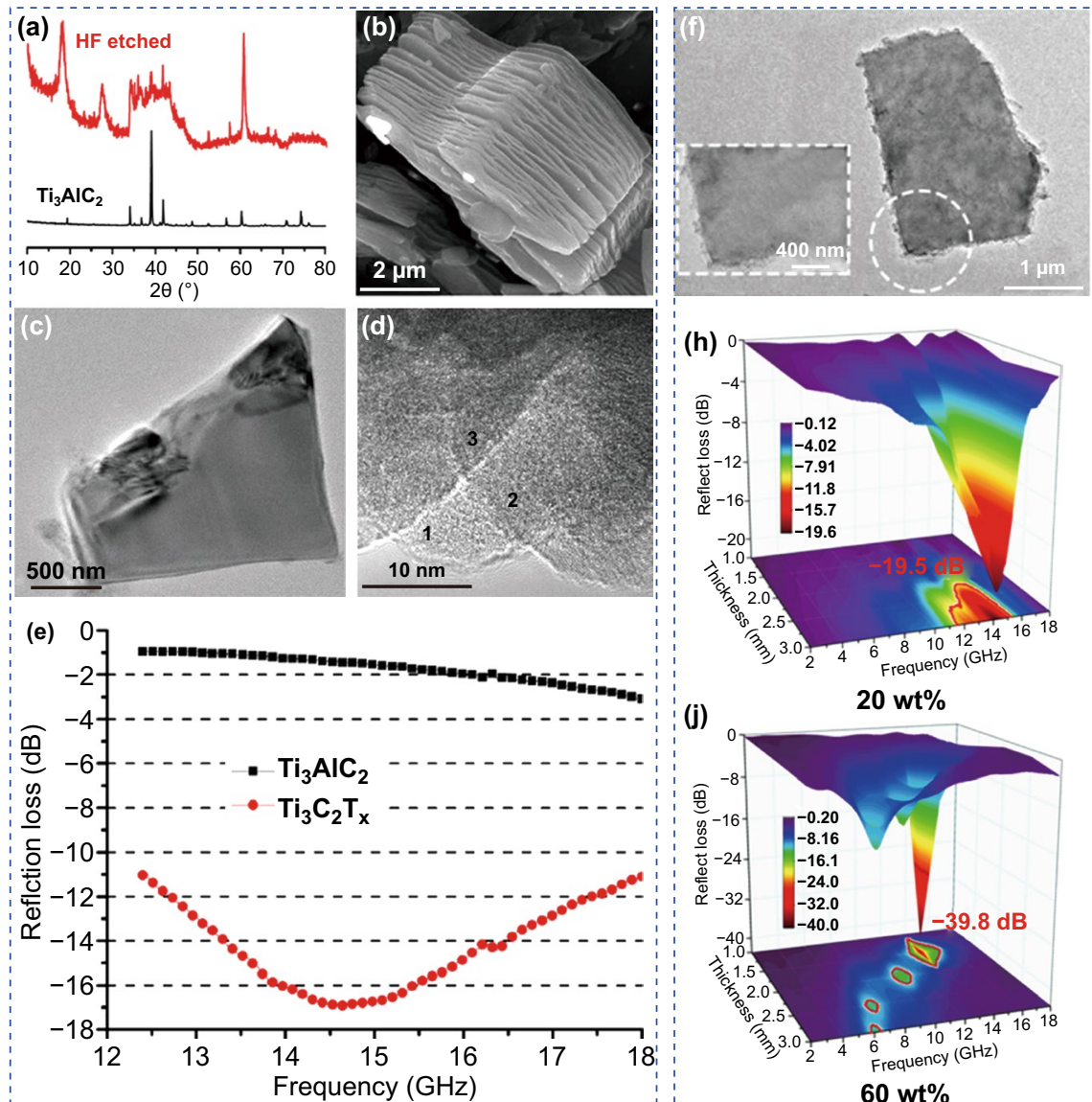
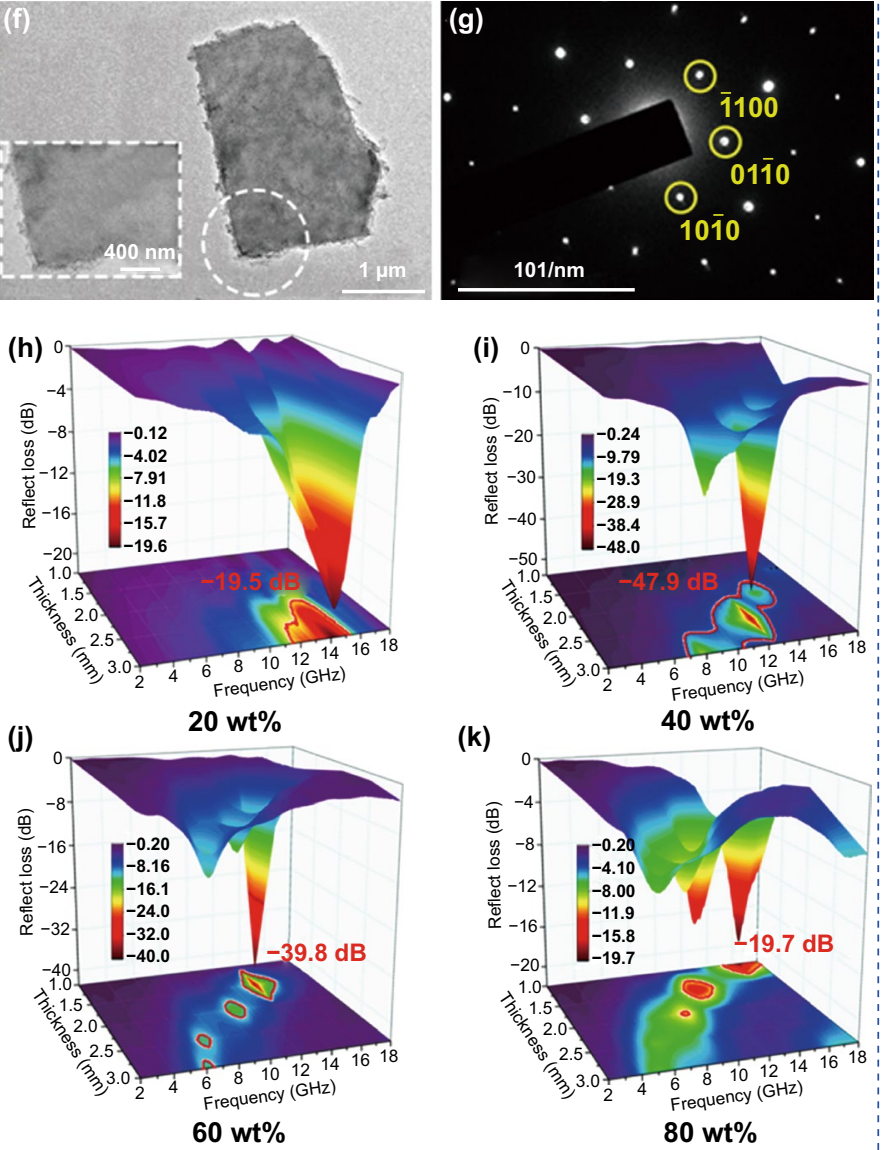

Fig. 9 a XRD patterns of the $\mathrm{Ti}_{3} \mathrm{AlC}_{2}$ before and after $\mathrm{HF}$ treatment at room temperature. $\mathbf{b} \mathrm{SEM}$ image of a multilayer $\mathrm{Ti}_{3} \mathrm{C}_{2} \mathrm{~T}_{\mathrm{x}}$ after $\mathrm{HF}$ treatment. c Transmitted light micrographs of exfoliated $\mathrm{Ti}_{3} \mathrm{C}_{2} \mathrm{~T}_{\mathrm{x}}$. d TEM images for $\mathrm{Ti}_{3} \mathrm{C}_{2} \mathrm{~T}_{\mathrm{x}}$ layers. e Thickness dependence of the reflection loss of the $50 \mathrm{wt} \% \mathrm{Ti}_{3} \mathrm{C}_{2} \mathrm{~T}_{\mathrm{x}}$ filled $\mathrm{Ti}_{3} \mathrm{C}_{2} \mathrm{~T}_{\mathrm{x}} /$ wax composites in the Ku-band. Reproduced with permission from Ref. [119]. Copyright 2016, Elsevier. f High-resolution (HR) TEM image of D- $\mathrm{Ti}_{3} \mathrm{C}_{2} \mathrm{~T}_{\mathrm{x}}$. $\mathbf{g}$ The selected area electron diffraction (SAED) pattern of D-Ti ${ }_{3} \mathrm{C}_{2} \mathrm{~T}_{\mathrm{x}}$. h-k Reflection loss of composite with different $\mathrm{D}-\mathrm{Ti}_{3} \mathrm{C}_{2} \mathrm{~T}_{\mathrm{x}} /$ wax weight fraction at different layer thickness. Reproduced with permission from Ref. [44]. Copyright 2019, American Chemical Society

\subsubsection{Others}

Yu's group prepared the silk fabric with biomimetic leaf-like MXene/silver nanowire by depositing in situ polymerized PPy-modified $\mathrm{Ti}_{3} \mathrm{C}_{2} \mathrm{~T}_{x}$ MXene sheets onto poly (ethylene terephthalate) textiles followed by a silicone coating [117]. The flexible fabric displayed a low sheet resistance of $0.8 \Omega$ $\mathrm{sq}^{-1}$, excellent EMI shielding performance of $54 \mathrm{~dB}$ in the $\mathrm{X}$-band at the thickness of $120 \mu \mathrm{m}$.

$\mathrm{Ti}_{3} \mathrm{C}_{2} \mathrm{~T}_{x}$ MXene-decorated wood-pulp fabric was fabricated by depositing highly conductive $\mathrm{Ti}_{3} \mathrm{C}_{2} \mathrm{~T}_{x}$ MXene networks onto wood-pulp fabric grid (FG) followed by hydrophobic methyltrimethoxysilane (MTMS) coating with multi-scaled roughness via a simple vacuum-filtration approach and sol-gel process [118]. The fabric possessed superior EMI SE up to 57.8-90.2 dB.

\section{MXene-Based Materials for EM Wave Absorption}

\subsection{Pure MXene Matrix}

\subsubsection{Non-annealing}

The earliest research was concerned with the EM waveabsorbing properties of multilayer $\mathrm{Ti}_{3} \mathrm{C}_{2} \mathrm{~T}_{x}$. Qing et al. prepared multilayer $\mathrm{Ti}_{3} \mathrm{C}_{2} \mathrm{~T}_{x}$ MXene by etching $\mathrm{Ti}_{3} \mathrm{AlC}_{2}$ 
with 50\% HF for $3 \mathrm{~h}$ (Fig. 9a-d) [119]. Compared with the $\mathrm{Ti}_{3} \mathrm{AlC}_{2} /$ wax, the multilayer $\mathrm{Ti}_{3} \mathrm{C}_{2} \mathrm{~T}_{x} /$ wax showed high EM wave absorption at the same filling concentration of $50 \mathrm{wt} \%$ (Fig. 9e). This result was due to the unique two-dimensional (2D) morphology of multilayer $\mathrm{Ti}_{3} \mathrm{C}_{2} \mathrm{~T}_{x}$ MXene, such as the large number of defects and larger internal boundary layer capacitance. Feng et al. further confirmed that the excellent EM wave-absorbing property of multilayer $\mathrm{Ti}_{3} \mathrm{C}_{2} \mathrm{~T}_{x} /$ wax was due to the high dielectric loss and the strong multi-reflections [120]. Luo et al. used a combination of experiment and simulation to study the EM wave absorption of multilayer $\mathrm{Ti}_{3} \mathrm{C}_{2} \mathrm{~T}_{x}$ [121], finding that the frequency dispersion effect and the double-peaked dielectric spectral features of $\mathrm{Ti}_{3} \mathrm{C}_{2} \mathrm{~T}_{x} /$ wax led to superior EM wave absorption.

The influence of different etching time on the EM waveabsorbing performance of multilayer $\mathrm{Ti}_{3} \mathrm{C}_{2} \mathrm{~T}_{x}$ has also been studied. Tong et al. investigated the effect of different etching time in $40 \mathrm{wt} \% \mathrm{HF}$ acid on the EM wave absorption of multilayer $\mathrm{Ti}_{3} \mathrm{C}_{2} \mathrm{~T}_{x}$ MXene $(0,6,24,48,96,144$, and $192 \mathrm{~h}$ ) [122]. With the increase of etching time, the morphology of $\mathrm{Ti}_{3} \mathrm{C}_{2} \mathrm{~T}_{x}$ was destroyed gradually. $\mathrm{Ti}_{3} \mathrm{C}_{2} \mathrm{~T}_{x}$ etched for $24 \mathrm{~h}$ afforded the best EM wave-absorbing properties among etching sample. A minimum RL value of $-42.5 \mathrm{~dB}$ was achieved at the thickness of $1.7 \mathrm{~mm}$. This result could be attributed to multiple reflections between MXene layers and interfacial polarizations. Zhao's group etched the multilayer $\mathrm{Ti}_{3} \mathrm{C}_{2} \mathrm{~T}_{x}$ in $\geq 40 \mathrm{wt} \% \mathrm{HF}$ acid for different time (1, 2, and $3 \mathrm{~h}$ ) [123] and then explored their EM wave absorption. Multilayer $\mathrm{Ti}_{3} \mathrm{C}_{2} \mathrm{~T}_{x}$ etched for $3 \mathrm{~h}\left(\mathrm{Ti}_{3} \mathrm{C}_{2} \mathrm{~T}_{x}-3\right)$ had excellent EM wave-absorbing property. Forty percentage ratio multilayer $\mathrm{Ti}_{3} \mathrm{C}_{2} \mathrm{~T}_{x}-3 /$ wax showed a minimum $\mathrm{RL}$ value of $-36.3 \mathrm{~dB}$ with a thickness of $4.5 \mathrm{~mm}$. Cui et al. produced multilayer $\mathrm{Ti}_{3} \mathrm{C}_{2} \mathrm{~T}_{x}$ etched by $\mathrm{HCl} / \mathrm{LiF}$ with different diverse etching times (12, 24, 36, 48, and $60 \mathrm{~h}$ ) [124] and studied their EM wave absorbing properties. They found the same result as HF etching. The $\mathrm{Ti}_{3} \mathrm{C}_{2} \mathrm{~T}_{x}$ etched $24 \mathrm{~h}$ showed best EM wave absorption, owing to multilayer scattering between the laminate structures.

The influence of different etchants on the EM waveabsorbing properties was reported by Xu's group [125]. Multilayer $\mathrm{Ti}_{3} \mathrm{C}_{2} \mathrm{~T}_{x}$ MXenes were obtained by ultrasonication-solvothermal treatment in different solvents including dimethylformamide (DMF), ethanol, and dimethyl sulfoxide (DMSO), respectively. Research showed that multilayer $\mathrm{Ti}_{3} \mathrm{C}_{2} \mathrm{~T}_{x}$ treated with DMF showed excellent wave-absorbing properties due to the larger layer space and diminished oxidation effects.

Cao's group was firstly investigated the EM wave absorption performance of the delaminated $\mathrm{Ti}_{3} \mathrm{C}_{2} \mathrm{~T}_{x}\left(\mathrm{~d}-\mathrm{Ti}_{3} \mathrm{C}_{2} \mathrm{~T}_{x}\right)$ nanosheet etched by $\mathrm{HCl} / \mathrm{LiF}$ (Fig. 9f, g) [44]. All $\mathrm{Ti}_{3} \mathrm{C}_{2} \mathrm{~T}_{x}$ nanosheet/wax composites with different concentrations showed excellent EM wave absorption (Fig. 9h-k). Especially for $40 \mathrm{wt} \%$ composite, a minimum RL value of $-47.9 \mathrm{~dB}$ and a corresponding absorption bandwidth of $3.6 \mathrm{GHz}$ were achieved at a thickness of $2.5 \mathrm{~mm}$. Moreover, they found the transformation mechanism between EM energy and thermal energy in the composite. The higher the concentration of delaminated $\mathrm{Ti}_{3} \mathrm{C}_{2} \mathrm{~T}_{x}$ nanosheet in the composite, more was the conversion of EM energy to thermal energy.

Xu's group fabricated the multilayer $\mathrm{Nb}_{2} \mathrm{CT}_{x}$ MXene by $49 \mathrm{wt} \%$ HF etching and solvothermal/hydrothermal treatment [126]. They found that multilayer $\mathrm{Nb}_{2} \mathrm{CT}_{x}$ further treated in ethanol showed much more superior absorption capability. This result could be due to the enlarged interlayer spacing, and increased surface functional groups after ethanol-based solvothermal treatment.

\subsubsection{Annealing}

Yin's group originally reported that the multilayer $\mathrm{Ti}_{3} \mathrm{C}_{2} \mathrm{~T}_{x}$ MXene annealed at $800{ }^{\circ} \mathrm{C}$ for $2 \mathrm{~h}$ in Ar atmosphere had excellent EM wave-absorbing properties [58]. Such excellent EM wave-absorbing properties were due to the surface functional groups of MXene modified by annealing. The annealing led to the formation of a local sandwich structure composed of $\mathrm{TiO}_{2}$ nanocrystals and amorphous carbon, which enhanced the EM wave absorption. After that, they investigated the EM wave-absorbing properties of multilayer $\mathrm{Ti}_{3} \mathrm{C}_{2} \mathrm{~T}_{x}$ at different annealing temperatures $(600,700$, and $800{ }^{\circ} \mathrm{C}$ ) for $1 \mathrm{~h}$ in $\mathrm{CO}_{2}$ [127]. The multilayer $\mathrm{Ti}_{3} \mathrm{C}_{2} \mathrm{~T}_{x}$ annealed at $800{ }^{\circ} \mathrm{C}$ showed best EM wave absorption performance with its RL value achieving $-36 \mathrm{~dB}$ and absorption bandwidth of $5.6 \mathrm{GHz}$. Meanwhile, they explored the EM wave absorption performance of multilayer $\mathrm{Ti}_{3} \mathrm{C}_{2} \mathrm{~T}_{x}$ annealed at 500, 800, and $900{ }^{\circ} \mathrm{C}$ for $1 \mathrm{~h}$ in $\mathrm{CO}_{2}$ [128]. The microwave absorption of multilayer $\mathrm{Ti}_{3} \mathrm{C}_{2} \mathrm{~T}_{x}$ annealed at 800 ${ }^{\circ} \mathrm{C}$ was best, which was due to the enhanced polarization loss and stronger conduction loss. 
Fan et al. fabricated the multilayer $\mathrm{Ti}_{3} \mathrm{C}_{2} \mathrm{~T}_{x}$, and annealed it in $\mathrm{O}_{2}$ at different temperatures $(100,200,300,400$, and $500{ }^{\circ} \mathrm{C}$ ) for $2 \mathrm{~h}$ [129]. The multilayer $\mathrm{Ti}_{3} \mathrm{C}_{2} \mathrm{~T}_{x}$ calcined at $100{ }^{\circ} \mathrm{C}$ showed excellent EM wave-absorbing properties, with a minimum RL value of $-40.07 \mathrm{~dB}$ at $19.2 \mathrm{GHz}$ and the absorption bandwidth of $3.8 \mathrm{GHz}$. This result was attributed to the appropriate complex permittivity and matching impendence.

\subsection{MXene Hybrid Matrix}

EM wave absorption can be improved by increasing the magnetic loss or dielectric loss. The magnetic loss of the absorber can be improved by doping with magnetic materials. Certain carbon-based materials with high conductivity can be doped into the absorber to enhance the dielectric loss.

\subsubsection{Magnetic Hybrid}

5.2.1.1 Fe-Based Liu et al. investigated the EM wave absorption of the multilayer $\mathrm{Ti}_{3} \mathrm{C}_{2} \mathrm{~T}_{x}$ doped with different concentrations of $\mathrm{Fe}_{3} \mathrm{O}_{4}(3,5$, and $10 \mathrm{wt} \%)\left(\mathrm{Ti}_{3} \mathrm{C}_{2} \mathrm{~T}_{x}-3\right.$, $\mathrm{Ti}_{3} \mathrm{C}_{2} \mathrm{~T}_{x}-5, \mathrm{Ti}_{3} \mathrm{C}_{2} \mathrm{~T}_{x}-10$ ) [130]. By tuning the doping concentration of $\mathrm{Fe}_{3} \mathrm{O}_{4}$, the sample showed improved microwave absorption performance. Among them, $\mathrm{Ti}_{3} \mathrm{C}_{2} \mathrm{~T}_{x}-10 /$ wax showed excellent absorption performance, with a maximum $\mathrm{RL}$ value of $-57.3 \mathrm{~dB}$. Zhao et al. further investigated the EM wave absorption of multilayer $\mathrm{Ti}_{3} \mathrm{C}_{2} \mathrm{~T}_{x} / \mathrm{Fe}_{3} \mathrm{O}_{4}$ [131]. The multilayer $\mathrm{Ti}_{3} \mathrm{C}_{2} \mathrm{~T}_{x} / \mathrm{Fe}_{3} \mathrm{O}_{4}$ exhibited enhanced EM wave absorption compared with pure multilayer $\mathrm{Ti}_{3} \mathrm{C}_{2} \mathrm{~T}_{x}$, which is due to the outstanding impedance matching and efficient attenuation. Yang's group studied the EM wave-absorbing properties of multilayer $\mathrm{Ti}_{3} \mathrm{C}_{2} \mathrm{~T}_{x}$ doped with $\mathrm{Fe}_{3} \mathrm{O}_{4}$ nanoparticles $\left(\mathrm{Fe}_{3} \mathrm{O}_{4} @ \mathrm{Ti}_{3} \mathrm{C}_{2} \mathrm{~T}_{x}\right)$ with different concentrations [132]. The sample contained $25 \mathrm{wt} \% \mathrm{Fe}_{3} \mathrm{O}_{4}$ nanoparticle displayed outstanding EM wave absorption, with a minimum RL value of $-57.2 \mathrm{~dB}$ at $15.7 \mathrm{GHz}$ and bandwidth of $1.4 \mathrm{GHz}$, caused by enhanced interface polarization. Che's group fabricated magnetized multilayer $\mathrm{Ti}_{3} \mathrm{C}_{2} \mathrm{~T}_{x}$ MXene microsphere by embedded $\mathrm{Ti}_{3} \mathrm{C}_{2} \mathrm{~T}_{x}$ MXene into a confined and magnetized $\mathrm{Fe}_{3} \mathrm{O}_{4}$ nanospheres (designated as $\mathrm{M} / \mathrm{F}$ ) [133]. This structure could enhance the specific interfaces and dielectric polarization. Meanwhile, these $\mathrm{Fe}_{3} \mathrm{O}_{4}$ magnetic led to the optimized impedance balance and EM coordination capability. As expected, the M/F composite with 15 wt $\% \mathrm{Fe}_{3} \mathrm{O}_{4}$ content hold distinct EM wave absorption property with the strong reflection loss $(-50.6 \mathrm{~dB})$ and absorption bandwidth $(4.67 \mathrm{GHz})$ at the thickness of $2 \mathrm{~mm}$.

The multilayer $\mathrm{Ti}_{3} \mathrm{C}_{2} \mathrm{~T}_{x} /$ flaky carbonyl iron (FCI) composite with different mass ratios were fabricated by the ultrasonic mixing method [134]. An excellent EM wave-absorbing properties can be realized by optimizing the $\mathrm{Ti}_{3} \mathrm{C}_{2} \mathrm{~T}_{x}$ and FCI content. Beneficial from the good impedance matching and moderate attenuation ability, the composite with $20 \mathrm{wt} \%$ $\mathrm{Ti}_{3} \mathrm{C}_{2} \mathrm{~T}_{x}$ and $40 \mathrm{wt} \%$ FCI loading presented the absorption bandwidth of $8.16 \mathrm{GHz}$ with a thickness of $1.0 \mathrm{~mm}$.

5.2.1.2 Ni-Based A $\quad \mathrm{Ti}_{3} \mathrm{C}_{2} \mathrm{~T}_{x} / \mathrm{Ni}$-nanoparticle hybrid was synthesized by in situ hydrothermal treatment. The $\mathrm{Ti}_{3} \mathrm{C}_{2} \mathrm{~T}_{x}$-Ni hybrid showed a $R L$ value of $-47.06 \mathrm{~dB}$ with a thickness of $1.5 \mathrm{~mm}$ and bandwidth of $3.6 \mathrm{GHz}$ [135]. The combined effect of magnetic loss, conduction loss and dielectric loss is the key to achieving such excellent EMabsorbing ability. Liang et al. prepared a $\mathrm{Ti}_{3} \mathrm{C}_{2} \mathrm{~T}_{x}$ MXene/ Ni-nanochain (Ni@MXene) hybrid via a facile and moderate co-solvothermal method [36]. The Ni@MXene hybrid displayed a minimum $R L$ of $-49.9 \mathrm{~dB}$ at the thickness of $1.75 \mathrm{~mm}$ when the Ni-nanochain content was $90 \mathrm{wt} \%$. It was further proved that the synergistic effect of conductive MXene and the magnetic Ni-nanochain led to the excellent EM wave-absorbing ability. Che's group also investigated the EM wave-absorbing properties of a multilayer $\mathrm{Ti}_{3} \mathrm{C}_{2} \mathrm{~T}_{x} /$ $\mathrm{Ni}$ hybrid [136]. The $\mathrm{Ni}$ nanoparticles were uniformly distributed on the surface and in the multilayered gaps of $\mathrm{Ti}_{3} \mathrm{C}_{2} \mathrm{~T}_{x}$. This unique structure led to excellent EM waveabsorbing properties. The hybrid showed a minimum $R L$ of $-50.5 \mathrm{~dB}$ at $5.5 \mathrm{GHz}$. Liang et al. investigated the EM wave-absorbing properties of $\mathrm{Ni}-, \mathrm{Co}-$ and $\mathrm{NiCo}-$ doped multilayer $\mathrm{Ti}_{3} \mathrm{C}_{2} \mathrm{~T}_{x}$ [137]. Among them, multilayer $\mathrm{Ti}_{3} \mathrm{C}_{2} \mathrm{~T}_{x}$ doped with $\mathrm{Ni}$ nanoparticles $\left(\mathrm{Ni} @ \mathrm{Ti}_{3} \mathrm{C}_{2} \mathrm{~T}_{x}\right)$ in a polyvinylidene fluoride (PVDF) matrix showed strong EM wave absorption. With $10 \mathrm{wt} \% \mathrm{Ni}$ dopant, the sample exhibited the optimal EM wave absorption, with a minimum $R L$ of $-52.6 \mathrm{~dB}$ at $8.4 \mathrm{GHz}$ and absorption bandwidth of $3.7 \mathrm{GHz}$. Liu et al. found that compared with the individual $\mathrm{Ti}_{3} \mathrm{C}_{2} \mathrm{~T}_{x}$ and Ni powders [138], hybrid $\mathrm{Ti}_{3} \mathrm{C}_{2} \mathrm{~T}_{x} / \mathrm{Ni}$ afforded the most favorable EM wave absorption performance with a minimum RL value of $-24.3 \mathrm{~dB}$ at $9.8 \mathrm{GHz}$.

5.2.1.3 Co-Based Deng et al. fabricated the $\mathrm{Co}_{3} \mathrm{O}_{4} /$ $\mathrm{Ti}_{3} \mathrm{C}_{2} \mathrm{~T}_{x}$ by the two-step method. When the mass ratio of $\mathrm{Ti}_{3} \mathrm{C}_{2} \mathrm{~T}_{x}$ to $\mathrm{Co}_{3} \mathrm{O}_{4}$ was 1:3 [139], the $\mathrm{Co}_{3} \mathrm{O}_{4} / \mathrm{Ti}_{3} \mathrm{C}_{2} \mathrm{~T}_{x}$ hybrid showed better than $90 \%$ absorption from 10.8 to $17 \mathrm{GHz}$. Such excellent performance is owing to combined effects of multilayer structure, defects, conductivity of $\mathrm{Ti}_{3} \mathrm{C}_{2} \mathrm{~T}_{x}$ and equivalent capacitance of $\mathrm{Co}_{3} \mathrm{O}_{4}$. 
5.2.1.4 Multi-based A CoFe $@ \mathrm{Ti}_{3} \mathrm{C}_{2} \mathrm{~T}_{x}$ hybrid was prepared by in situ reduction, and a minimum $R L$ value of $36.29 \mathrm{~dB}$ could be obtained with a thickness of $2.2 \mathrm{~mm}$ [140]. The excellent EM wave absorption performance was due to the sandwich-like structure and enhanced interfacial polarization. He et al. further confirmed that multilayer $\mathrm{Ti}_{3} \mathrm{C}_{2} \mathrm{~T}_{x}$ modified by $\mathrm{CoFe}$ could improve the EM wave absorption.

A FeCo@ $\mathrm{Ti}_{3} \mathrm{C}_{2} \mathrm{~T}_{x}$ hybrid was fabricated by in situ hydrothermal treatment [141]. The incorporation of magnetic FeCo could improve the EM wave-absorbing property. The FeCo@ $\mathrm{Ti}_{3} \mathrm{C}_{2} \mathrm{~T}_{x}$ hybrid exhibited a broad EM wave-absorbing bandwidth of $8.8 \mathrm{GHz}$, due to enhanced impedance matching and microwave attenuation.

A Co-doped NiZn ferrite (CNZF)/polyaniline (PANI) on $\mathrm{Ti}_{3} \mathrm{C}_{2} \mathrm{~T}_{x}$ hybrid (CNZF/PANI/Ti ${ }_{3} \mathrm{C}_{2} \mathrm{~T}_{x}$ ) was synthesized by hydrothermal reaction and interfacial polymerization [142]. The dipole polarization, interfacial polarization, natural resonance, eddy current loss, and multiple reflections contributed to the improved EM wave absorption performance of CNZFO/PANI/ $/ \mathrm{Ti}_{3} \mathrm{C}_{2} \mathrm{~T}_{x}$ hybrid. The multiple-layer hybrid exhibited excellent EM wave absorption with a minimum $R L$ of $-37.1 \mathrm{~dB}$ and absorption bandwidth of $4.1 \mathrm{GHz}$.

Hou et al. investigated the EM wave-absorbing properties of $\mathrm{NiCo}_{2} \mathrm{O}_{4}$-doped multilayer $\mathrm{Ti}_{3} \mathrm{C}_{2} \mathrm{~T}_{x}$ at different annealing temperatures $\left(350,400,450\right.$, and $\left.500{ }^{\circ} \mathrm{C}\right)$ for $2 \mathrm{~h}$ in argon [143]. The $\mathrm{NiCo}_{2} \mathrm{O}_{4} / \mathrm{Ti}_{3} \mathrm{C}_{2} \mathrm{~T}_{x}$ annealed at $350{ }^{\circ} \mathrm{C}$ displayed the best $\mathrm{EM}$ wave absorption, with the $R L$ value of $-50.96 \mathrm{~dB}$. This result was attributed to the polarization behavior and multiple scattering produced by unique structures.

The EM wave-absorbing properties of $\mathrm{Ba}_{3} \mathrm{Co}_{2} \mathrm{Fe}_{24} \mathrm{O}_{41}$, multilayer $\mathrm{Ti}_{3} \mathrm{C}_{2} \mathrm{~T}_{x}$, and polyvinyl butyral (PVB) after physical mixing were investigated by Yang's group [144]. The as-synthesized $\mathrm{PVB} / \mathrm{Ba}_{3} \mathrm{Co}_{2} \mathrm{Fe}_{24} \mathrm{O}_{41} / \mathrm{Ti}_{3} \mathrm{C}_{2} \mathrm{~T}_{x}$ exhibited outstanding and efficient $\mathrm{EM}$ wave attenuation. A minimum $\mathrm{RL}$ value for the $\mathrm{PVB} / \mathrm{Ba}_{3} \mathrm{Co}_{2} \mathrm{Fe}_{24} \mathrm{O}_{41} / \mathrm{Ti}_{3} \mathrm{C}_{2} \mathrm{~T}_{x}$ composite reached $-46.3 \mathrm{~dB}$ at $5.8 \mathrm{GHz}$; the absorption bandwidth was $1.6 \mathrm{GHz}$, with a thickness of only $2.8 \mathrm{~mm}$.

\subsubsection{Carbon-Based Hybrid}

A graphite/TiC/ $\mathrm{Ti}_{3} \mathrm{C}_{2} \mathrm{~T}_{x}\left(\mathrm{G} / \mathrm{TiC} / \mathrm{Ti}_{3} \mathrm{C}_{2} \mathrm{~T}_{x}\right)$ hybrid was obtained by two steps [145]. Firstly, the graphite/TiC/ $\mathrm{Ti}_{3} \mathrm{AlC}_{2}\left(\mathrm{G} / \mathrm{TiC} / \mathrm{Ti}_{3} \mathrm{AlC}_{2}\right)$ hybrid was prepared in a bath of molten salts. $\mathrm{G} / \mathrm{TiC} / \mathrm{Ti}_{3} \mathrm{C}_{2} \mathrm{~T}_{x}$ was obtained after etching the $\mathrm{Al}$ atoms from $\mathrm{G} / \mathrm{TiC} / \mathrm{Ti}_{3} \mathrm{AlC}_{2}$ (Fig. 10a-c). It was found that the graphite/TiC/Ti ${ }_{3} \mathrm{AlC}_{2}$-wax matrix with a thickness of $2.1 \mathrm{~mm}$ exhibited a minimum $R L$ of $-63 \mathrm{~dB}$ and the effective absorption bandwidth was more than $3.5 \mathrm{GHz}$ (Fig. 10d, e).

Multilayer $\mathrm{Ti}_{3} \mathrm{C}_{2} \mathrm{~T}_{x}$ MXene modified with in situ grown carbon nanotubes $\left(\mathrm{Ti}_{3} \mathrm{C}_{2} \mathrm{~T}_{x} / \mathrm{CNT}\right)$ was fabricated by Yin's group (Fig. 10f, g) [146]. Compared with the pure multilayer
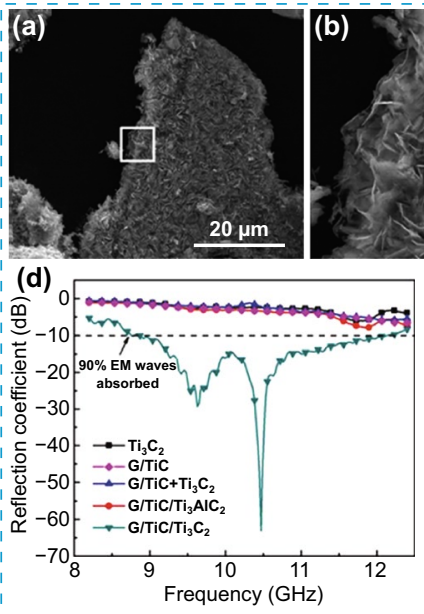
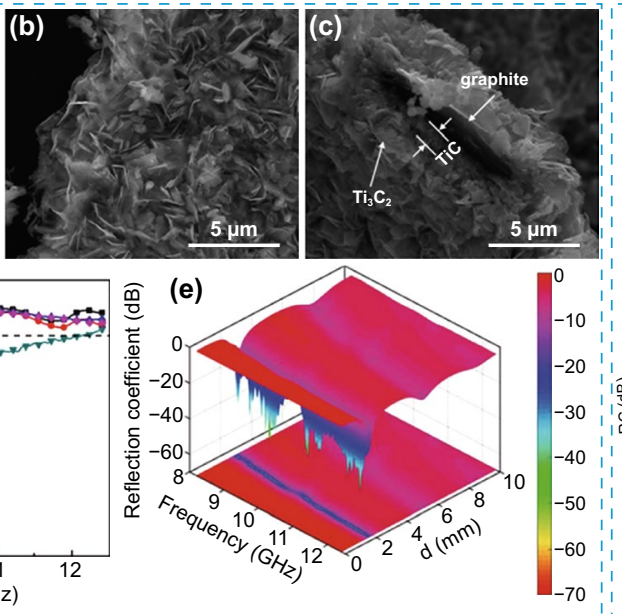

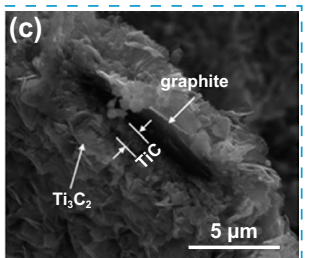

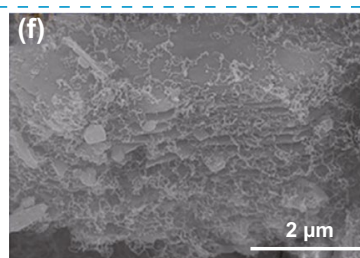

(h)

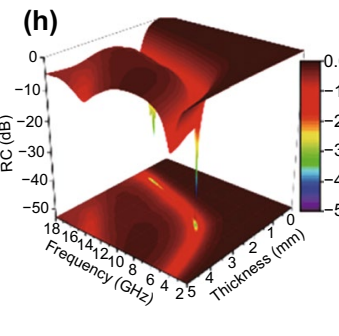

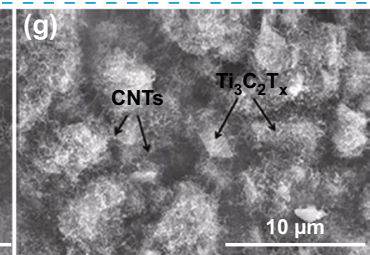

(i)

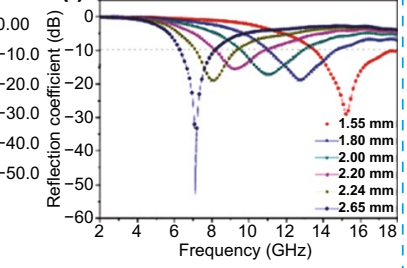

Fig. 10 SEM image of a-c G/TiC/Ti ${ }_{3} C_{2} T_{x}$. d RC of G/TiC/Ti ${ }_{3} C_{2} T_{x}, T_{3} C_{2} T_{x}, G / T i C / T_{3} A_{1 C}$, G/TiC, and G/TiC + Ti ${ }_{3} C_{2} T_{x}$ in paraffin matrix with the loading of $50 \mathrm{wt} \%$ with the sample thickness of $2.1 \mathrm{~mm}$. e 3D RC of G/TiC/Ti ${ }_{3} \mathrm{C}_{2} \mathrm{~T}_{\mathrm{x}}$ versus frequency and sample thickness. Reproduced with permission from Ref. [145]. Copyright 2018, WILEY-VCH. SEM images of $\mathbf{f}$ and $\mathbf{g} \mathrm{Ti}_{3} \mathrm{C}_{2} \mathrm{~T}_{\mathrm{x}} / \mathrm{CNT}$. $\mathbf{h}$ 3D representations and $\mathbf{i}$ theoretical curves of $\mathrm{RC}$ versus frequency and thickness of $\mathrm{Ti}_{3} \mathrm{C}_{2} \mathrm{~T}_{\mathrm{x}} / \mathrm{CNT}$ with a filler loading of $35 \mathrm{wt} \%$. Reproduced with permission form Ref. [146]. Copyright 2017, The Royal Society of Chemistry 
$\mathrm{Ti}_{3} \mathrm{C}_{2} \mathrm{~T}_{x}$ MXenes, the hierarchical microstructure makes a contribution to the outstanding EM wave absorption performance, with a minimum $R L$ value of $-52.9 \mathrm{~dB}$ and absorption bandwidth of $4.46 \mathrm{GHz}$ (Fig. 10h, i).

Dai et al. reported that the $\mathrm{Ti}_{3} \mathrm{C}_{2} \mathrm{~T}_{x}$ MXenes/nano-carbon sphere hybrid exhibited $R L$ of $-54.67 \mathrm{~dB}$ at $3.97 \mathrm{GHz}$ [147], owing to the unique structure of $\mathrm{Ti}_{3} \mathrm{C}_{2} \mathrm{~T}_{x}$ MXenes/nano-carbon and the formation of a heterogeneous interface structure.

Nitrogen-doped graphene (N-GP) and $\mathrm{Ti}_{3} \mathrm{C}_{2} \mathrm{~T}_{x}$ composites were prepared by Qing group [148]. The values and frequency dependencies of EM properties of N-GP/Ti ${ }_{3} \mathrm{C}_{2} \mathrm{~T}_{x}$ could be tuned by the combination of the unique structure and dielectric characteristics of the N-GP and $\mathrm{Ti}_{3} \mathrm{C}_{2} \mathrm{~T}_{x}$. A minimum $\mathrm{RL}$ of the $\mathrm{N}-\mathrm{GP} / \mathrm{Ti}_{3} \mathrm{C}_{2} \mathrm{~T}_{x}$ composite reached up to $-52 \mathrm{~dB}$, and absorption bandwidth could be obtained in the frequency range of $10.9-18 \mathrm{GHz}$ with a thickness of only $1.4 \mathrm{~mm}$.

\subsubsection{Others Hybrid}

Qian et al. prepared an urchin-like $\mathrm{ZnO}-\mathrm{Ti}_{3} \mathrm{C}_{2} \mathrm{~T}_{x}$ hybrid through a coprecipitation process [149]. Compared with pure multilayer $\mathrm{Ti}_{3} \mathrm{C}_{2} \mathrm{~T}_{x}, \mathrm{ZnO}-\mathrm{Ti}_{3} \mathrm{C}_{2} \mathrm{~T}_{x}$ hybrid showed significant enhanced EM wave absorption. The minimum RL of $75 \mathrm{wt} \% \mathrm{ZnO}-\mathrm{Ti}_{3} \mathrm{C}_{2} \mathrm{~T}_{x} /$ wax realized $-26.30 \mathrm{~dB}$, which is much better than that of pure multilayer $\mathrm{Ti}_{3} \mathrm{C}_{2} \mathrm{~T}_{x}(-6.70 \mathrm{~dB})$, owing to larger interfaces and the construction of semiconductive networks.

$\mathrm{Ti}_{3} \mathrm{C}_{2} \mathrm{~T}_{x}$ MXenes/polypyrrole microspheres $\left(\mathrm{Ti}_{3} \mathrm{C}_{2} \mathrm{~T}_{x} /\right.$ $\mathrm{PPy}$ ) composites with delaminated structure were fabricated for significant enhancement of EM wave-absorbing properties [150]. Thanks to the synergistic effect between $\mathrm{Ti}_{3} \mathrm{C}_{2} \mathrm{~T}_{x}$ and PPy microspheres, the obtained $\mathrm{Ti}_{3} \mathrm{C}_{2} \mathrm{~T}_{x} @ \mathrm{PPy}$ composite exhibited excellent EM absorption performance. The $10 \mathrm{wt} \% \mathrm{Ti}_{3} \mathrm{C}_{2} \mathrm{~T}_{x} @ \mathrm{PPy}$ composites in wax matrix displayed a minimum RL of $-49.5 \mathrm{~dB}$ at $7.6 \mathrm{GHz}$, and the absorption bandwidth was $5.14 \mathrm{GHz}$. Tong et al. reported that multilayer $\mathrm{Ti}_{3} \mathrm{C}_{2} \mathrm{~T}_{x}$ MXene decorated with PPy chains is a good microwave-absorbing material [151]. The $25 \mathrm{wt} \%$ $\mathrm{Ti}_{3} \mathrm{C}_{2} \mathrm{~T}_{x} / \mathrm{PPy}$ hybrids in a wax matrix showed a minimum $R L$ of $-49.2 \mathrm{~dB}$.

A multilayer $\mathrm{Ti}_{3} \mathrm{C}_{2} \mathrm{~T}_{x}$ modified by $\mathrm{MoS}_{2}$ was fabricated by a hydrothermal method [152]. The complex permittivity of $\mathrm{MoS}_{2} / \mathrm{Ti}_{3} \mathrm{C}_{2} \mathrm{~T}_{x}$ increased compared with that of multilayer $\mathrm{Ti}_{3} \mathrm{C}_{2} \mathrm{~T}_{x}$. This result led to enhanced EM wave-absorbing performance. When the thickness of $\mathrm{MoS}_{2} / \mathrm{Ti}_{3} \mathrm{C}_{2} \mathrm{~T}_{x}$-wax was $2.5 \mathrm{~mm}$, the corresponding absorption bandwidth was $2.6 \mathrm{GHz}$.

A multilayer $\mathrm{Ti}_{3} \mathrm{C}_{2} \mathrm{~T}_{x}$ MXene/polyaniline (PANI) was prepared by the hydrothermal reaction [153]. The EM wave absorption of sample with different PANI doping concentrations was systematically studied. When the mass ratio of $\mathrm{Ti}_{3} \mathrm{C}_{2} \mathrm{~T}_{x}$ to polyaniline is $1: 2$, the sample showed best EM wave absorption. The maximum $R L$ reached $-56.30 \mathrm{~dB}$ at $13.80 \mathrm{GHz}$ with a thickness of $1.8 \mathrm{~mm}$.

The $\mathrm{Nb}_{2} \mathrm{O}_{5}$ with different morphologies was prepared in situ and implanted between the layers of the $\mathrm{Nb}_{2} \mathrm{CT}_{x}$ MXene via hydrothermal method [154]. The $\mathrm{Nb}_{2} \mathrm{O}_{5} / \mathrm{Nb}_{2} \mathrm{CT}_{x}$ exhibited the enhanced EM wave absorption compared with primary $\mathrm{Nb}_{2} \mathrm{CT}_{x}$ MXene. Especially, $\mathrm{Nb}_{2} \mathrm{CT}_{x}$ doped with columnar $\mathrm{Nb}_{2} \mathrm{O}_{5}$ showed a minimum $R L$ of $-44.1 \mathrm{~dB}$ at $2.8 \mathrm{GHz}$, owing to the increased lamellar spacing of the $\mathrm{Nb}_{2} \mathrm{CT}_{x}$.

\subsection{Foam}

Yin's group fabricated reduced graphene oxide (RGO)/ $\mathrm{Ti}_{3} \mathrm{C}_{2} \mathrm{~T}_{x}$ hybrids foam via self-assembly and sacrificial template processes [155]. The $\mathrm{RGO} / \mathrm{Ti}_{3} \mathrm{C}_{2} \mathrm{~T}_{x}$ foam with the density is merely $0.0033 \mathrm{~g} \mathrm{~cm}^{-3}$ possessed outstanding EM absorption performance superior to all reported foambased counterparts, and the absorption bandwidth covers the whole X-band at $3.2 \mathrm{~mm}$, and its specific EM absorption performance value exceeds $14,299.2 \mathrm{~dB} \mathrm{~cm}^{-2} \mathrm{~g}^{-1}$. Those results were attributed to the unique heterogeneous interface associated with core-shell structures. Meanwhile, they synthesized ordered lamellar few-layered $\mathrm{Ti}_{3} \mathrm{C}_{2} \mathrm{~T}_{x} / \mathrm{SiC}$ nanowires (f- $\mathrm{Ti}_{3} \mathrm{C}_{2} \mathrm{~T}_{x} / \mathrm{SiCnws}$ ) hybrid foams with ultralow density via a combination of self-assembly and bidirectional freezing processes (Fig. 11a-d) [156].

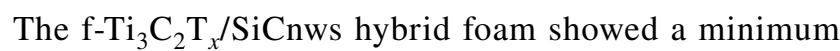
$R L$ of $-55.7 \mathrm{~dB}$ at an ultralow density of only about $0.029 \mathrm{~g} \mathrm{~cm}^{-3}$ (Fig. 11e, f). Compared with most of the current foam-based counterparts, the free-standing foams exhibited enhanced EM absorption properties, owing to enhanced polarization loss and balance the conductive loss and impedance matching characteristics caused by the unique microstructure and phase compositions. After that, they prepared porous $\mathrm{Ti}_{2} \mathrm{CT}_{x}$ MXene/poly vinyl alcohol (PVA) composite foams constructed by a facile 

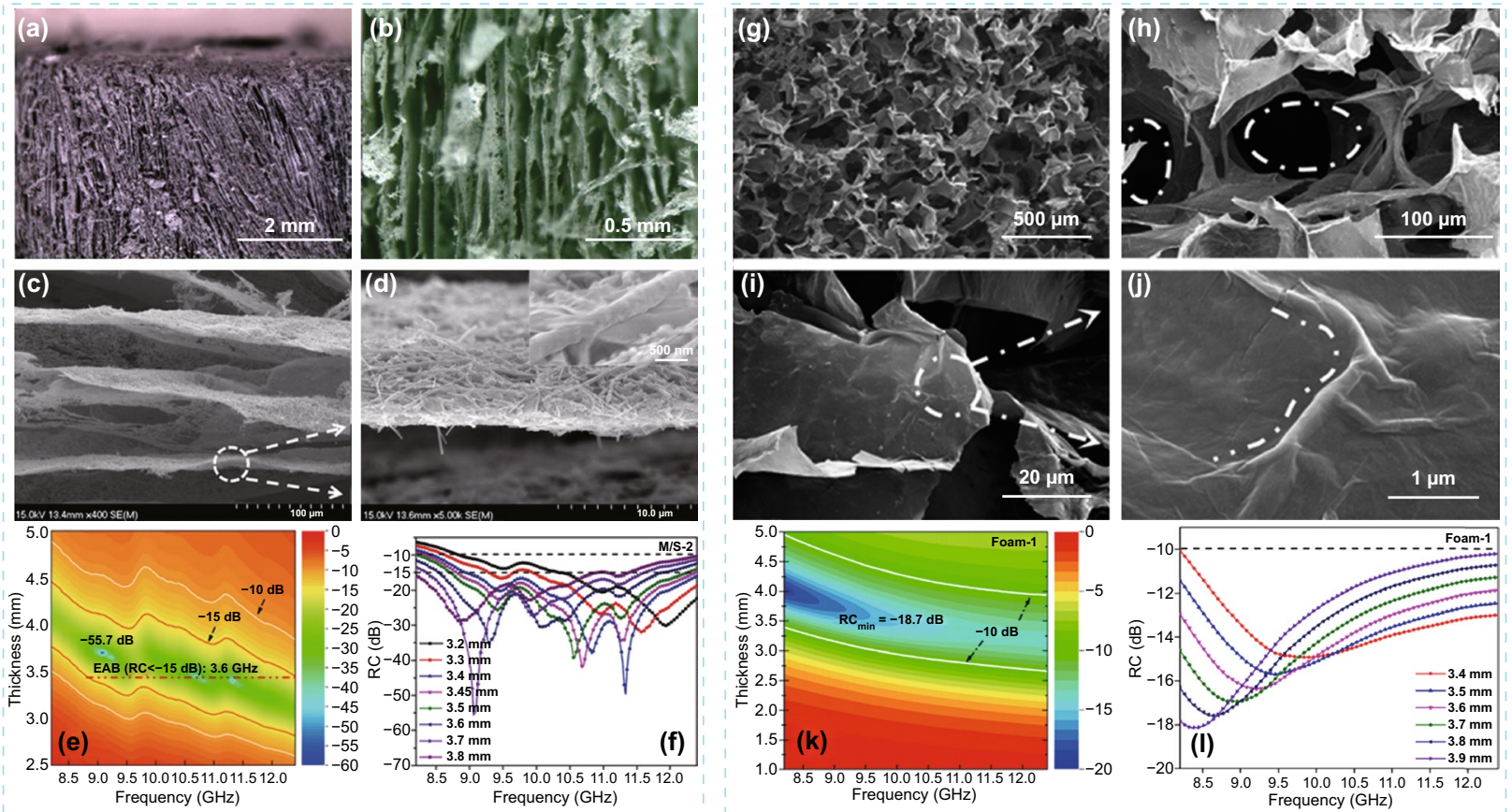

Fig. 11 a, b Digital photographs of $\mathrm{f}-\mathrm{Ti}_{2} \mathrm{CT}_{\mathrm{x}} / \mathrm{SiCnws}$ hybrid foams. c, $\mathbf{d}$ Typical cross-sectional $\mathrm{SEM}$ images of $\mathrm{f}-\mathrm{Ti}_{2} \mathrm{CT}_{\mathrm{x}} / \mathrm{SiCnws} \mathrm{hybrid}$ layers. $2 \mathrm{D}$ contours $(\mathbf{e})$ and $\mathrm{RC}$ curves $(\mathbf{f})$ vs. frequency $(8.2-12.4 \mathrm{GHz})$ and thickness $(0-5 \mathrm{~mm})$ of $\mathrm{f}-\mathrm{Ti}_{2} \mathrm{CT}_{\mathrm{x}} / \mathrm{SiCnw}$ hybrid foam. Reproduced with permission from Ref. [156]. Copyright 2018, American Chemical Society. g-j Typical images of f-Ti ${ }_{2} \mathrm{CT}_{\mathrm{x}} / \mathrm{PVA}$ foam. 2D contours $\mathbf{k}$ and reflection coefficient $\mathbf{l}$ curves versus frequency and thickness of $\mathrm{f}-\mathrm{Ti}_{2} \mathrm{CT}_{\mathrm{x}} / \mathrm{PVA}$ foams. Reproduced with permission from Ref. [100]. Copyright 2019, American Chemical Society

freeze-drying method (Fig. 11g-j) [100]. $\mathrm{Ti}_{2} \mathrm{CT}_{x} / \mathrm{PVA}$ foam possessed an outstanding EM absorption performance with a minimum $R L$ of $-18.7 \mathrm{~dB}$ and an absorption covering the whole X-band with any thickness from 3.4 to $3.9 \mathrm{~mm}$ (Fig. 11k, 1).

A new ultralight carbon foam modified by $\mathrm{Ti}_{3} \mathrm{C}_{2} \mathrm{~T}_{x}$ nanosheet $\left(\mathrm{CF} / \mathrm{Ti}_{3} \mathrm{C}_{2} \mathrm{~T}_{x}\right)$ with three-dimensional network structure was prepared by vacuum impregnation and freeze-drying process [157]. The $\mathrm{CF} / \mathrm{Ti}_{3} \mathrm{C}_{2} \mathrm{~T}_{x}$ foam with ultralow density of only $5-7 \mathrm{mg} \mathrm{cm}^{-3}$ showed excellent flexibility and steady compression-resilience properties. Meanwhile, the foam showed higher EM absorption than most foam-based EM absorbers, with a minimum $R L$ of $-45 \mathrm{~dB}$ at $8.8 \mathrm{GHz}$.

\subsection{Aerogel}

Yang et al. prepared aligned $\mathrm{Ti}_{3} \mathrm{C}_{2} \mathrm{~T}_{x}$ MXene/gelatin $(\mathrm{M} @ \mathrm{G})$ nanocomposite aerogel using a unidirectional freeze casting method [158]. The composite aerogel showed a minimum RL of $-59.5 \mathrm{~dB}$ at $14.04 \mathrm{GHz}$ and an absorption bandwidth of $6.24 \mathrm{GHz}$ in the parallel direction but presented a minimum $R L$ of $-57.3 \mathrm{~dB}$ at $4.08 \mathrm{GHz}$ with an absorption bandwidth covering of $3.72-4.56 \mathrm{GHz}$ in the vertical direction. The aerogel exhibited significantly anisotropic EM wave-absorbing properties, owing to the unidirectional aligned microstructure.

Jiang et al. fabricated the hierarchically structured cellulose aerogels with interconnected $\mathrm{Ti}_{3} \mathrm{C}_{2} \mathrm{~T}_{x}$ MXene nanosheet networks via a freeze-casting and chemical cross-linking strategy [159]. The aerogel with a low density $\left(0.31 \mathrm{~g} \mathrm{~cm}^{-3}\right)$ presented a minimum RL of $-43.4 \mathrm{~dB}$ at $11.2 \mathrm{GHz}$ and an absorption bandwidth of $4.5 \mathrm{GHz}$, which was due to enhanced conductive loss and multiple reflection attenuating.

A $\mathrm{TiO}_{2} / \mathrm{Ti}_{3} \mathrm{C}_{2} \mathrm{~T}_{x} / \mathrm{RGO}$ ternary composite aerogel with a three-dimensional hierarchical architecture was synthesized by a hydrothermal method [160]. The minimum $\mathrm{RL}$ of the aerogel reached $-65.3 \mathrm{~dB}$ at the thickness of $2.5 \mathrm{~mm}$. At the same time, the absorption bandwidth was 
Table 1 The comprehensive performance of patch antennas made of different materials

\begin{tabular}{|c|c|c|c|c|c|c|c|}
\hline Type & $d(\mu \mathrm{m})$ & Efficiency (100\%) & Frequency $(\mathrm{GHz})$ & Substrate & $\begin{array}{l}\text { Substrate } \\
\text { thickness } \\
(\mathrm{mm})\end{array}$ & $\sigma\left(\mathrm{S} \mathrm{m}^{-1}\right)$ & References \\
\hline $\mathrm{Ti}_{3} \mathrm{C}_{2} \mathrm{~T}_{x}$ MXene & $\begin{array}{l}1 \\
3.2 \\
5.5\end{array}$ & $\begin{array}{l}80-93.4 \\
87-98.4 \\
90.6-99\end{array}$ & $5.6,10.9$, and 16.4 & RT 5880 & 1.6 & $1.5 \times 10^{6}$ & {$[51]$} \\
\hline Copper & 35 & $95-100$ & & RT 5880 & 1.6 & $5.8 \times 10^{7}$ & {$[51]$} \\
\hline EGaIn & 100 & $46-60$ & 3.45 & PDMS & 1 & $3.4 \times 10^{6}$ & {$[25]$} \\
\hline Copper mesh & 20 & $49-56.88$ & $2.4-2.5$ & acrylic & 1.2 & $1 \times 10^{6}$ & {$[26]$} \\
\hline SWCNTS/EGaIn & 100 & 90 & 4 & PDMS & 0.5 & $3.4 \times 10^{6}$ & [27] \\
\hline $\mathrm{NbSe}_{2}$ & 0.8 & 70.6 & $2.01-2.8$ & PET & - & $9.7 \times 10^{5}$ & {$[28]$} \\
\hline IZTO/Ag/IZTO & 0.1 & 7.76 & 2.45 & Acryl & 1 & - & [29] \\
\hline $\mathrm{Cu}$ mesh & 5 & 42.69 & 2.45 & Acryl & 1 & - & [29] \\
\hline EGaIn & 1500 & 75 & 5.2 & Photopolymer resin & 6 & $5.1 \times 10^{6}$ & {$[30]$} \\
\hline Aligned CNTs & 8.16 & 94 & 10,14 & RT 5870 & - & $4.63 \times 10^{6}$ & {$[31]$} \\
\hline Graphene & 25 & 64.9 & 6 & PDMS & 2 & - & {$[32]$} \\
\hline Graphene/CNTs/PMMA & - & 44.9 & 3.11 & PET & - & - & {$[33]$} \\
\hline Silver & 3 & 11 & 2.45 & Cardboard & 0.56 & $2 \times 10^{7}$ & [34] \\
\hline Silver nanowire & 500 & 41.83 & 2.92 & PDMS & 1 & $8.1 \times 10^{5}$ & {$[35]$} \\
\hline $\mathrm{Ni} / \mathrm{Ag} / \mathrm{Cu}$ fabric & 130 & 58.6 & 2.45 & PDMS & 3 & - & {$[36]$} \\
\hline Silver paint & 26.5 & 2.8 & 2.45 & NinjaFlex & 1.2 & $1.7 \times 10^{4}$ & {$[37]$} \\
\hline
\end{tabular}

$4.3 \mathrm{GHz}$, with a thickness of only $2.0 \mathrm{~mm}$. The improved EM wave absorption performance was attributed to the highly porous conductive networks, multiple reflection, and scattering and defective polarization properties.

Wang et al. reported a multilayer $\mathrm{Ti}_{3} \mathrm{C}_{2} \mathrm{~T}_{x} @ \mathrm{RGO}$ hybrid aerogel prepared by a hydrothermal method and freezedrying treatment [161]. Compared with pure multilayer $\mathrm{Ti}_{3} \mathrm{C}_{2} \mathrm{~T}_{x}$, the EM wave absorption of the $\mathrm{Ti}_{3} \mathrm{C}_{2} \mathrm{~T}_{x} @ \mathrm{RGO}$ aerogel improved significantly. The minimum $\mathrm{RL}$ achieved for the $\mathrm{Ti}_{3} \mathrm{C}_{2} \mathrm{~T}_{x} @ \mathrm{RGO}$ aerogel was $-31.2 \mathrm{~dB}$ at $8.2 \mathrm{GHz}$, and the absorption bandwidth reached $5.4 \mathrm{GHz}$. Such good performance was due to the conductive network, interface polarization, dipole polarization, and multiple scattering, as important contributors.

\subsection{Fabric}

To obtain the enhanced EM wave absorption performance, the hierarchical $\mathrm{Ti}_{3} \mathrm{C}_{2} \mathrm{~T}_{x}$ MXene/Ni chain/ZnO array hybrid nanostructures were rationally constructed on cotton fabric [162]. The impedance matching could be modulated by adjusting the concentration of $\mathrm{Ni}$ chains to manipulate the magnetic loss. The minimum $R L$ value for the hybrid fabric could reach $-35.1 \mathrm{~dB}$ at $8.3 \mathrm{GHz}$ at the thickness of $2.8 \mathrm{~mm}$, and its absorption bandwidth could cover the whole X-band with thickness of $2.2 \mathrm{~mm}$.

\section{Overview and Perspectives}

As shown in Table 1, MXene antennas exhibit excellent comprehensive performance compared with other materials [163-169], as clearly confirmed by Fig. 12a, b. This indicates that MXene antennas have great development prospects for the future. Research on the EM attenuation properties of MXenes was initiated in 2016. Thereafter, a large number of MXene-based structures have been designed for EMI shielding and EM wave absorption based on the principle of "lightweight, wide, and strong." Tables 2 and 3 list the EMI shielding and EM wave absorption performances of MXene-based materials, respectively. Research on MXene-based shielding and absorption materials has mainly focused on film and hybrid materials (Fig. 12c-f), respectively. MXene-based films afford the highest conductivity among this class of materials (Table 2), which is the reason why MXene films are the most widely used materials for EMI shielding. However, the high conductivity leads to 

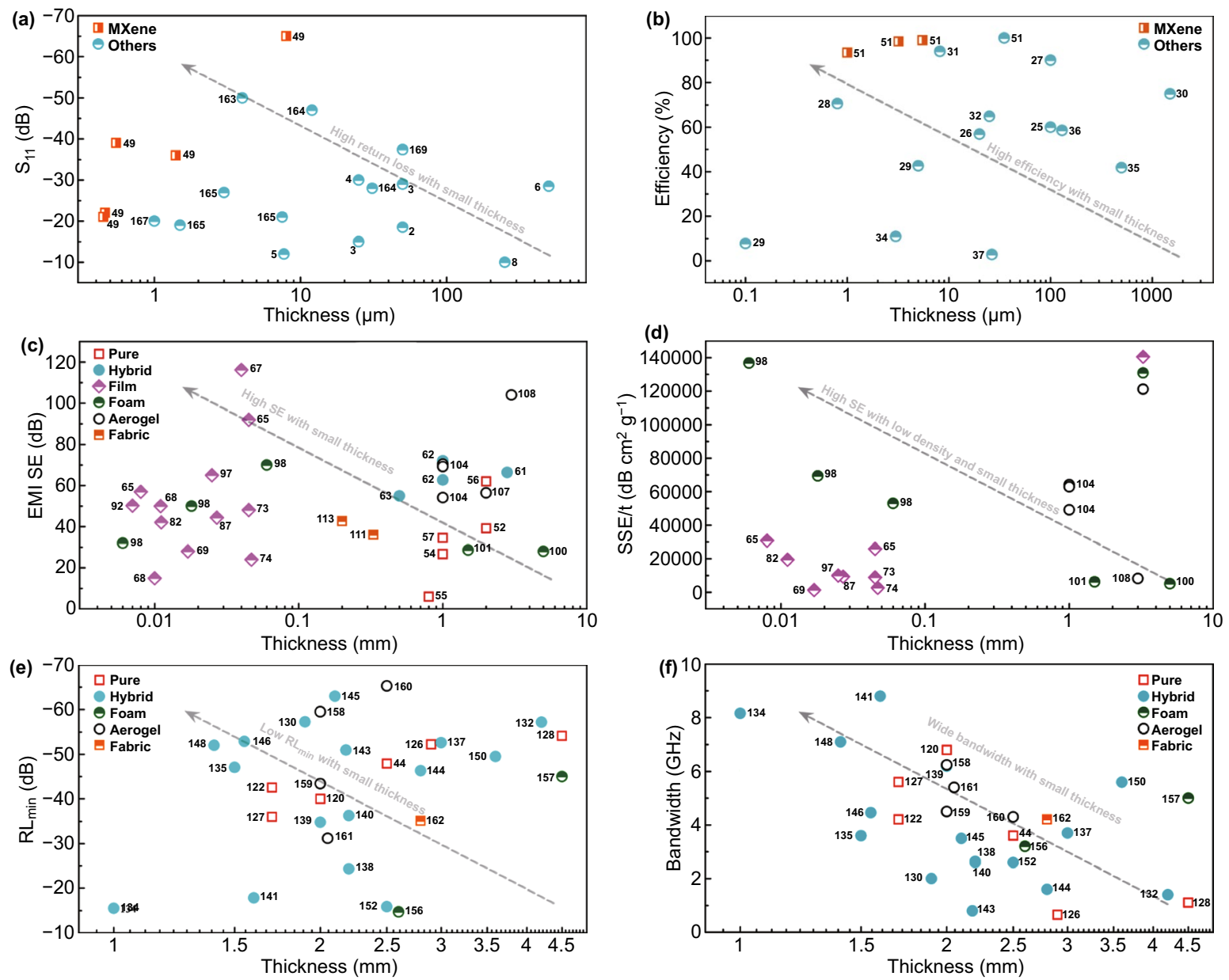

Fig. 12 Comparison of $\mathbf{a}$ the return loss and $\mathbf{b}$ efficiency of MXene antenna with other materials. $\mathbf{c}$ EMI SE and $\mathbf{d} \mathrm{SEE}_{\mathrm{t}}$ versus thickness for MXene-based shielding materials. $\mathbf{e} \mathrm{RL}_{\min }$ and $\mathbf{f}$ absorption bandwidth versus thickness of typical MXene-based absorbing materials

impedance mismatch. Therefore, no research has been performed on MXene films for EM wave absorption (Table 3). MXene hybrids for EM wave absorption are the most extensively studied materials, owing to their easily tunable EM parameters. Moreover, the addition of a matrix also simplifies adjustment for impedance matching. The choice of foam and aerogel is based on their lightweight characteristics (Fig. 12d), and the porous structure can increase multiple reflections to improve the attenuation of EM waves. The advantage of using a fabric as the EM attenuation material is that it has satisfactory porosity and permeability. In addition, it is more practical.

To summarize, the core outstanding areas to be addressed in the wireless communication and EM attenuation fields include the following: conduction design, because the conduction directly affects the thickness and transmission performance of the antenna, the strength of the first interface reflection is dominated by conduction, and conduction loss plays an important role in EM wave absorption; EM transmission and attenuation mechanisms in MXenes that are not understood and may fundamentally differ from the behavior in other 2D materials, such as graphene; how to balance EM wave absorption and reflection in MXenes to achieve green shielding, and how wireless communication devices employing MXenes can be adapted to large-scale industrial production in the future.

Based on the above overview of MXenes, there are still some challenges that need to be addressed in the future. The conduction is mainly decided by the type of MXene, number and types of surface functional groups, and the construction mode of MXenes. Conduction varies greatly in different kinds of MXenes. For example, the conductivity 
Table 2 Typical MXene-based materials and their EMI shielding properties

\begin{tabular}{|c|c|c|c|c|c|c|c|c|}
\hline Type & Materials & Matrix & Ratio (wt\%) & $d(\mathrm{~mm})$ & $\sigma\left(\mathrm{S} \mathrm{m}^{-1}\right)$ & $\mathrm{SE}(\mathrm{dB})$ & 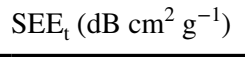 & References \\
\hline \multirow[t]{5}{*}{ Pure MXene } & $\mathrm{Ti}_{3} \mathrm{C}_{2} \mathrm{~T}_{x}$ & Wax & 60 & 2 & - & 39.1 & - & {$[52]$} \\
\hline & $\mathrm{Ti}_{3} \mathrm{C}_{2} \mathrm{~T}_{x}$ & $\mathrm{SiO}_{2}$ & 60 & 1 & 0.42 & 26.7 & - & {$[54]$} \\
\hline & $\mathrm{Ti}_{2} \mathrm{CT}_{x}$ & Wax & 40 & 0.8 & $1.63 \times 10^{-16}$ & 6 & - & {$[55]$} \\
\hline & $\mathrm{Ti}_{3} \mathrm{C}_{2} \mathrm{~T}_{x}$ & PS & 1.9 vol $\%$ & 2 & 1081 & 62 & - & {$[56]$} \\
\hline & $\mathrm{Ti}_{3} \mathrm{C}_{2} \mathrm{~T}_{x}$ & PVDF & 50 & 1 & 0.988 & 34.49 & - & {$[57]$} \\
\hline \multirow[t]{4}{*}{ MXene hybrid } & $\mathrm{Ti}_{3} \mathrm{C}_{2} \mathrm{~T}_{x}-\mathrm{Ni}$ & Wax & 50 & 2.8 & 4 & 66.4 & - & {$[61]$} \\
\hline & $\mathrm{Ti}_{3} \mathrm{C}_{2} \mathrm{~T}_{x}-\mathrm{Ag}$ & Wax & 60 & 1 & 3.813 & 62.7 & & {$[62]$} \\
\hline & $\mathrm{Nb}_{2} \mathrm{CT}_{x}-\mathrm{Ag}$ & Wax & 60 & 1 & 3.123 & 72.04 & - & {$[62]$} \\
\hline & r GO- $\mathrm{Ti}_{3} \mathrm{C}_{2} \mathrm{~T}_{x}$ & Epoxy & 4.5 & 0.5 & 387.1 & 55 & - & {$[63]$} \\
\hline \multirow[t]{13}{*}{ MXene film } & $\mathrm{Ti}_{3} \mathrm{C}_{2} \mathrm{~T}_{x}$ & - & 100 & 0.045 & $4.665 \times 10^{5}$ & 92 & 25,863 & {$[65]$} \\
\hline & $\mathrm{Ti}_{3} \mathrm{C}_{2} \mathrm{~T}_{x}$ & - & 100 & $5.5 \times 10^{-5}$ & $5 \times 10^{5}$ & 20 & $3.89 \times 10^{6}$ & [66] \\
\hline & $\mathrm{Ti}_{3} \mathrm{CNT}_{x}$ & - & 100 & 0.04 & $1.786 \times 10^{5}$ & 116.2 & - & [67] \\
\hline & $\mathrm{Ti}_{2} \mathrm{CT}_{x}$ & - & 100 & 0.011 & $1.6 \times 10^{5}$ & 50 & - & {$[68]$} \\
\hline & $\mathrm{Nb}_{2} \mathrm{CT}_{x}$ & - & 100 & 0.01 & 500 & 15 & - & {$[68]$} \\
\hline & $\mathrm{Ti}_{3} \mathrm{C}_{2} \mathrm{~T}_{x}-\mathrm{SA}$ & - & 90 & 0.008 & $2.9 \times 10^{5}$ & 57 & 30,830 & {$[65]$} \\
\hline & $\mathrm{Ti}_{3} \mathrm{C}_{2} \mathrm{~T}_{x} / \mathrm{ANF}$ & - & 80 & 0.017 & $1.733 \times 10^{4}$ & 28 & 1317.64 & [69] \\
\hline & $\mathrm{ANF} / \mathrm{Ti}_{3} \mathrm{C}_{2} \mathrm{~T}_{x} / \mathrm{Ag}$ & - & 20 & 0.045 & $9.22 \times 10^{4}$ & 48.1 & 8907.4 & {$[73]$} \\
\hline & $\mathrm{Ti}_{3} \mathrm{C}_{2} \mathrm{~T}_{x} / \mathrm{CNF}$ & - & 90 & 0.047 & 739.4 & 24 & 2647 & [74] \\
\hline & $\mathrm{Ti}_{3} \mathrm{C}_{2} \mathrm{~T}_{x} / \mathrm{PEDOT}: \mathrm{PSS}$ & - & 87.5 & 0.0111 & $3.405 \times 10^{4}$ & 42.10 & $19,497.8$ & [82] \\
\hline & $\mathrm{Ti}_{3} \mathrm{C}_{2} \mathrm{~T}_{x} / \mathrm{PVA}$ & - & 19.5 & 0.027 & 716 & 44.4 & 9343 & [87] \\
\hline & $\mathrm{Ti}_{3} \mathrm{C}_{2} \mathrm{~T}_{x} / \mathrm{GO}$ & - & 90 & 0.007 & $2.64 \times 10^{5}$ & 50.2 & - & {$[92]$} \\
\hline & $\mathrm{Ti}_{3} \mathrm{C}_{2} \mathrm{~T}_{x} / \mathrm{MMT}$ & - & 90 & 0.025 & 4420 & 65 & 10,000 & [97] \\
\hline \multirow[t]{3}{*}{ MXene foam } & $\mathrm{Ti}_{3} \mathrm{C}_{2} \mathrm{~T}_{x}$ & - & 100 & 0.006 & 58,820 & 32 & 136,752 & [98] \\
\hline & $\mathrm{Ti}_{2} \mathrm{CT}_{x} / \mathrm{PVA}$ & - & 0.15 vol $\%$ & 5 & $8.3 \times 10^{-6}$ & 28 & 5136 & {$[100]$} \\
\hline & $\mathrm{Ti}_{3} \mathrm{C}_{2} \mathrm{~T}_{x} / \mathrm{rGO}$ & - & 33 & 1.5 & 1000 & 28.6 & 6217 & [101] \\
\hline \multirow[t]{5}{*}{ MXene aerogel } & $\mathrm{Ti}_{3} \mathrm{C}_{2} \mathrm{~T}_{x}$ & - & 100 & 1 & - & 70.5 & 64,182 & [104] \\
\hline & $\mathrm{Ti}_{2} \mathrm{CT}_{x}$ & - & 100 & 1 & - & 69.2 & 62,909 & [104] \\
\hline & $\mathrm{Ti}_{3} \mathrm{CNT}_{x}$ & - & 100 & 1 & - & 54.1 & 49,182 & [104] \\
\hline & $\mathrm{Ti}_{3} \mathrm{C}_{2} \mathrm{~T}_{x} / \mathrm{rGO}$ & Epoxy & 0.99 vol\% & 2 & 695.9 & 56.4 & - & [107] \\
\hline & $\mathrm{Ti}_{3} \mathrm{C}_{2} \mathrm{~T}_{x} / \mathrm{CNT}$ & - & 25 & 3 & 943 & 103.99 & 8253.17 & {$[108]$} \\
\hline \multirow[t]{3}{*}{ MXene fabric } & $\mathrm{Ti}_{3} \mathrm{C}_{2} \mathrm{~T}_{x}$ & Cotton & 6 & 0.33 & $5 \Omega \mathrm{sq}^{-1}$ & 36 & - & [111] \\
\hline & $\mathrm{Ti}_{3} \mathrm{C}_{2} \mathrm{~T}_{x}$ & Cotton & $5.2 \mathrm{mg} / \mathrm{cm}^{2}$ & - & 670.3 & 31.04 & - & {$[112]$} \\
\hline & $\mathrm{Ti}_{3} \mathrm{C}_{2} \mathrm{~T}_{x}$ & Cellulose & 1.89 vol $\%$ & 0.2 & 2756 & 42.7 & - & [113] \\
\hline
\end{tabular}

of a free-standing $\mathrm{Mo}_{2} \mathrm{Ti}_{2} \mathrm{C}_{3}$ film is $100 \mathrm{~S} \mathrm{~cm}^{-1}$, while the conductivity of a free-standing $\mathrm{Ta}_{4} \mathrm{C}_{3}$ film is $0.476 \mathrm{~S} \mathrm{~cm}^{-1}$ [24]. However, current research has mainly focused on $\mathrm{Ti}_{3} \mathrm{C}_{2} \mathrm{~T}_{x}$ MXene. It is necessary to study the wireless communication performance and EM response mechanism of other MXenes. The number and types of surface functional groups are mainly affected by the etching method. For example, $\mathrm{Ti}_{3} \mathrm{C}_{2} \mathrm{~T}_{x}$ etched with $\mathrm{LiF} / \mathrm{HCl}$ has a high content of $=\mathrm{O}$ terminal groups compared with $\mathrm{Ti}_{3} \mathrm{C}_{2} \mathrm{~T}_{x}$ etched with $\mathrm{HF}$, which leads to conductivity differences [54]. The annealing temperature also has a certain influence on the type of surface functional groups [24]. Researchers need to study how to control the conductivity of MXenes by selecting different etchants and annealing temperatures. Moreover, the method used to construct MXenes also affects the conductivity of MXenes. For example, the conductivity of a pressed $\mathrm{Ti}_{3} \mathrm{C}_{2} \mathrm{~T}_{x}$ disk $\left(2 \mathrm{~S} \mathrm{~cm}^{-1}\right)$ is lower than that of a free-standing $\mathrm{Ti}_{3} \mathrm{C}_{2} \mathrm{~T}_{x}$ film (1500 S cm ${ }^{-1}$ ). Designing different methods of constructing MXenes to regulate the conduction will also be a direction for future research. The oxidation of MXenes is an unavoidable problem, especially in the case of few-layer or monolayer MXenes. After oxidation, the conductivity of 
Table 3 Typical MXene-based materials and their EM wave absorption properties

\begin{tabular}{|c|c|c|c|c|c|c|c|}
\hline Type & Materials & Matrix & Ratio (wt\%) & $d(\mathrm{~mm})$ & $\mathrm{RL}_{\min }(\mathrm{dB})$ & $\begin{array}{l}\text { Bandwidth }(<- \\
10 \mathrm{~dB})(\mathrm{GHz})\end{array}$ & References \\
\hline \multirow{6}{*}{ Pure MXene } & $\mathrm{Ti}_{3} \mathrm{C}_{2} \mathrm{~T}_{x}$ & Wax & 40 & 2.5 & -47.9 & 3.6 & [44] \\
\hline & $\mathrm{Ti}_{3} \mathrm{C}_{2} \mathrm{~T}_{x}$ & Wax & 50 & 2 & -40 & 6.8 & {$[120]$} \\
\hline & $\mathrm{Ti}_{3} \mathrm{C}_{2} \mathrm{~T}_{x}$ & Wax & 55 & 1.7 & -42.5 & 4.2 & [122] \\
\hline & $\mathrm{Nb}_{2} \mathrm{CT}_{x}$ & Wax & 70 & 2.9 & -52.2 & 0.65 & [126] \\
\hline & $\mathrm{Ti}_{3} \mathrm{C}_{2} \mathrm{~T}_{x}$ & Wax & 45 & 1.7 & -36 & 5.6 & [127] \\
\hline & $\mathrm{Ti}_{2} \mathrm{CT}_{x}$ & Wax & 55 & 4.5 & -54.1 & 1.1 & [128] \\
\hline \multirow[t]{16}{*}{ MXene hybrid } & $\mathrm{TiO}_{2} / \mathrm{Ti}_{3} \mathrm{C}_{2} \mathrm{~T}_{x} / \mathrm{Fe}_{3} \mathrm{O}_{4}$ & Wax & 70 & 1.9 & -57.3 & 2 & [130] \\
\hline & $\mathrm{Fe}_{3} \mathrm{O}_{4} @ \mathrm{Ti}_{3} \mathrm{C}_{2} \mathrm{~T}_{x}$ & Wax & 60 & 4.2 & -57.2 & 1.4 & [132] \\
\hline & $\mathrm{Ti}_{3} \mathrm{C}_{2} \mathrm{~T}_{x} / \mathrm{FCI}$ & Epoxy & 60 & 1 & -15.52 & 8.16 & [134] \\
\hline & $\mathrm{Ti}_{3} \mathrm{C}_{2} \mathrm{~T}_{x} / \mathrm{Ni}$ & Wax & 50 & 1.5 & -47.06 & 3.6 & [135] \\
\hline & $\mathrm{Ni} @ \mathrm{Ti}_{3} \mathrm{C}_{2} \mathrm{~T}_{x}$ & PVDF & 10 & 3 & -52.6 & 3.7 & [137] \\
\hline & $\mathrm{Ti}_{3} \mathrm{C}_{2} \mathrm{~T}_{x} / \mathrm{Ni}$ & Wax & 60 & 2.2 & -24.3 & 2.6 & [138] \\
\hline & $\mathrm{Ti}_{3} \mathrm{C}_{2} \mathrm{~T}_{x} / \mathrm{Co}_{3} \mathrm{O}_{4}$ & Wax & 50 & 2 & -34.8 & 6.2 & [139] \\
\hline & $\mathrm{CoFe} @ \mathrm{Ti}_{3} \mathrm{C}_{2} \mathrm{~T}_{x}$ & Wax & 60 & 2.2 & -36.29 & 2.64 & {$[140]$} \\
\hline & $\mathrm{FeCo} @ \mathrm{Ti}_{3} \mathrm{C}_{2} \mathrm{~T}_{x}$ & Wax & 70 & 1.6 & -17.86 & 8.8 & [141] \\
\hline & $\mathrm{Ti}_{3} \mathrm{C}_{2} \mathrm{~T}_{x}-\mathrm{NiCo}_{2} \mathrm{O}_{4}$ & Wax & 50 & 2.18 & -50.96 & 0.8 & [143] \\
\hline & $\mathrm{Co}_{2} \mathrm{Z} / \mathrm{Ti}_{3} \mathrm{C}_{2} \mathrm{~T}_{x}$ & PVB & 30 & 2.8 & -46.3 & 1.6 & [144] \\
\hline & $\mathrm{G} / \mathrm{TiC} / \mathrm{Ti}_{3} \mathrm{C}_{2} \mathrm{~T}_{x}$ & Wax & 50 & 2.1 & -63 & 3.5 & [145] \\
\hline & $\mathrm{CNT} / \mathrm{Ti}_{3} \mathrm{C}_{2} \mathrm{~T}_{x}$ & Wax & 35 & 1.55 & -52.9 & 4.46 & {$[146]$} \\
\hline & $\mathrm{N}-\mathrm{GP} / \mathrm{Ti}_{3} \mathrm{C}_{2} \mathrm{~T}_{x}$ & Epoxy/PA & 32 & 1.4 & -52 & 7.1 & [148] \\
\hline & $\mathrm{Ti}_{3} \mathrm{C}_{2} \mathrm{~T}_{x} @ \mathrm{PPy}$ & Wax & 10 & 3.6 & -49.5 & 5.6 & {$[150]$} \\
\hline & $\mathrm{MoS}_{2} @ \mathrm{TiO}_{2} / \mathrm{Ti}_{3} \mathrm{C}_{2} \mathrm{~T}_{x}$ & Wax & 50 & 2.5 & -15.9 & 2.6 & {$[152]$} \\
\hline \multirow[t]{2}{*}{ MXene foam } & $\mathrm{Ti}_{3} \mathrm{C}_{2} \mathrm{~T}_{x} / \mathrm{SiC}$ & - & 100 & 2.6 & -14.7 & 3.2 & {$[156]$} \\
\hline & $\mathrm{CF} / \mathrm{Ti}_{3} \mathrm{C}_{2} \mathrm{~T}_{x}$ & Wax & - & 4.5 & -45 & 5 & {$[157]$} \\
\hline \multirow[t]{4}{*}{ MXene aerogel } & $\mathrm{Ti}_{3} \mathrm{C}_{2} \mathrm{~T}_{x} @$ gelatin & - & 100 & 2 & -59.5 & 6.24 & {$[158]$} \\
\hline & $\mathrm{Ti}_{3} \mathrm{C}_{2} \mathrm{~T}_{x} /$ Cellulose & Wax & 24 & 2 & -43.4 & 4.5 & [159] \\
\hline & $\mathrm{TiO}_{2} / \mathrm{Ti}_{3} \mathrm{C}_{2} \mathrm{~T}_{x} / \mathrm{RGO}$ & Wax & 10 & 2.5 & -65.3 & 4.3 & {$[160]$} \\
\hline & $\mathrm{Ti}_{3} \mathrm{C}_{2} \mathrm{~T}_{x} @ \mathrm{RGO}$ & Wax & 15 & 2.05 & -31.2 & 5.4 & {$[161]$} \\
\hline MXene fabric & $\mathrm{Ti}_{3} \mathrm{C}_{2} \mathrm{~T}_{x} / \mathrm{Ni} / \mathrm{ZnO}$ & Cotton & 13.39 & 2.8 & -35.1 & 4.2 & {$[162]$} \\
\hline
\end{tabular}

MXenes decreases significantly. How to inhibit the oxidation of MXenes is a key point for future research.

At present, research on the wireless communication performance of MXenes is still in the exploratory stage. The mechanism of transmission of EM waves in MXene antennas is not very clear. Although research on EM attenuation in MXenes is more extensive, the exact mechanism of EMI shielding and EM wave absorption is still poorly understood. Since the concept of "green shielding" was put forward, realizing green shielding by using MXenebased materials has become a major challenge. Therefore, a series of thorough studies on EM wave transmission, dielectric relaxation, and the EM response of MXenebased materials is urgently needed.

The low yield of MXenes limits their commercial application in wireless communication, EMI shielding, and EM wave absorption materials. Increasing the production of MXenes is the only way to realize commercialization. Moreover, the hydrophilic nature of MXenes limits the fabrication of composites or hybrids with polymers and other materials to only aqueous media. To broaden the path of structural design, it is essential to investigate organic dispersions of MXenes.

In summary, MXenes, as the newest and fastest growing family of $2 \mathrm{D}$ materials, will open new avenues for 
realizing various classes of wireless communication and EM protection devices. This review is expected to serve as a guide to those exploring wireless communication and EM attenuation properties of MXenes.

Acknowledgements This work was supported by National Natural Science Foundation of China (Nos. 11774027, 51132002, 51977009 and 51372282).

Open Access This article is licensed under a Creative Commons Attribution 4.0 International License, which permits use, sharing, adaptation, distribution and reproduction in any medium or format, as long as you give appropriate credit to the original author(s) and the source, provide a link to the Creative Commons licence, and indicate if changes were made. The images or other third party material in this article are included in the article's Creative Commons licence, unless indicated otherwise in a credit line to the material. If material is not included in the article's Creative Commons licence and your intended use is not permitted by statutory regulation or exceeds the permitted use, you will need to obtain permission directly from the copyright holder. To view a copy of this licence, visit http://creativecommons.org/licenses/by/4.0/.

\section{References}

1. K.Y. Shin, J.Y. Hong, J. Jang, Micropatterning of graphene sheets by inkjet printing and its wideband dipole-antenna application. Adv. Mater. 23(18), 2113-2118 (2011). https:// doi.org/10.1002/adma.201100345

2. K.Y. Shin, M. Kim, J.S. Lee, J. Jang, Highly omnidirectional and frequency controllable carbon/polyaniline-based 2D and 3D monopole antenna. Sci. Rep. 5, 13615 (2015). https://doi. org/10.1038/srep13615

3. A. Lamminen, K. Arapov, G. de With, S. Haque, H.G.O. Sandberg et al., Graphene-flakes printed wideband elliptical dipole antenna for low-cost wireless communications applications. IEEE Antennas Wirel. Propag. Lett. 16, 18831886 (2017). https://doi.org/10.1109/LAWP.2017.2684907

4. I. Puchades, J.E. Rossi, C.D. Cress, E. Naglich, B.J. Landi, Carbon nanotube thin-film antennas. ACS Appl. Mater. Interfaces 8(32), 20986-20992 (2016). https://doi.org/10. 1021/acsami.6b05146

5. X.J. Huang, T. Leng, K.H. Chang, J.C. Chen, K.S. Novoselov et al., Graphene radio frequency and microwave passive components for low cost wearable electronics. 2D Mater. 3(2), 025021 (2016). https://doi.org/10.1088/2053$1583 / 3 / 2 / 025021$

6. T.A. Elwi, H.M. Al-Rizzo, D.G. Rucker, E. Dervishi, Z.R. Li et al., Multi-walled carbon nanotube-based RF antennas. Nanotechnology 21(4), 045301 (2010). https://doi.org/10. 1088/0957-4484/21/4/045301

7. G. Deligeorgis, M. Dragoman, D. Neculoiu, D. Dragoman, G. Konstantinidis et al., Microwave propagation in graphene.
Appl. Phys. Lett. 95(7), 073107 (2009). https://doi.org/10. 1063/1.3202413

8. N.A. Vacirca, J.K. McDonough, K. Jost, Y. Gogotsi, T.P. Kurzweg, Onion-like carbon and carbon nanotube film antennas. Appl. Phys. Lett. 103(7), 073301 (2013). https://doi.org/10. 1063/1.4818464

9. P.J. Burke, S.D. Li, Z. Yu, Quantitative theory of nanowire and nanotube antenna performance. IEEE Trans. Nanotechnol. 5(4), 314-334 (2006). https://doi.org/10.1109/TNANO. 2006.877430

10. M.S. Cao, X.X. Wang, M. Zhang, W.Q. Cao, X.Y. Fang et al., Variable-temperature electron transport and dipole polarization turning flexible multifunctional microsensor beyond electrical and optical energy. Adv. Mater. 32(10), 1907156 (2020). https://doi.org/10.1002/adma.201907156

11. X.X. Wang, W.Q. Cao, M.S. Cao, J. Yuan, Assembling nanomicroarchitecture for electromagnetic absorbers and smart devices. Adv. Mater. 32(36), 2002112 (2020). https://doi.org/ 10.1002/adma.202002112

12. B. Wen, M.S. Cao, M.M. Lu, W.Q. Cao, H.L. Shi et al., Reduced graphene oxides: light-weight and high-efficiency electromagnetic interference shielding at elevated temperatures. Adv. Mater. 26(21), 3484-3489 (2014). https://doi.org/ 10.1002/adma.201400108

13. Z. Zhang, Z. Cai, Z. Wang, Y. Peng, L. Xia et al., A review on metal-organic framework-derived porous carbon-based novel microwave absorption materials. Nano-Micro Lett. 13(1), 56 (2021). https://doi.org/10.1007/s40820-020-00582-3

14. M.S. Cao, X.X. Wang, M. Zhang, J.C. Shu, W.Q. Cao et al., Electromagnetic response and energy conversion for functions and devices in low-dimensional materials. Adv. Funct. Mater. 29(25), 1807398 (2019). https://doi.org/10.1002/adfm. 201807398

15. D. Zhang, T. Liu, J. Cheng, Q. Cao, G. Zheng et al., Lightweight and high-performance microwave absorber based on 2D WS $\mathrm{W}_{2}$-RGO heterostructures. Nano-Micro Lett. 11(1), 38 (2019). https://doi.org/10.1007/s40820-019-0270-4

16. Y. Dai, X. Wu, Z. Liu, H.B. Zhang, Z.Z. Yu, Highly sensitive, robust and anisotropic MXene aerogels for efficient broadband microwave absorption. Compos. B-Eng. 200, 108263 (2020). https://doi.org/10.1016/j.compositesb.2020.108263

17. P. He, Z.L. Hou, W.Q. Cao, J. Yuan, M.S. Cao, Rutile $\mathrm{TiO}_{2}$ nanorod with anomalous resonance for charge storage and frequency selective absorption. Ceram. Int. 47(2), 2016-2021 (2021). https://doi.org/10.1016/j.ceramint.2020.09.033

18. Y. Cheng, J.Z.Y. Seow, H.Q. Zhao, Z.C.J. Xu, G.B. Ji, A flexible and lightweight biomass-reinforced microwave absorber. Nano-Micro Lett. 12(1), 125 (2020). https://doi.org/10.1007/ s40820-020-00461-x

19. P. He, Z.L. Hou, K.L. Zhang, J. Li, K. Yin et al., Lightweight ferroferric oxide nanotubes with natural resonance property and design for broadband microwave absorption. J. Mater. Sci. 52(13), 8258-8267 (2017). https://doi.org/10.1007/ s10853-017-1041-6

20. M. Zhang, C. Han, W.Q. Cao, M.S. Cao, H.J. Yang et al., A nano-micro engineering nanofiber for 
electromagnetic absorber, green shielding and sensor. Nano-Micro Lett. 13(1), 27 (2021). https://doi.org/10.1007/ s40820-020-00552-9

21. J. Liu, H.B. Zhang, X. Xie, R. Yang, Z.S. Liu et al., Multifunctional, superelastic, and lightweight MXene/polyimide aerogels. Small 14(45), 1802479 (2018). https://doi.org/10. 1002/smll.201802479

22. Y. Lian, B. Han, D. Liu, Y. Wang, H. Zhao et al., Solventfree synthesis of ultrafine tungsten carbide nanoparticlesdecorated carbon nanosheets for microwave absorption. Nano-Micro Lett. 12(1), 153 (2020). https://doi.org/10.1007/ s40820-020-00491-5

23. S.W. Shi, B.Q. Qian, X.Y. Wu, H.L. Sun, H.Q. Wang et al., Self-assembly of MXene-surfactants at liquid-liquid interfaces: from structured liquids to 3D aerogels. Angew. Chem. Int. Ed. 58, 18171-18176 (2019). https://doi.org/10.1002/ anie. 201908402

24. K. Hantanasirisakul, Y. Gogotsi, Electronic and optical properties of 2D transition metal carbides and nitrides (MXenes). Adv. Mater. 30(52), 1804779 (2018). https://doi.org/10.1002/ adma.201804779

25. G.J. Hayes, J.H. So, A. Qusba, M.D. Dickey, G. Lazzi, Flexible liquid metal alloy (EGaIn) microstrip patch antenna. IEEE Trans. Antennas Propag. 60(5), 2151-2156 (2012). https:// doi.org/10.1109/TAP.2012.2189698

26. S.H. Kang, C.W. Jung, Transparent patch antenna using metal mesh. IEEE Trans. Antennas Propag. 66(4), 2095-2100 (2018). https://doi.org/10.1109/TAP.2018.2804622

27. B. Aissa, M. Nedil, M.A. Habib, E. Haddad, W. Jamroz et al., Fluidic patch antenna based on liquid metal alloy/single-wall carbon-nanotubes operating at the S-band frequency. Appl. Phys. Lett. 103(6), 063101 (2013). https://doi.org/10.1063/1. 4817861

28. G.S. Gund, M.G. Jung, K.Y. Shin, H.S. Park, Two-dimensional metallic niobium diselenide for sub-micrometer-thin antennas in wireless communication systems. ACS Nano 13(12), 14114-14121 (2019). https://doi.org/10.1021/acsna no. 9 b06732

29. S. Hong, Y. Kim, C.W. Jung, Transparent microstrip patch antennas with multilayer and metal-mesh films. IEEE Antennas Wirel. Propag. Lett. 16, 772-775 (2017). https://doi.org/ 10.1109/LAWP.2016.2602389

30. G.L. Huang, J.J. Liang, L.Y. Zhao, D.P. He, C.Y.D. Sim, Package-in-dielectric liquid patch antenna based on liquid metal alloy. IEEE Antennas Wirel. Propag. Lett. 18(11), 2360-2364 (2019). https://doi.org/10.1109/LAWP.2019. 2932048

31. E.A. Bengio, D. Senic, L.W. Taylor, R.J. Headrick, M. King et al., Carbon nanotube thin film patch antennas for wireless communications. Appl. Phys. Lett. 114(20), 203102 (2019). https://doi.org/10.1063/1.5093327

32. H.A. Elmobarak, S.K.A. Rahim, M. Abedian, P.J. Soh, G.A.E. Vandenbosch et al., Assessment of multilayered graphene technology for flexible antennas at microwave frequencies. Microw. Opt. Technol. Lett. 59(10), 2604-2610 (2017). https://doi.org/10.1002/mop.30783
33. Y.K. Kim, Y. Lee, K.Y. Shin, J. Jang, Highly omnidirectional and frequency tunable multilayer graphene-based monopole patch antennas. J. Mater. Chem. C 7(26), 7915-7921 (2019). https://doi.org/10.1039/c9tc02454a

34. H. Saghlatoon, L. Sydanheimo, L. Ukkonen, M. Tentzeris, Optimization of inkjet printing of patch antennas on low-cost fibrous substrates. IEEE Antennas Wirel. Propag. Lett. 13, 915-918 (2014). https://doi.org/10.1109/LAWP.2014.23225 72

35. L.N. Song, A.C. Myers, J.J. Adams, Y. Zhu, Stretchable and reversibly deformable radio frequency antennas based on silver nanowires. ACS Appl. Mater. Interfaces 6(6), 4248-4253 (2014). https://doi.org/10.1021/am405972e

36. R.B.V.B. Simorangkir, Y. Yang, L. Matekovits, K.P. Esselle, Dual-band dual-mode textile antenna on PDMS substrate for body-centric communications. IEEE Antennas Wirel. Propag. Lett. 16, 677-680 (2017). https://doi.org/10.1109/LAWP. 2016.2598729

37. M. Rizwan, M.W.A. Khan, L. Sydanheimo, J. Virkki, L. Ukkonen, Flexible and stretchable brush-painted wearable antenna on a three-dimensional (3-D) printed substrate. IEEE Antennas Wirel. Propag. Lett. 16, 3108-3112 (2017). https:// doi.org/10.1109/LAWP.2017.2763743

38. A. Razaq, A.A. Khan, U. Shakir, A. Arshad, Next generation flexible antennas for radio frequency applications. Trans. Electr. Electron. Mater. 19(5), 311-318 (2018). https://doi. org/10.1007/s42341-018-0051-7

39. L. Li, S. Zhao, X.J. Luo, H.B. Zhang, Z.Z. Yu, Smart MXenebased janus films with multi-responsive actuation capability and high electromagnetic interference shielding performances. Carbon 175, 594-602 (2021). https://doi.org/10. 1016/j.carbon.2020.10.090

40. D. Nepal, W.J. Kennedy, R. Pachter, R.A. Vaia, Toward architected nanocomposites: MXenes and beyond. ACS Nano 15, 21-28 (2021). https://doi.org/10.1021/acsnano.0c09834

41. J.C. Shu, M.S. Cao, M. Zhang, X.X. Wang, W.Q. Cao et al., Molecular patching engineering to drive energy conversion as efficient and environment-friendly cell toward wireless power transmission. Adv. Funct. Mater. 30(10), 1908299 (2020). https://doi.org/10.1002/adfm.201908299

42. M.S. Cao, W.L. Song, Z.L. Hou, B. Wen, J. Yuan, The effects of temperature and frequency on the dielectric properties, electromagnetic interference shielding and microwaveabsorption of short carbon fiber/silica composites. Carbon 48(3), 788-796 (2010). https://doi.org/10.1016/j.carbon. 2009.10.028

43. B. Wen, M.S. Cao, Z.L. Hou, W.L. Song, L. Zhang et al., Temperature dependent microwave attenuation behavior for carbon-nanotube/silica composites. Carbon 65, 124-139 (2013). https://doi.org/10.1016/j.carbon.2013.07.110

44. P. He, M.S. Cao, J.C. Shu, Y.Z. Cai, X.X. Wang et al., Atomic layer tailoring titanium carbide MXene to tune transport and polarization for utilization of electromagnetic energy beyond solar and chemical energy. ACS Appl. Mater. Interfaces 11(13), 12535-12543 (2019). https://doi.org/10.1021/acsami. 9b00593 
45. X.L. Shi, M.S. Cao, J. Yuan, X.Y. Fang, Dual nonlinear dielectric resonance and nesting microwave absorption peaks of hollow cobalt nanochains composites with negative permeability. Appl. Phys. Lett. 95(16), 163108 (2009). https://doi. org/10.1063/1.3250170

46. M.S. Cao, J. Yang, W.L. Song, D.Q. Zhang, B. Wen et al., Ferroferric oxide/multiwalled carbon nanotube vs. polyaniline/ferroferric oxide/multiwalled carbon nanotube multiheterostructures for highly effective microwave absorption. ACS Appl. Mater. Interfaces 4(12), 6949-6956 (2012). https://doi. org/10.1021/am3021069

47. W.Q. Cao, X.X. Wang, J. Yuan, W.Z. Wang, M.S. Cao, Temperature dependent microwave absorption of ultrathin graphene composites. J. Mater. Chem. C 3(38), 10017-10022 (2015). https://doi.org/10.1039/c5tc02185e

48. M.S. Cao, X.X. Wang, W.Q. Cao, X.Y. Fang, B. Wen et al., Thermally driven transport and relaxation switching selfpowered electromagnetic energy conversion. Small 14(29), 1800987 (2018). https://doi.org/10.1002/smll.201800987

49. A. Sarycheva, A. Polemi, Y.L. Liu, K. Dandekar, B. Anasori et al., 2D titanium carbide (MXene) for wireless communication. Sci. Adv. 4(9), eaau0920 (2018). https://doi.org/10. 1126/sciadv.aau0920

50. Y. Li, X. Tian, S.P. Gao, L. Jing, K.R. Li et al., Reversible crumpling of 2D titanium carbide (MXene) nanocoatings for stretchable electromagnetic shielding and wearable wireless communication. Adv. Funct. Mater. 30(5), 1907451 (2020). https://doi.org/10.1002/adfm.201907451

51. M.K. Han, Y.Q. Liu, R. Rakhmanov, C. Israel, M.A. Tajin et al., Solution-processed $\mathrm{Ti}_{3} \mathrm{C}_{2} \mathrm{~T}_{\mathrm{x}}$ MXene antennas for radio-frequency communication. Adv. Mater. 33(1), 2003225 (2021). https://doi.org/10.1002/adma.202003225

52. X. Liu, J. Wu, J. He, L. Zhang, Electromagnetic interference shielding effectiveness of titanium carbide sheets. Mater. Lett. 205, 261-263 (2017). https://doi.org/10.1016/j.matlet. 2017.06.101

53. S. Hu, S. Li, W. Xu, J. Zhang, Y. Zhou et al., Rapid preparation, thermal stability and electromagnetic interference shielding properties of two-dimensional $\mathrm{Ti}_{3} \mathrm{C}_{2}$ MXene. Ceram. Int. 45(16), 19902-19909 (2019). https://doi.org/10. 1016/j.ceramint.2019.06.246

54. P. He, X.X. Wang, Y.Z. Cai, J.C. Shu, Q.L. Zhao et al., Tailoring $\mathrm{Ti}_{3} \mathrm{C}_{2} \mathrm{~T}_{\mathrm{x}}$ nanosheets to tune local conductive network as an environmentally friendly material for highly efficient electromagnetic interference shielding. Nanoscale 11(13), 6080-6088 (2019). https://doi.org/10.1039/c8nr10489a

55. X.L. Li, X.W. Yin, S. Liang, M.H. Li, L.F. Cheng et al., 2D carbide MXene $\mathrm{Ti}_{2} \mathrm{CT}_{\mathrm{x}}$ as a novel high-performance electromagnetic interference shielding material. Carbon 146, 210-217 (2019). https://doi.org/10.1016/j.carbon.2019.02. 003

56. R.H. Sun, H.B. Zhang, J. Liu, X. Xie, R. Yang et al., Highly conductive transition metal carbide/carbonitride (MXene)@polystyrene nanocomposites fabricated by electrostatic assembly for highly efficient electromagnetic interference shielding. Adv. Funct. Mater. 27(45), 1702807 (2017). https://doi.org/10.1002/adfm.201702807

57. K. Rajavel, S.B. Luo, Y.J. Wan, X.C. Yu, Y.G. Hu et al., 2D $\mathrm{Ti}_{3} \mathrm{C}_{2} \mathrm{~T}_{\mathrm{x}} \mathrm{MXene} /$ polyvinylidene fluoride (PVDF) nanocomposites for attenuation of electromagnetic radiation with excellent heat dissipation. Compos. A: Appl. Sci. Manufac. 129, 105693 (2020). https://doi.org/10.1016/j.compositesa. 2019.105693

58. M. Han, X. Yin, H. Wu, Z. Hou, C. Song et al., $\mathrm{Ti}_{3} \mathrm{C}_{2}$ MXenes with modified surface for high-performance electromagnetic absorption and shielding in the X-Band. ACS Appl. Mater. Interfaces 8(32), 21011-21019 (2016). https:// doi.org/10.1021/acsami.6b06455

59. L. Wang, L. Chen, P. Song, C. Liang, Y. Lu et al., Fabrication on the annealed $\mathrm{Ti}_{3} \mathrm{C}_{2} \mathrm{~T}_{\mathrm{x}}$ MXene/epoxy nanocomposites for electromagnetic interference shielding application. Compos. B-Eng. 171, 111-118 (2019). https://doi.org/10. 1016/j.compositesb.2019.04.050

60. B. Ji, S.W. Fan, X. Ma, K.Y. Hu, L. Wang et al., Electromagnetic shielding behavior of heat-treated $\mathrm{Ti}_{3} \mathrm{C}_{2} \mathrm{~T}_{\mathrm{x}}$ MXene accompanied by structural and phase changes. Carbon $\mathbf{1 6 5}$, 150-162 (2020). https://doi.org/10.1016/j.carbon.2020.04. 041

61. L.Y. Liang, G.J. Han, Y. Li, B. Zhao, B. Zhou et al., Promising $\mathrm{Ti}_{3} \mathrm{C}_{2} \mathrm{~T}_{\mathrm{x}}$ MXene/Ni chain hybrid with excellent electromagnetic wave absorption and shielding capacity. ACS Appl. Mater. Interfaces 11(28), 25399-25409 (2019). https://doi.org/10.1021/acsami.9b07294

62. K. Rajavel, Y.G. Hu, P.L. Zhu, R. Sun, C.P. Wong, MXene/ metal oxides-Ag ternary nanostructures for electromagnetic interference shielding. Chem. Eng. J. 399, 125791 (2020). https://doi.org/10.1016/j.cej.2020.125791

63. P. Song, H. Qiu, L. Wang, X.Y. Liu, Y.L. Zhang et al., Honeycomb structural rGO-MXene/epoxy nanocomposites for superior electromagnetic interference shielding performance. Sustain. Mater. Technol. 24, e00153 (2020). https://doi.org/10.1016/j.susmat.2020.e00153

64. K. Raagulan, R. Braveenth, B.M. Kim, K.J. Lim, S.B. Lee et al., An effective utilization of MXene and its effect on electromagnetic interference shielding: flexible, free-standing and thermally conductive composite from MXene-PATpoly(p-aminophenol)-polyaniline co-polymer. RSC Adv. 10(3), 1613-1633 (2020). https://doi.org/10.1039/c9ra0 $9522 \mathrm{e}$

65. F. Shahzad, M. Alhabeb, C.B. Hatter, B. Anasori, S.M. Hong et al., Electromagnetic interference shielding with 2D transition metal carbides (MXenes). Science 353(6304), 11371140 (2016). https://doi.org/10.1126/science.aag2421

66. T. Yun, H. Kim, A. Iqbal, Y.S. Cho, G.S. Lee et al., Electromagnetic shielding of monolayer MXene assemblies. Adv. Mater. 32(9), 1906769 (2020). https://doi.org/10.1002/adma. 201906769

67. A. Iqbal, F. Shahzad, K. Hantanasirisakul, M.K. Kim, J. Kwon et al., Anomalous absorption of electromagnetic waves by $2 \mathrm{D}$ transition metal carbonitride $\mathrm{Ti}_{3} \mathrm{CNT}_{\mathrm{x}}$ 
(MXene). Science 369(6502), 446-450 (2020). https://doi. org/10.1126/science.aba7977

68. M.K. Han, C.E. Shuck, R. Rakhmanov, D. Parchment, B. Anasori et al., Beyond $\mathrm{Ti}_{3} \mathrm{C}_{2} \mathrm{~T}_{\mathrm{x}}$ : MXenes for electromagnetic interference shielding. ACS Nano 14(4), 5008-5016 (2020). https://doi.org/10.1021/acsnano.0c01312

69. F. Xie, F.F. Jia, L.H. Zhuo, Z.Q. Lu, L.M. Si et al., Ultrathin MXene/aramid nanofiber composite paper with excellent mechanical properties for efficient electromagnetic interference shielding. Nanoscale 11(48), 23382-23391 (2019). https://doi.org/10.1039/c9nr07331k

70. C.X. Weng, T.L. Xing, H. Jin, G.R. Wang, Z.H. Dai et al., Mechanically robust ANF/MXene composite films with tunable electromagnetic interference shielding performance. Compos. A: Appl. Sci. Manuf. 135, 105927 (2020). https://doi.org/10.1016/j.compositesa.2020.105927

71. C.X. Lei, Y.Z. Zhang, D.Y. Liu, K. Wu, Q. Fu, Metal-level robust, folding endurance, and highly temperature-stable MXene-based film with engineered aramid nanofiber for extreme-condition electromagnetic interference shielding applications. ACS Appl. Mater. Interfaces 12(23), 2648526495 (2020). https://doi.org/10.1021/acsami.0c07387

72. H.W. Wei, M.Q. Wang, W.H. Zheng, Z.X. Jiang, Y.D. Huang, 2D $\mathrm{Ti}_{3} \mathrm{C}_{2} \mathrm{~T}_{\mathrm{x}}$ MXene/aramid nanofibers composite films prepared via a simple filtration method with excellent mechanical and electromagnetic interference shielding properties. Ceram. Int. 46(5), 6199-6204 (2020). https:// doi.org/10.1016/j.ceramint.2019.11.087

73. Z.L. Ma, S.L. Kang, J.Z. Ma, L. Shao, Y.L. Zhang et al., Ultraflexible and mechanically strong double-layered aramid nanofiber- $\mathrm{Ti}_{3} \mathrm{C}_{2} \mathrm{~T}_{\mathrm{x}}$ MXene/silver nanowire nanocomposite papers for high-performance electromagnetic interference shielding. ACS Nano 14(7), 8368-8382 (2020). https://doi.org/10.1021/acsnano.0c02401

74. W.T. Cao, F.F. Chen, Y.J. Zhu, Y.G. Zhang, Y.Y. Jiang et al., Binary strengthening and toughening of MXene/ cellulose nanofiber composite paper with nacre-inspired structure and superior electromagnetic interference shielding properties. ACS Nano 12(5), 4583-4593 (2018). https:// doi.org/10.1021/acsnano.8b00997

75. B. Zhou, Z. Zhang, Y.L. Li, G.J. Han, Y.Z. Feng et al., Flexible, robust, and multifunctional electromagnetic interference shielding film with alternating cellulose nanofiber and MXene layers. ACS Appl. Mater. Interfaces 12(4), 4895-4905 (2020). https://doi.org/10.1021/acsami.9b197 68

76. C. Cui, C. Xiang, L. Geng, X.X. Lai, R.H. Guo et al., Flexible and ultrathin electrospun regenerate cellulose nanofibers and $\mathrm{d}-\mathrm{Ti}_{3} \mathrm{C}_{2} \mathrm{~T}_{\mathrm{x}}$ (MXene) composite film for electromagnetic interference shielding. J. Alloy Compd. 788, 1246-1255 (2019). https://doi.org/10.1016/j.jallcom.2019.02.294

77. Q.F. Zhou, K.P. Qian, J.H. Fang, M. Miao, S.M. Cao et al., UV-light modulated $\mathrm{Ti}_{3} \mathrm{C}_{2} \mathrm{~T}_{\mathrm{x}} \mathrm{MXene} / \mathrm{g}-\mathrm{C}_{3} \mathrm{~N}_{4}$ heterojunction film for electromagnetic interference shielding. Compos. A
Appl. Sci. Manuf. 134, 105899 (2020). https://doi.org/10. 1016/j.compositesa.2020.105899

78. W. Xin, G.Q. Xi, W.T. Cao, C. Ma, T. Liu et al., Lightweight and flexible MXene/CNF/silver composite membranes with a brick-like structure and high-performance electromagnetic interference shielding. RSC Adv. 9(51), 29636-29644 (2019). https://doi.org/10.1039/c9ra06399d

79. W.T. Cao, C. Ma, S. Tan, M.G. Ma, P.B. Wan et al., Ultrathin and flexible CNTs/MXene/cellulose nanofibrils composite paper for electromagnetic interference shielding. NanoMicro Lett. 11(1), 72 (2019). https://doi.org/10.1007/ s40820-019-0304-y

80. P. He, M.S. Cao, Y.Z. Cai, J.C. Shu, W.Q. Cao et al., Selfassembling flexible 2D carbide MXene film with tunable integrated electron migration and group relaxation toward energy storage and green EMI shielding. Carbon 157, 80-89 (2020). https://doi.org/10.1016/j.carbon.2019.10.009

81. M. Vural, A. Pena-Francesch, J. Bars-Pomes, H. Jung, H. Gudapati et al., Inkjet printing of self-assembled 2D titanium carbide and protein electrodes for stimuli-responsive electromagnetic shielding. Adv. Funct. Mater. 28(32), 1801972 (2018). https://doi.org/10.1002/adfm.201801972

82. R.T. Liu, M. Miao, Y.H. Li, J.F. Zhang, S.M. Cao et al., Ultrathin biomimetic polymeric $\mathrm{Ti}_{3} \mathrm{C}_{2} \mathrm{~T}_{\mathrm{x}}$ MXene composite films for electromagnetic interference shielding. ACS Appl. Mater. Interfaces 10(51), 44787-44795 (2018). https://doi. org/10.1021/acsami.8b18347

83. J.Q. Luo, S. Zhao, H.B. Zhang, Z.M. Deng, L.L. Li et al., Flexible, stretchable and electrically conductive MXene/natural rubber nanocomposite films for efficient electromagnetic interference shielding. Compos. Sci. Technol. 182, 107754 (2019). https://doi.org/10.1016/j.compscitech.2019.107754

84. S.J. Wang, D.S. Li, L. Jiang, Synergistic effects between MXenes and Ni chains in flexible and ultrathin electromagnetic interference shielding films. Adv. Mater. Interfaces 6(19), 1900961 (2019). https://doi.org/10.1002/admi.20190 0961

85. Z.H. Zhou, J.Z. Liu, X.X. Zhang, D. Tian, Z.Y. Zhan et al., Ultrathin MXene/calcium alginate aerogel film for highperformance electromagnetic interference shielding. Adv. Mater. Interfaces 6(6), 1802040 (2019). https://doi.org/10. 1002/admi.201802040

86. Z.X. Liu, W.Y. Wang, J.J. Tan, J. Liu, M.F. Zhu et al., Bioinspired ultra-thin polyurethane/MXene nacre-like nanocomposite films with synergistic mechanical properties for electromagnetic interference shielding. J. Mater. Chem. C 8(21), 7170-7180 (2020). https://doi.org/10.1039/d0tc01249a

87. X.X. Jin, J.F. Wang, L.Z. Dai, X.Y. Liu, L. Li et al., Flameretardant poly (vinyl alcohol)/MXene multilayered films with outstanding electromagnetic interference shielding and thermal conductive performances. Chem. Eng. J. 380, 122475 (2020). https://doi.org/10.1016/j.cej.2019.122475

88. F. Liu, Y.C. Li, S. Hao, Y. Cheng, Y.H. Zhan et al., Wellaligned MXene/chitosan films with humidity response for high-performance electromagnetic interference shielding. 
Carbohyd. Polym. 243, 116467 (2020). https://doi.org/10. 1016/j.carbpol.2020.116467

89. Y. Zhang, W.H. Cheng, W.X. Tian, J.Y. Lu, L. Song et al., Nacre-inspired tunable electromagnetic interference shielding sandwich films with superior mechanical and fire-resistant protective performance. ACS Appl. Mater. Interfaces 12(5), 6371-6382 (2020). https://doi.org/10.1021/acsami.9b18750

90. G.M. Weng, J.Y. Li, M. Alhabeb, C. Karpovich, H. Wang et al., Layer-by-layer assembly of cross-functional semitransparent MXene-carbon nanotubes composite films for next-generation electromagnetic interference shielding. Adv. Funct. Mater. 28(44), 1803360 (2018). https://doi.org/ 10.1002/adfm. 201803360

91. C. Xiang, R.H. Guo, S.J. Lin, S.X. Jiang, J.W. Lan et al., Lightweight and ultrathin $\mathrm{TiO}_{2}-\mathrm{Ti}_{3} \mathrm{C}_{2} \mathrm{~T}_{\mathrm{x}}$ /graphene film with electromagnetic interference shielding. Chem. Eng. J. 360, 1158-1166 (2019). https://doi.org/10.1016/j.cej.2018.10.174

92. J. Liu, Z.S. Liu, H.B. Zhang, W. Chen, Z.F. Zhao et al., Ultrastrong and highly conductive MXene-based films for high-performance electromagnetic interference shielding. Adv. Electron. Mater. 6(1), 1901094 (2020). https://doi.org/ 10.1002/aelm.201901094

93. X.M. Fan, M.H. Li, X. Li, F. Ye, J.M. Xue et al., Electromagnetic interference shielding $\mathrm{Ti}_{3} \mathrm{C}_{2} \mathrm{~T}_{\mathrm{x}}$-bonded carbon black films with enhanced absorption performance. Chin. Chem. Lett. 31(4), 1026-1029 (2020). https://doi.org/10.1016/j. cclet.2020.01.030

94. Z.S. Liu, Y. Zhang, H.B. Zhang, Y. Dai, J. Liu et al., Electrically conductive aluminum ion-reinforced MXene films for efficient electromagnetic interference shielding. J. Mater. Chem. C 8(5), 1673-1678 (2020). https://doi.org/10.1039/ c9tc06304h

95. X. Feng, J. Ning, B.Y. Wang, H.B. Guo, M.Y. Xia et al., Functional integrated electromagnetic interference shielding in flexible micro-supercapacitors by cation-intercalation typed $\mathrm{Ti}_{3} \mathrm{C}_{2} \mathrm{~T}_{\mathrm{x}}$ MXene. Nano Energy 72, 104741 (2020). https://doi.org/10.1016/j.nanoen.2020.104741

96. M. Miao, R.T. Liu, S. Thaiboonrod, L.Y. Shi, S.M. Cao et al., Silver nanowires intercalating $\mathrm{Ti}_{3} \mathrm{C}_{2} \mathrm{~T}_{\mathrm{x}}$ MXene composite films with excellent flexibility for electromagnetic interference shielding. J. Mater. Chem. C 8(9), 3120-3126 (2020). https://doi.org/10.1039/c9tc06361g

97. L. Li, Y.X. Cao, X.Y. Liu, J.F. Wang, Y.Y. Yang et al., Multifunctional MXene-based fireproof electromagnetic shielding films with exceptional anisotropic heat dissipation capability and joule heating performance. ACS Appl. Mater. Interfaces 12(24), 27350-27360 (2020). https://doi.org/10.1021/acsami. 0c05692

98. J. Liu, H.B. Zhang, R.H. Sun, Y.F. Liu, Z.S. Liu et al., Hydrophobic, flexible, and lightweight MXene foams for high-performance electromagnetic-interference shielding. Adv. Mater. 29(38), 1702367 (2017). https://doi.org/10.1002/adma.20170 2367

99. L. Wang, H. Qiu, P. Song, Y.L. Zhang, Y.J. Lu et al., 3D $\mathrm{Ti}_{3} \mathrm{C}_{2} \mathrm{~T}_{\mathrm{x}}$ MXene/C hybrid foam/epoxy nanocomposites with superior electromagnetic interference shielding performances and robust mechanical properties. Compos. A: Appl. Sci. Manufac. 123, 293-300 (2019). https://doi.org/10.1016/j. compositesa.2019.05.030

100. H.L. Xu, X.W. Yin, X.L. Li, M.H. Li, S. Liang et al., Lightweight $\mathrm{Ti}_{2} \mathrm{CT}_{\mathrm{x}} \mathrm{MXene/poly(vinyl} \mathrm{alcohol)} \mathrm{composite} \mathrm{foams}$ for electromagnetic wave shielding with absorption-dominated feature. ACS Appl. Mater. Interfaces 11(10), 1019810207 (2019). https://doi.org/10.1021/acsami.8b21671

101. Z.M. Fan, D.L. Wang, Y. Yuan, Y.S. Wang, Z.J. Cheng et al., A lightweight and conductive MXene/graphene hybrid foam for superior electromagnetic interference shielding. Chem. Eng. J. 381, 122696 (2020). https://doi.org/10.1016/j.cej. 2019.122696

102. H.Y. Yin, L.L. Bi, Z. Wu, G.X. Wang, M. Li et al., 2D foaming of ultrathin MXene sheets with highly conductive silver nanowires for wearable electromagnetic interference shielding applications owing to multiple reflections within created free space. Nano Futur. 4(3), 035002 (2020). https://doi.org/ 10.1088/2399-1984/ab92f5

103. X.Y. Wu, B.Y. Han, H.B. Zhang, X. Xie, T.X. Tu et al., Compressible, durable and conductive polydimethylsiloxanecoated MXene foams for high-performance electromagnetic interference shielding. Chem. Eng. J. 381, 122622 (2020). https://doi.org/10.1016/j.cej.2019.122622

104. M.K. Han, X.W. Yin, K. Hantanasirisakul, X.L. Li, A. Iqbal et al., Anisotropic MXene aerogels with a mechanically tunable ratio of electromagnetic wave reflection to absorption. Adv. Opt. Mater. 7(10), 1900267 (2019). https://doi.org/10. 1002/adom.201900267

105. R.J. Bian, G.L. He, W.Q. Zhi, S.L. Xiang, T.W. Wang et al., Ultralight MXene-based aerogels with high electromagnetic interference shielding performance. J. Mater. Chem. C 7(3), 474-478 (2019). https://doi.org/10.1039/c8tc04795b

106. Z.H. Zeng, C.X. Wang, G. Siqueira, D.X. Han, A. Huch et al., Nanocellulose-MXene biomimetic aerogels with orientationtunable electromagnetic interference shielding performance. Adv. Sci. 7(15), 2000979 (2020). https://doi.org/10.1002/ advs.202000979

107. S. Zhao, H.B. Zhang, J.Q. Luo, Q.W. Wang, B. Xu et al., Highly electrically conductive three-dimensional $\mathrm{Ti}_{3} \mathrm{C}_{2} \mathrm{~T}_{\mathrm{x}}$ $\mathrm{MXene} /$ reduced graphene oxide hybrid aerogels with excellent electromagnetic interference shielding performances. ACS Nano 12(11), 11193-11202 (2018). https://doi.org/10. 1021/acsnano.8b05739

108. P. Sambyal, A. Iqbal, J. Hong, H. Kim, M.K. Kim et al., Ultralight and mechanically robust $\mathrm{Ti}_{3} \mathrm{C}_{2} \mathrm{~T}_{\mathrm{x}}$ hybrid aerogel reinforced by carbon nanotubes for electromagnetic interference shielding. ACS Appl. Mater. Interfaces 11(41), 3804638054 (2019). https://doi.org/10.1021/acsami.9b12550

109. C.B. Liang, H. Qiu, P. Song, X.T. Shi, J. Kong et al., Ultralight MXene aerogel/wood-derived porous carbon composites with wall-like "mortar/brick" structures for electromagnetic interference shielding. Sci. Bull. 65(8), 616-622 (2020). https://doi.org/10.1016/j.scib.2020.02.009 
110. L. Geng, P.X. Zhu, Y.J. Wei, R.H. Guo, C. Xiang et al., A facile approach for coating $\mathrm{Ti}_{3} \mathrm{C}_{2} \mathrm{~T}_{\mathrm{x}}$ on cotton fabric for electromagnetic wave shielding. Cellulose 26(4), 2833-2847 (2019). https://doi.org/10.1007/s10570-019-02284-5

111. X.S. Zhang, X.F. Wang, Z.W. Lei, L.L. Wang, M.W. Tian et al., Flexible MXene-decorated fabric with interwoven conductive networks for integrated joule heating, electromagnetic interference shielding, and strain sensing performances. ACS Appl. Mater. Interfaces 12(12), 14459-14467 (2020). https:// doi.org/10.1021/acsami.0c01182

112. W.H. Cheng, Y. Zhang, W.X. Tian, J.J. Liu, J.Y. Lu et al., Highly efficient MXene-coated flame retardant cotton fabric for electromagnetic interference shielding. Ind. Eng. Chem. Res. 59(31), 14025-14036 (2020). https://doi.org/10.1021/ acs.iecr.0c02618

113. D.W. Hu, X.Y. Huang, S.T. Li, P.K. Jiang, Flexible and durable cellulose/MXene nanocomposite paper for efficient electromagnetic interference shielding. Compos. Sci. Technol. 188, 107995 (2020). https://doi.org/10.1016/j.compscitech. 2020.107995

114. Q.W. Wang, H.B. Zhang, J. Liu, S. Zhao, X. Xie et al., Multifunctional and water-resistant MXene-decorated polyester textiles with outstanding electromagnetic interference shielding and joule heating performances. Adv. Funct. Mater. 29(7), 1806819 (2019). https://doi.org/10.1002/adfm.201806819

115. W.J. Yuan, J.Z. Yang, F.X. Yin, Y.B. Li, Y. Ye, Flexible and stretchable MXene/polyurethane fabrics with delicate wrinkle structure design for effective electromagnetic interference shielding at a dynamic stretching process. Compos. Commun. 19, 90-98 (2020). https://doi.org/10.1016/j.coco.2020.03.003

116. G. Yin, Y. Wang, W. Wang, D. Yu, Multilayer structured PANI/MXene/CF fabric for electromagnetic interference shielding constructed by layer-by-layer strategy. Colloid. Surface. A 601, 125047 (2020). https://doi.org/10.1016/j. colsurfa.2020.125047

117. L.X. Liu, W. Chen, H.B. Zhang, Q.W. Wang, F.L. Guan et al., Flexible and multifunctional silk textiles with biomimetic leaf-like MXene/silver nanowire nanostructures for electromagnetic interference shielding, humidity monitoring, and self-derived hydrophobicity. Adv. Funct. Mater. 29(44), 1905197 (2019). https://doi.org/10.1002/adfm.201905197

118. X.C. Jia, B. Shen, L.H. Zhang, W.G. Zheng, Waterproof MXene-decorated wood-pulp fabrics for high-efficiency electromagnetic interference shielding and Joule heating. Compos. B-Eng. 198, 108250 (2020). https://doi.org/10.1016/j. compositesb.2020.108250

119. Y.C. Qing, W.C. Zhou, F. Luo, D.M. Zhu, Titanium carbide (MXene) nanosheets as promising microwave absorbers. Ceram. Int. 42(14), 16412-16416 (2016). https://doi.org/10. 1016/j.ceramint.2016.07.150

120. W.L. Feng, H. Luo, Y. Wang, S.F. Zeng, L.W. Deng et al., $\mathrm{Ti}_{3} \mathrm{C}_{2}$ MXene: a promising microwave absorbing material. RSC Adv. 8(5), 2398-2403 (2018). https://doi.org/10.1039/ c7ra12616f

121. H. Luo, W.L. Feng, C.W. Liao, L.W. Deng, S. Liu et al., Peaked dielectric responses in $\mathrm{Ti}_{3} \mathrm{C}_{2}$ MXene nanosheets enabled composites with efficient microwave absorption. J. Appl. Phys. 123(10), 104103 (2018). https://doi.org/10. 1063/1.5008323

122. Y. Tong, M. He, Y.M. Zhou, X. Zhong, L.D. Fan et al., Electromagnetic wave absorption properties in the centimetreband of $\mathrm{Ti}_{3} \mathrm{C}_{2} \mathrm{~T}_{\mathrm{x}}$ MXenes with diverse etching time. J. Mater. Sci Mater. El. 29(10), 8078-8088 (2018). https://doi.org/10. 1007/s10854-018-8814-9

123. B.B. Fan, N. Li, B.Z. Dai, S.Y. Shang, L. Guan et al., Investigation of adjacent spacing dependent microwave absorption properties of lamellar structural $\mathrm{Ti}_{3} \mathrm{C}_{2} \mathrm{~T}_{\mathrm{x}}$ MXenes. Adv. Powder Technol. 31(2), 808-815 (2020). https://doi.org/10. 1016/j.apt.2019.11.035

124. G.Z. Cui, X.D. Sun, G.Y. Zhang, Z. Zhang, H. Liu et al., Electromagnetic absorption performance of two-dimensional MXene $\mathrm{Ti}_{3} \mathrm{C}_{2} \mathrm{~T}_{\mathrm{x}}$ exfoliated by $\mathrm{HCl}+\mathrm{LiF}$ etchant with diverse etching times. Mater. Lett. 252, 8-10 (2019). https://doi.org/ 10.1016/j.matlet.2019.05.053

125. G.F. Xu, X.X. Wang, S.D. Gong, S. Wei, J.Q. Liu et al., Solvent-regulated preparation of well-intercalated $\mathrm{Ti}_{3} \mathrm{C}_{2} \mathrm{~T}_{\mathrm{x}}$ MXene nanosheets and application for highly effective electromagnetic wave absorption. Nanotechnology 29(35), 355201 (2018). https://doi.org/10.1088/1361-6528/aac8f6

126. Z.Y. Jin, Y.F. Fang, X.X. Wang, G.F. Xu, M.L. Liu et al., Ultra-efficient electromagnetic wave absorption with ethanol-thermally treated two-dimensional $\mathrm{Nb}_{2} \mathrm{CT}_{\mathrm{x}}$ nanosheets. J. Colloid. Interfaces Sci. 537, 306-315 (2019). https://doi. org/10.1016/j.jcis.2018.11.034

127. M.K. Han, X.W. Yin, X.L. Li, B. Anasori, L.T. Zhang et al., Laminated and two-dimensional carbon-supported microwave absorbers derived from MXenes. ACS Appl. Mater. Interfaces 9(23), 20038-20045 (2017). https://doi.org/10. 1021/acsami.7b04602

128. X.L. Li, X.W. Yin, M.K. Han, C.Q. Song, X.N. Sun et al., A controllable heterogeneous structure and electromagnetic wave absorption properties of $\mathrm{Ti}_{2} \mathrm{CT}_{\mathrm{x}}$ MXene. J. Mater. Chem. C 5(30), 7621-7628 (2017). https://doi.org/10.1039/ c7tc01991b

129. B.B. Fan, S.Y. Shang, B.Z. Dai, B. Zhao, N. Li et al., 2D-layered $\mathrm{Ti}_{3} \mathrm{C}_{2} / \mathrm{TiO}_{2}$ hybrids derived from $\mathrm{Ti}_{3} \mathrm{C}_{2}$ MXenes for enhanced electromagnetic wave absorption. Ceram. Int. 46(10), 17085-17092 (2020). https://doi.org/10.1016/j.ceram int.2020.04.004

130. P.J. Liu, Z.J. Yao, V.M.H. Ng, J.T. Zhou, L.B. Kong et al., Facile synthesis of ultrasmall $\mathrm{Fe}_{3} \mathrm{O}_{4}$ nanoparticles on MXenes for high microwave absorption performance. Compos. A: Appl. Sci. Manuf. 115, 371-382 (2018). https://doi.org/10. 1016/j.compositesa.2018.10.014

131. G.L. Zhao, H.P. Lv, Y. Zhou, X.T. Zheng, C. Wu et al., Selfassembled sandwich-like MXene-derived nanocomposites for enhanced electromagnetic wave absorption. ACS Appl. Mater. Interfaces 10(49), 42925-42932 (2018). https://doi. org/10.1016/10.1021/acsami.8b16727

132. X. Zhang, H.H. Wang, R. Hu, C.Y. Huang, W.J. Zhong et al., Novel solvothermal preparation and enhanced microwave absorption properties of $\mathrm{Ti}_{3} \mathrm{C}_{2} \mathrm{~T}_{\mathrm{x}}$ MXene modified by in situ 
coated $\mathrm{Fe}_{3} \mathrm{O}_{4}$ nanoparticles. Appl. Surf. Sci. 484, 383-391 (2019). https://doi.org/10.1016/j.apsusc.2019.03.264

133. X. Li, M. Zhang, W.B. You, K. Pei, Q.W. Zeng et al., Magnetized MXene microspheres with multiscale magnetic coupling and enhanced polarized interfaces for distinct microwave absorption via a spray-drying method. Appl. Mater. Interfaces 12(15), 18138-18147 (2020). https://doi.org/10.1021/acsami. 0c00935

134. S.Q. Yan, C. Cao, J. He, L.H. He, Z.W. Qu et al., Investigation on the electromagnetic and broadband microwave absorption properties of $\mathrm{Ti}_{3} \mathrm{C}_{2}$ Mxene/flaky carbonyl iron composites. J. Mater. Sci. Mater. El. 30(7), 6537-6543 (2019). https://doi. org/10.1007/s10854-019-00959-0

135. N. Li, X. Xie, H.X. Lu, B.B. Fan, X.H. Wang et al., Novel two-dimensional $\mathrm{Ti}_{3} \mathrm{C}_{2} \mathrm{~T}_{\mathrm{X}} / \mathrm{Ni}$-spheres hybrids with enhanced microwave absorption properties. Ceram. Int. 45(17), 22880 22888 (2019). https://doi.org/10.1016/j.ceramint.2019.07.331

136. X. Li, W.B. You, L. Wang, J.W. Liu, Z.C. Wu et al., Selfassembly-magnetized MXene avoid dual-agglomeration with enhanced interfaces for strong microwave absorption through a tunable electromagnetic property. Appl. Mater. Interfaces 11(47), 44536-44544 (2019). https://doi.org/10.1021/acsami. 9b11861

137. L.Y. Liang, R.S. Yang, G.J. Han, Y.Z. Feng, B. Zhao et al., Enhanced electromagnetic wave-absorbing performance of magnetic nanoparticles-anchored 2D $\mathrm{Ti}_{3} \mathrm{C}_{2} \mathrm{~T}_{\mathrm{x}}$ MXene. Appl. Mater. Interfaces 12(2), 2644-2654 (2020). https://doi.org/ 10.1021/acsami.9b18504

138. Y. Liu, S. Zhang, X.L. Su, J. Xu, Y.Y. Li, Enhanced microwave absorption properties of $\mathrm{Ti}_{3} \mathrm{C}_{2}$ MXene powders decorated with Ni particles. J. Mater. Sci. 55(24), 10339-10350 (2020). https://doi.org/10.1007/s10853-020-04739-8

139. R.X. Deng, B.B. Chen, H.G. Li, K. Zhang, T. Zhang et al., MXene $/ \mathrm{Co}_{3} \mathrm{O}_{4}$ composite material: stable synthesis and its enhanced broadband microwave absorption. Appl. Surf. Sci. 488, 921-930 (2019). https://doi.org/10.1016/j.apsusc.2019. 05.058

140. C.L. Zhou, X.X. Wang, H. Luo, L.W. Deng, S.L. Wang et al., Interfacial design of sandwich-like $\mathrm{CoFe} @ \mathrm{Ti}_{3} \mathrm{C}_{2} \mathrm{~T}_{\mathrm{x}}$ composites as high efficient microwave absorption materials. Appl. Surf. Sci. 494, 540-550 (2019). https://doi.org/10.1016/j. apsusc.2019.07.208

141. J. He, D.Y. Shan, S.Q. Yan, H. Luo, C. Cao et al., Magnetic FeCo nanoparticles-decorated $\mathrm{Ti}_{3} \mathrm{C}_{2}$ MXene with enhanced microwave absorption performance. J. Magn. Magn. Mater. 492, 165639 (2019). https://doi.org/10.1016/j.jmmm.2019. 165639

142. Y.M. Lei, Z.J. Yao, S.Z. Li, J.T. Zhou, A.A. Haidry et al., Broadband high-performance electromagnetic wave absorption of Co-doped NiZn ferrite/polyaniline on MXenes. Ceram. Int. 46(8), 10006-10015 (2020). https://doi.org/10. 1016/j.ceramint.2019.12.189

143. T.Q. Hou, B.B. Wang, M.L. Ma, A.L. Feng, Z.Y. Huang et al., Preparation of two-dimensional titanium carbide $\left(\mathrm{Ti}_{3} \mathrm{C}_{2} \mathrm{~T}_{\mathrm{x}}\right)$ and $\mathrm{NiCo}_{2} \mathrm{O}_{4}$ composites to achieve excellent microwave absorption properties. Compos. B-Eng. 180,
107577 (2020). https://doi.org/10.1016/j.compositesb.2019. 107577

144. H.B. Yang, J.J. Dai, X. Liu, Y. Lin, J.J. Wang et al., Layered $\mathrm{PVB} / \mathrm{Ba}_{3} \mathrm{Co}_{2} \mathrm{Fe}_{24} \mathrm{O}_{41} / \mathrm{Ti}_{3} \mathrm{C}_{2}$ Mxene composite: Enhanced electromagnetic wave absorption properties with high impedance match in a wide frequency range. Mater. Chem. Phys. 200, 179-186 (2017). https://doi.org/10.1016/j.matchemphys. 2017.05.057

145. M. Li, M.K. Han, J. Zhou, Q.H. Deng, X.B. Zhou et al., Novel scale-like structures of graphite/ $\mathrm{TiC} / \mathrm{Ti}_{3} \mathrm{C}_{2}$ hybrids for electromagnetic absorption. Adv. Electron. Mater. 4(5), 1700617 (2018). https://doi.org/10.1002/aelm.201700617

146. X.L. Li, X.W. Yin, M.K. Han, C.Q. Song, H.L. Xu et al., $\mathrm{Ti}_{3} \mathrm{C}_{2}$ MXenes modified with in situ grown carbon nanotubes for enhanced electromagnetic wave absorption properties. J. Mater. Chem. C 5(16), 4068-4074 (2017). https://doi.org/10. 1039/c6tc05226f

147. B.Z. Dai, B. Zhao, X. Xie, T.T. Su, B.B. Fan et al., Novel twodimensional $\mathrm{Ti}_{3} \mathrm{C}_{2} \mathrm{~T}_{\mathrm{x}}$ MXenes/nano-carbon sphere hybrids for high-performance microwave absorption. J. Mater. Chem. C 6(21), 5690-5697 (2018). https://doi.org/10.1039/c8tc01404c

148. Y.C. Qing, H.Y. Nan, F. Luo, W.C. Zhou, Nitrogen-doped graphene and titanium carbide nanosheet synergistically reinforced epoxy composites as high-performance microwave absorbers. RSC Adv. 7(44), 27755-27761 (2017). https://doi. org/10.1039/c7ra02417g

149. Y. Qian, H.W. Wei, J.D. Dong, Y.Z. Du, X.J. Fang et al., Fabrication of urchin-like ZnO-MXene nanocomposites for high-performance electromagnetic absorption. Ceram. Int. 43(14), 10757-10762 (2017). https://doi.org/10.1016/j.ceram int.2017.05.082

150. T.S. Liu, N. Liu, Q.D. An, Z.Y. Xiao, S.R. Zhai et al., Designed construction of $\mathrm{Ti}_{3} \mathrm{C}_{2} \mathrm{~T}_{\mathrm{x}} @ \mathrm{PPY}$ composites with enhanced microwave absorption performance. J. Alloy. Compd. 802, 445-457 (2019). https://doi.org/10.1016/j.jallc om.2019.06.243

151. Y. Tong, M. He, Y.M. Zhou, X. Zhong, L.D. Fan et al., Hybridizing polypyrrole chains with laminated and twodimensional $\mathrm{Ti}_{3} \mathrm{C}_{2} \mathrm{~T}_{\mathrm{x}}$ toward high-performance electromagnetic wave absorption. Appl. Surf. Sci. 434, 283-293 (2018). https://doi.org/10.1016/j.apsusc.2017.10.140

152. H.Y. Wang, H.B. Ma, The electromagnetic and microwave absorbing properties of $\mathrm{MoS}_{2}$ modified $\mathrm{Ti}_{3} \mathrm{C}_{2} \mathrm{~T}_{\mathrm{x}}$ nanocomposites. J. Mater. Sci. Mater. El. 30(16), 15250-15256 (2019). https://doi.org/10.1007/s10854-019-01897-7

153. H.W. Wei, J.D. Dong, X.J. Fang, W.H. Zheng, Y.T. Sun et al., $\mathrm{Ti}_{3} \mathrm{C}_{2} \mathrm{~T}_{\mathrm{x}}$ MXene/polyaniline (PANI) sandwich intercalation structure composites constructed for microwave absorption. Compos. Sci. Technol. 169, 52-59 (2019). https://doi.org/10. 1016/j.compscitech.2018.10.016

154. S.W. Song, J.Q. Liu, C.L. Zhou, Q. Jia, H. Luo et al., $\mathrm{Nb}_{2} \mathrm{O}_{5} /$ $\mathrm{Nb}_{2} \mathrm{CT}_{\mathrm{x}}$ composites with different morphologies through oxidation of $\mathrm{Nb}_{2} \mathrm{CT}_{\mathrm{x}}$ MXene for high-performance microwave absorption. J. Alloy. Compd. 843, 155713 (2020). https://doi. org/10.1016/j.jallcom.2020.155713 
155. X.L. Li, X.W. Yin, C.Q. Song, M.K. Han, H.L. Xu et al., Self-assembly core-shell graphene-bridged hollow MXenes spheres 3D foam with ultrahigh specific EM absorption performance. Adv. Funct. Mater. 28(41), 1803938 (2018). https://doi.org/10.1002/adfm.201803938

156. X.L. Li, X.W. Yin, H.L. Xu, M.K. Han, M.H. Li et al., Ultralight MXene-coated, interconnected SiCnws threedimensional lamellar foams for efficient microwave absorption in the X-band. Appl. Mater. Interfaces 10(40), 3452434533 (2018). https://doi.org/10.1021/acsami.8b13658

157. Y. Wang, J. Yang, Z.F. Chen, Y.L. Hu, A new flexible and ultralight carbon foam $/ \mathrm{Ti}_{3} \mathrm{C}_{2} \mathrm{~T}_{\mathrm{X}}$ MXene hybrid for highperformance electromagnetic wave absorption. RSC Adv. 9(70), 41038-41049 (2019). https://doi.org/10.1039/c9ra0 $9817 \mathrm{~h}$

158. M.L. Yang, Y. Yuan, Y. Li, X.X. Sun, S.S. Wang et al., Anisotropic electromagnetic absorption of aligned $\mathrm{Ti}_{3} \mathrm{C}_{2} \mathrm{~T}_{\mathrm{x}}$ $\mathrm{MXene/gelatin} \mathrm{nanocomposite} \mathrm{aerogels.} \mathrm{Appl.} \mathrm{Mater.} \mathrm{Inter-}$ faces 12(29), 33128-33138 (2020). https://doi.org/10.1021/ acsami.0c09726

159. Y. Jiang, X. Xie, Y. Chen, Y.J. Liu, R. Yang et al., Hierarchically structured cellulose aerogels with interconnected MXene networks and their enhanced microwave absorption properties. J. Mater. Chem. C 6(32), 8679-8687 (2018). https://doi.org/10.1039/c8tc02900h

160. Y. Tong, M. He, Y.M. Zhou, S.X. Nie, X. Zhong et al., Threedimensional hierarchical architecture of the $\mathrm{TiO}_{2} / \mathrm{Ti}_{3} \mathrm{C}_{2} \mathrm{~T}_{\mathrm{x}}$ I RGO ternary composite aerogel for enhanced electromagnetic wave absorption. ACS Sustain. Chem. Eng. 6(7), 8212-8222 (2018). https://doi.org/10.1021/acssuschemeng.7b04883

161. L.B. Wang, H. Liu, X.L. Lv, G.Z. Cui, G.X. Gu, Facile synthesis $3 \mathrm{D}$ porous MXene $\mathrm{Ti}_{3} \mathrm{C}_{2} \mathrm{~T}_{\mathrm{x}} @ \mathrm{RGO}$ composite aerogel with excellent dielectric loss and electromagnetic wave absorption. J. Alloy. Compd. 828, 154251 (2020). https://doi. org/10.1016/j.jallcom.2020.154251
162. S.J. Wang, D.S. Li, Y. Zhou, L. Jiang, Hierarchical $\mathrm{Ti}_{3} \mathrm{C}_{2} \mathrm{~T}_{\mathrm{x}}$ $\mathrm{MXene} / \mathrm{Ni}$ chain/ZnO array hybrid nanostructures on cotton fabric for durable self-cleaning and enhanced microwave absorption. ACS Nano 14(7), 8634-8645 (2020). https://doi. org/10.1021/acsnano.0c03013

163. H. Koga, T. Inui, I. Miyamoto, T. Sekiguchi, M. Nogi et al., A high-sensitivity printed antenna prepared by rapid lowtemperature sintering of silver ink. RSC Adv. 6(87), 8436384368 (2016). https://doi.org/10.1039/c6ra19687j

164. D.Y. Shin, Y. Lee, C.H. Kim, Performance characterization of screen printed radio frequency identification antennas with silver nanopaste. Thin Solid Films 517(21), 6112-6118 (2009). https://doi.org/10.1016/j.tsf.2009.05.019

165. A. Chauraya, W.G. Whittow, J.C. Vardaxoglou, Y. Li, R. Torah et al., Inkjet printed dipole antennas on textiles for wearable communications. IET Microw. Antennas Propag. 7(9), 760-767 (2013). https://doi.org/10.1049/iet-map.2013. 0076

166. Y. Bayram, Y.J. Zhou, B.S. Shim, S.M. Xu, J.A. Zhu et al., E-textile conductors and polymer composites for conformal lightweight antennas. IEEE Trans. Antennas. Propag. 58(8), 2732-2736 (2010). https://doi.org/10.1109/TAP.2010.20504 39

167. Q.Y. Tang, Y.M. Pan, Y.C. Chan, K.W. Leung, Frequencytunable soft composite antennas for wireless sensing. Sens. Actuat. A Phys. 179, 137-145 (2012). https://doi.org/10. 1016/j.sna.2012.03.024

168. Y. Tikhov, J.H. Won, Impedance-matching arrangement for microwave transponder operating over plurality of bent installations of antenna. Electron. Lett. 40(10), 574-575 (2004). https://doi.org/10.1049/el:20040413

169. J.S. Lee, M. Kim, C. Lee, S. Cho, J. Oh et al., Platinumdecorated reduced graphene oxide/polyaniline:poly (4-styrenesulfonate) hybrid paste for flexible dipole tag-antenna applications. Nanoscale 7(8), 3668-3674 (2015). https://doi. org/10.1039/c4nr06189f 